\section{AEC \\ RESEARCH \\ and \\ DEVELOPMENT}

REPORT
BNWL-89

$84-$

\title{
FAST NEUTRON FLUX CHARACTERISTICS OF THE ETR, G-7 HOT WATER LOOP
}

A. L. BEMENT

R. E. DAHL

J. E. IRVIN

AUGUST, 1965

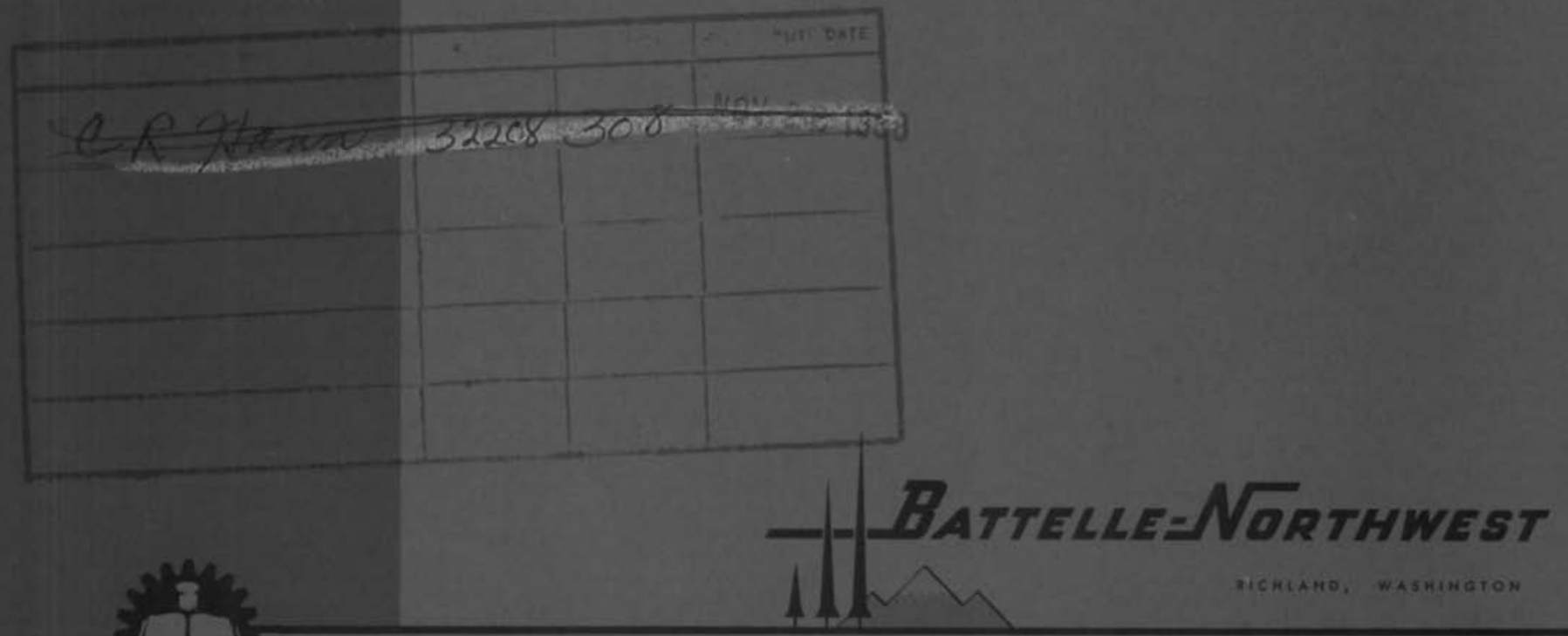

PACIFIC NORTHWEST LABORATORY operated bY BATTELLE MEMORIAL INSTITUTE 


\section{LEGAL NOTICE}

This report was prepared as an account of Government sponsored work. Neither the United States, nor the Commission, nor any person acting on behalf of the Commission:

A. Makes any warranty or representation, expressed or implied, with respect to the accuracy, complefeness, or usefulness of the information contained in this report, or that the use of any information, apporatus, method, or process disclosed in this report may not infringe privately owned rights; or

B. Assumes any liabilities with respect to the use of, or for damages resulting from the use of any information, apparalus, method, or process disclosed in this report.

As used in the above, "person acting on behalf of the Commission" includes any employee or contractor of the Commission, or employee of such contractor, to the extent that such employee or contractor of the Commission, or employee of such contractor prepares, disseminates, or provides access to, any information pursuant to his employment or contract with the Commission, or his employment with such contractor.

\section{PACIFIC NORTHWEST LABORATORY \\ RICHLAND, WASHINGTON \\ operated by \\ BATTELLE MEMORIAL INSTITUTE}

for the

UNITED STATES ATOMIC ENERGY COMMISSION UNDER CONTRACT AT(45-1)-1830 


\title{
BNWL- 89
}

UC-25, Metals, Ceramics, and Materials

\section{FAST NEUTRON FLUX CHARACTERISTICS}

OF THE ETR, G-7 HOT WATER LOOP

\section{By}

\author{
A. L. Bement \\ J. E. Irvin \\ Metallurgy Research Section \\ R. E. Dah1 \\ Materials Research and Services Section \\ Reactor and Materials Technology Department
}

August, 1965 
Printed in USA. Price \$3.00. Available from the Clearinghouse for Federal Scientific and Technical Information, National Bureau of Standards U. S. Department of Commerce, Springield, Virginia 


\section{ABSTRACT \\ FAST NEUTRON FLUX CHARACTERISTICS \\ OF THE ETR, G-7 HOT WATER LOOP}

In the course of conducting irradiations on reactor structural materials in the ETR, G-7, hot-water loop, nearly 1000 dosimeters of $\mathrm{Fe}, \mathrm{Ni}$, Ti, and A1-0. $1 \mathrm{wt} \%$ Co were activated, counted, and analyzed. From these measurements, the mean spatial neutron flux distribution in the G-7 position was mapped, and variations in the flux intensity and configuration of this distribution from cycle to cycle were determined. The greatest reliability in flux measurement was obtained with iron detectors counted nondestructively. Iron detectors subjected to chemical isotopic separation gave values as much as $20 \%$ lower than companion samples counted nondestructively. Flux values measured from nickel dosimeters were often erratic, particularly after long exposures where corrections of the thermal neutron burnout of cobalt are expectantly inaccurate. Contributing factors in the erratic response for nickel were thermal flux perturbations caused by adjacent experiments and from materials inserted into the loop. The accuracy in measured flux was estimated to be within $\pm 10 \%$, and flux maps and spatial coefficients were derived which permitted calculating the flux at any position within the loop within $\pm 20 \%$ accuracy. A 4 to $8 \%$ correction resulted in normalizing the effective cross sections for iron and nickel, respectively, over the slightlymoderated ETR spectrum compared to a fission spectrum for energies above $1 \mathrm{MeV}$. 


\section{FAST NEUTRON FLUX CHARACTERISTICS \\ OF THE ETR, G-7 HOT WATER LOOP}

\section{INTRODUCTION}

A critical part of any neutron damage study is the accurate determination of neutron exposures. It is now generally recognized that errors in measuring neutron flux can negate careful property measurements of irradiated specimens. These errors not only obscure important irradiation effects on properties, but also make correlations of irradiation effects data obtained in various reactor facilities highly inaccurate. Only a few comprehensive damage investigations are accompanied with equally comprehensive flux measurements. However, in such cases, the data are not always reported in the desired detail.

Specimens of several reactor structural alloys have been irradiated in the G-7, hot-water loop of the Engineering Test Reactor (ETR) starting with Cycle 39. These irradiations are part of the Irradiation Damage to Reactor Metals Program of the Pacific Northwest Laboratories, BattelleNorthwest.* During the course of these irradiations, fast fluxes have been measured from $\mathrm{Fe}, \mathrm{Ni}$, and $\mathrm{Ti}$ activations and thermal fluxes from $\mathrm{Co}$ activations. Approximately 45 independent dosimeters were positioned and analyzed for each cycle totaling nearly 1000 separate determinations throughout Cycles 39 to 63 . From these measurements, the mean spatial neutron flux distribution in the $G-7$ position has been mapped, and variations in the intensity and configuration of this distribution from cycle to cycle have been determined。

The threshold monitors employed in this study respond to a relatively small percentage of the neutron energy range known to cause damage in metals. Therefore, considerable error can occur, depending upon the amount of irradiation, if a fission spectrum is used to extrapolate activation data over the entire energy range assumed to cause damage. Furthermore,

* Formerly Hanford Laboratories, General Electric Company 
if the arbitrary energy limit selected (usually $1 \mathrm{MeV}$ ) does not adequately account for damage at lower energy levels, errors can occur in comparing damage obtained from facilities having differing degrees of moderation. These problems are considered in this report, and detailed calculations are made of neutron spectrum and the effect of spectrum on dosimeter activations as a function of space in the $G-7$ position. Finally, neutron flux and effective cross sections are determined for an energy limit other than $1 \mathrm{MeV}--\mathrm{a}$ limit $(0.5 \mathrm{MeV})$ which is considered to be more accurate for correlating test data obtained under a wide variety of spectra.

\section{CONCLUSIONS}

1. Flux measurements conducted with iron, titanium, and nickel detectors showed that iron dosimeters analyzed nondestructively are generally most reliable for long-term irradiations in a position with a high ratio of fast to thermal neutrons.

2. Specific disintegration rates for iron and Al-Co dosimeters were reproduced within $\pm 3 \%$ when counted at two different laboratories after 6-month intervals. Agreement was poorer for nickel and titanium dosimeters due to gamma ray interference from impurity and contaminant isotopes.

3. A comparison of measured flux distributions with flux isopleths calculated from neutron transport theory revealed that flux perturbations in the vertical and horizontal flux topography resulted from irradiation experiments conducted outside the northwest quadrant of the ETR core.

4. Through the use of flux maps, neutron flux extrapolations from the loop centerline to the quadrant monitor positions were in agreement with measured values within $\pm 20 \%$ 。

5. A 4 to $8 \%$ correction resulted in normalizing the effective cross sections for iron and nickel, respectively, over the slightly-moderated ETR spectrum compared to a fission spectrum for energies above $1 \mathrm{MeV}$.

6. The flux of neutrons in the GEH-20 loop having energies above $0.5 \mathrm{MeV}$ was found to be 1.4 times greater than for neutrons with energies above $1 \mathrm{MeV}$. 
BNWL-89

\section{PROCEDURES}

Measurement

Specimens irradiated in the ETR, G-7 hot-water loop were placed in quadrant fixtures which were in turn suspended on the rod hanger assembly illustrated in Figure 1. One full loading of the loop consisted of 28 quadrants, each quadrant having the capacity of either 18 tensile specimens or 12 notched tensile or bend test specimens. A dosimeter assembly of the type illustrated in Figure 2 was welded to each specimen quadrant at the center of the outer periphery and parallel with the centerline of the loop. The quadrant dosimeters consisted of a capillary stainless steel tube, crimped to retain dosimeter wires in desired positions. Referring to Figure 2, the arrangement of the dosimeter wires from top to bottom was $\mathrm{Fe}, \mathrm{Ni}, \mathrm{Al}-0.1 \mathrm{wt} \% \mathrm{Co}$, and $\mathrm{Ti}$.

Central flux monitor rods were used beginning with ETR Cycle 45. The dosimeter wires for these measurements were wrapped about a slotted aluminum rod at vertical positions coinciding with the quadrant dosimeters. Thus, a wire each of $\mathrm{Fe}, \mathrm{Ni}, \mathrm{Al}-0.1 \mathrm{wt} \% \mathrm{Co}$, and $\mathrm{Ti}$ (in order from top to bottom) were located at each of seven quadrant levels for a total of $28 \mathrm{dosim-}$ eters per assembly. The aluminum rod containing the dosimeter wires was encapsulated in a stainless-steel tube fitted with a threaded cap. The stainless-steel tube was then inserted into the central cavity of the rod hanger assembly. Figure 3 shows a layout of the aluminum dosimeter container, the stainless-steel capsule, the specimen-quadrant rod hanger, and the hotwater flow basket. Figure 4 shows the assembled components ready for insertion into the G-7 loop.

The combination of central and quadrant dosimeters provided extensive data for mapping both fast and thermal flux at the seven irradiation levels of the G-7 position. The central flux monitoring assembly was replaced each cycle giving cycle-to-cycle records of neutron flux, and the quadrant dosimeters gave average values over the duration of quadrant exposures. 

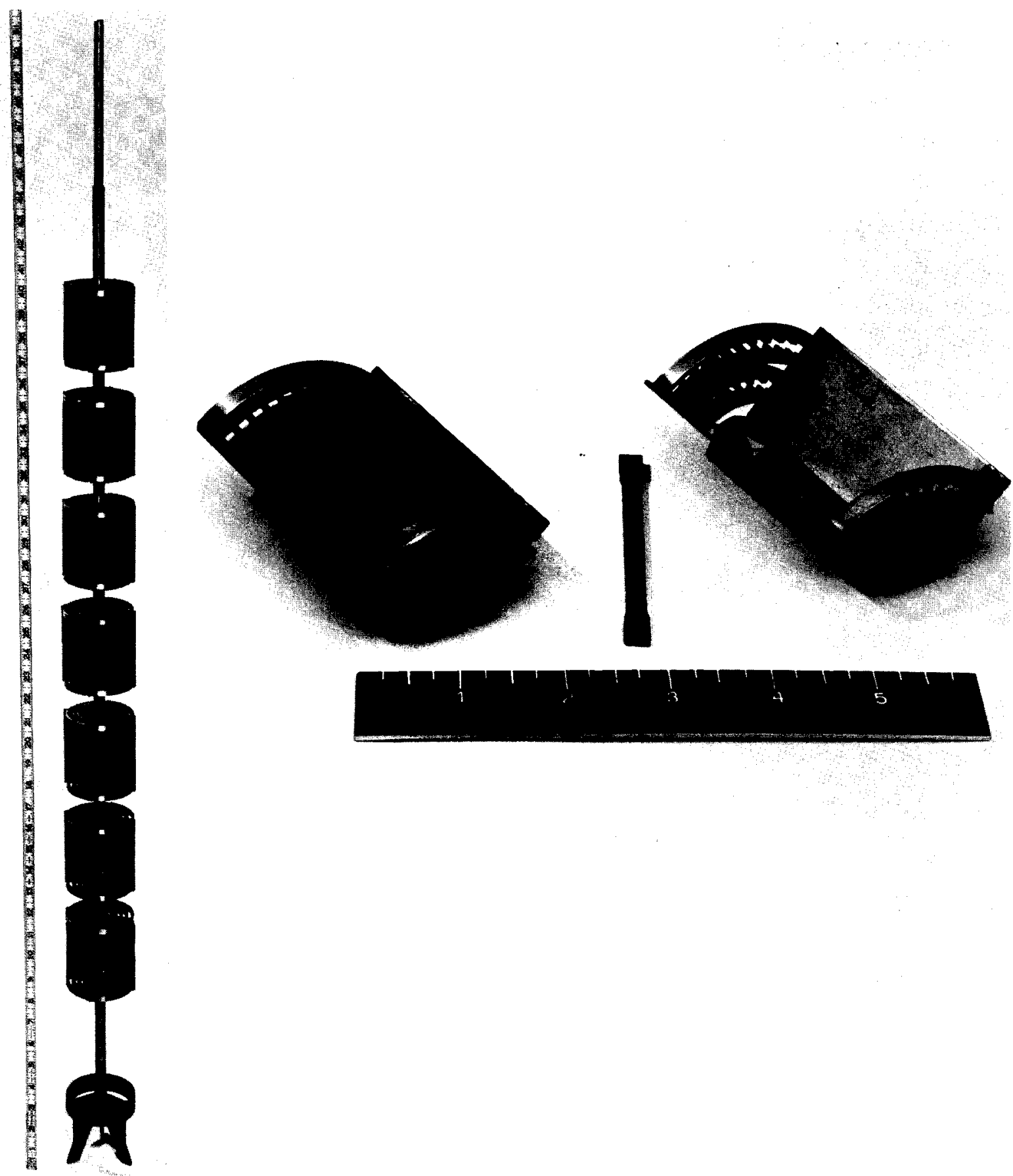

FIGURE 1

Typical Tensile Specimen Quadrant and Hanger Assembly 0611009 


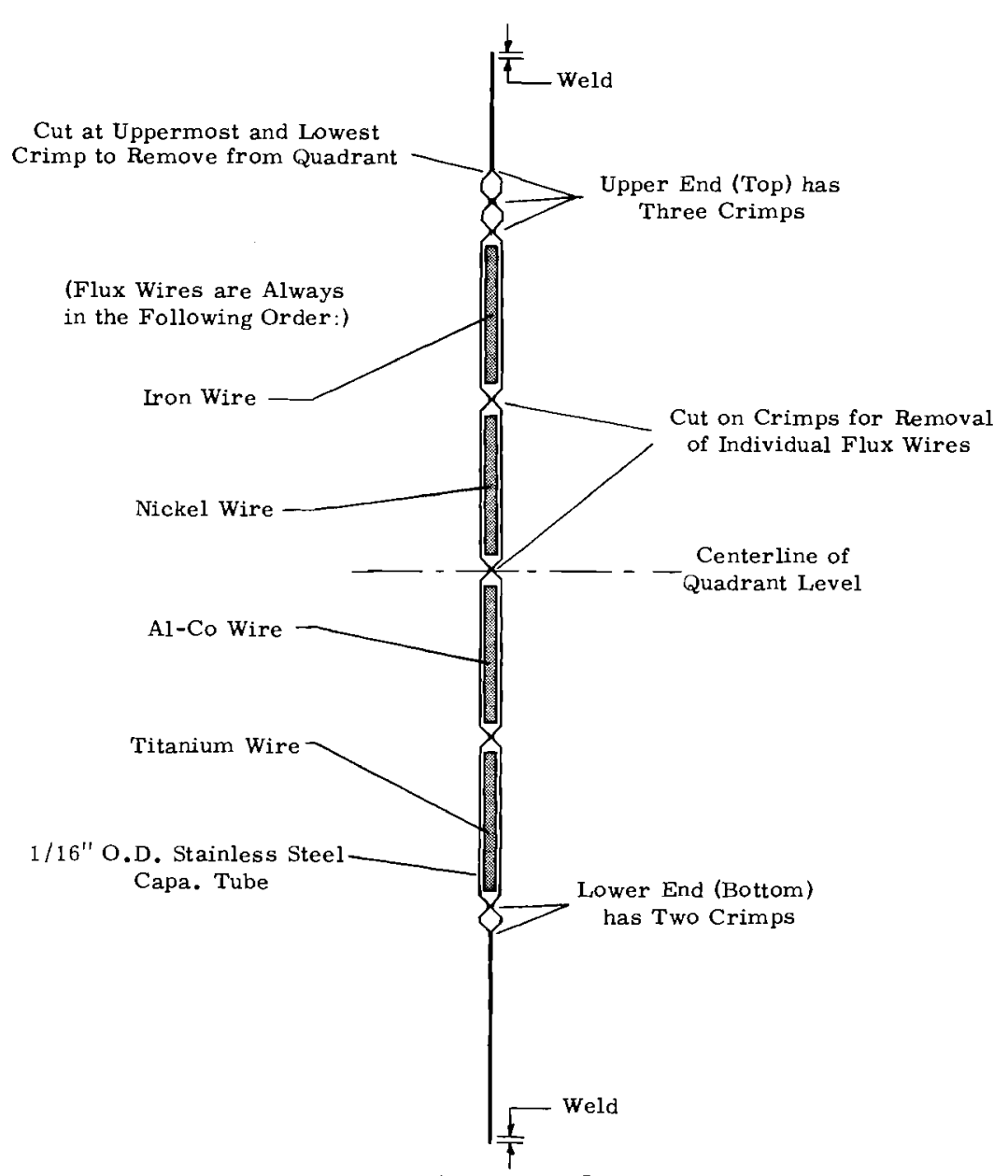

FIGURE 2

Quadrant Flux Monitor

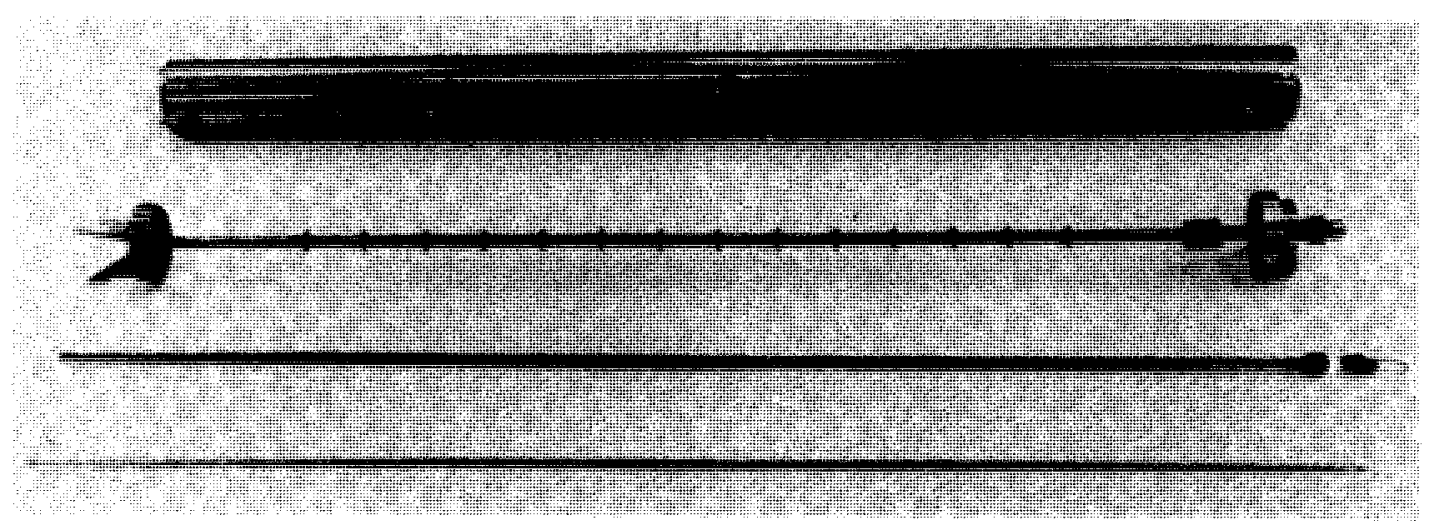

FIGURE 3

ETR 6 × 9 Loop Basket and Hanger Assembly

Disassembled View 


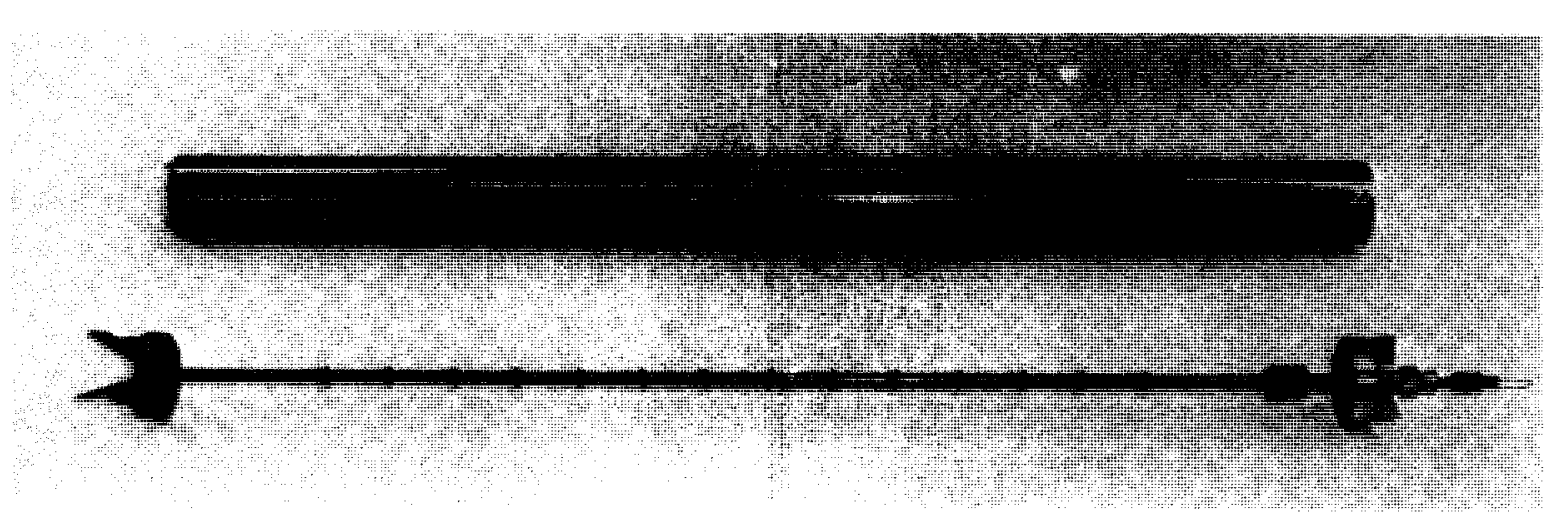

\section{FIGURE 4}

ETR $6 \times 9$ Loop Basket and Hanger Assembly

(Central Monitor Inserted in Hanger)

Procedures for measuring neutron fluxes at the specimen quadrants were not changed from the start of irradiations with Cycle 39. Procedures for measuring flux in the central position, however, developed by stages. Initial flux mapping of the $G-7$ position was accomplished by continuous wires of nickel placed in "weep holes" located in the aluminum support block. The positions of the weep holes are shown in Figure 5. The wires were activated in holes $1,3,11$, and 19 during the low-power run preceding Cycle 37, and the measured activities were extrapolated to full reactor power. Cycle-tocycle measurements in the center of the loop commenced with Cycle 45 by which time a flux monitoring assembly had been developed.

The use of 28 individual threshold detectors every cycle to measure fluxes along the central axis of the loop involved awkward disassembly procedures, exacting inventory methods, and extensive handling and transfer steps. To eliminate these problems and reduce costs, procedures were developed for gamma radiation spectroscopy of continuous wires. As a preliminary step, continuous flux wires were irradiated in 6 of the 14 "weep holes" of the G-7 support block for the duration of Cycle 57 .

Continuous gamma "scans" were performed on the wires in the ETR canal after discharge, and samples of the wires were removed and counted by established procedures to check the accuracy of flux readings at corresponding positions along the wires. This scanning technique proved acceptable, 
and continuous wires have been used for central flux measurements since Cycle 58 .

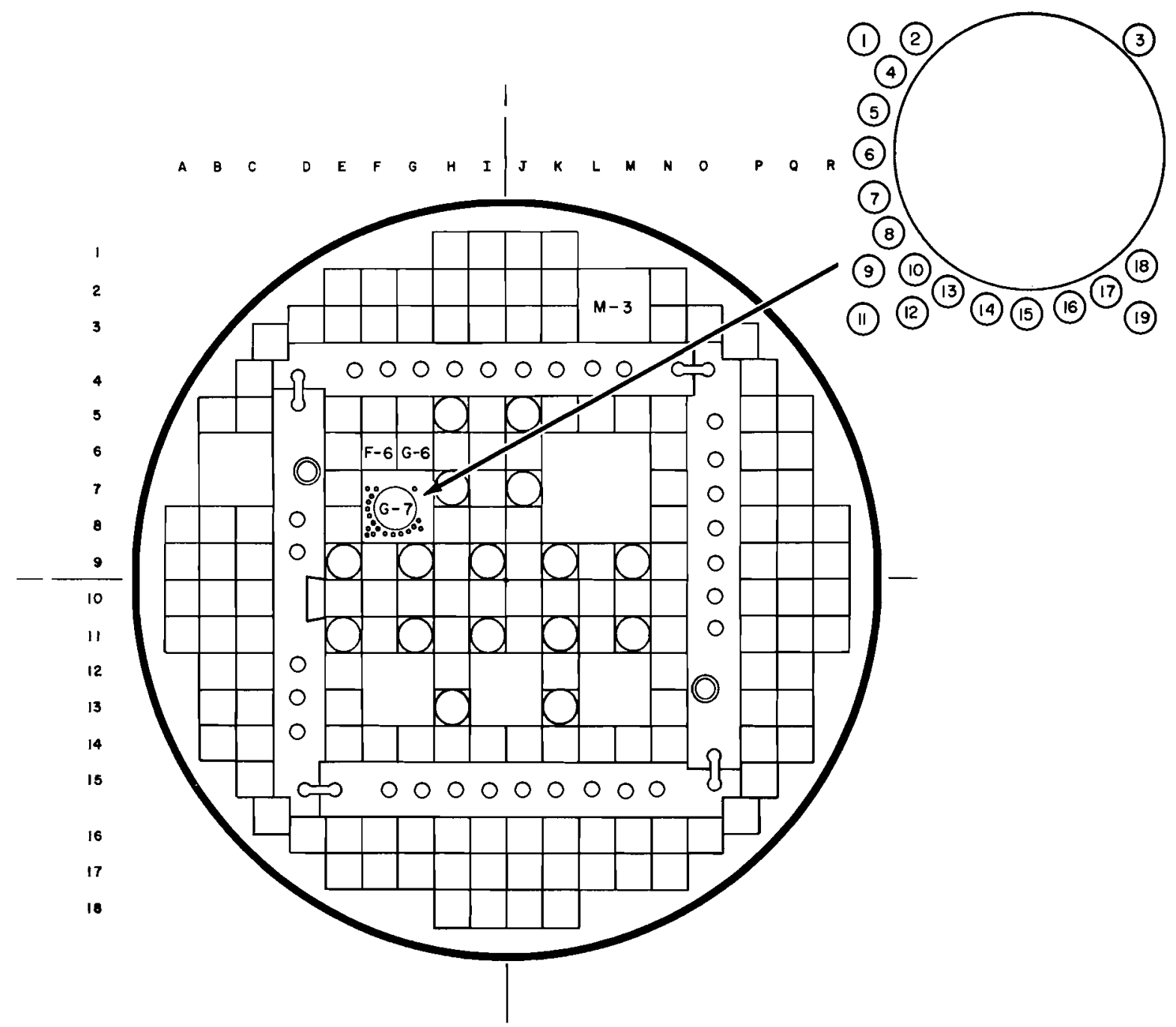

FIGURE 5

Weep Hole Positions Near the G-7 Loop

0640354

Wire stock procured for the detectors for the first 50 specimen quadrants was specified to be of high purity $(99.95 \%$ for iron and nickel and $99.8 \%$ for titanium). Although certified chemical analyses were not obtained for these materials, gamma-ray spectroscopy revealed no serious impurity peaks. Al-Co alloy wires were not included with these quadrants, and corrections of flux data from nickel wires to account for cobalt burnup were based on estimated thermal fluxes for the respective positions. The 
initial source of $\mathrm{Al}-0.1 \mathrm{wt} \%$ Co wire used on the program was provided by the MTR-ETR counting laboratory, Phillips Petroleum Company, Arco, Idaho.

Shortly after the beginning of irradiations in the G-7 loop, standard sources of dosimeter wires were procured for use on the coordinated Irradiation Effects on Reactor Structural Materials program involving nine participating organizations. The analyses of these wires, which have been used since Cycle 45, are listed in Table I.

\section{TABLE I}

CERTIFIED CHEMICAL ANALYSES OF DETECTOR WIRES

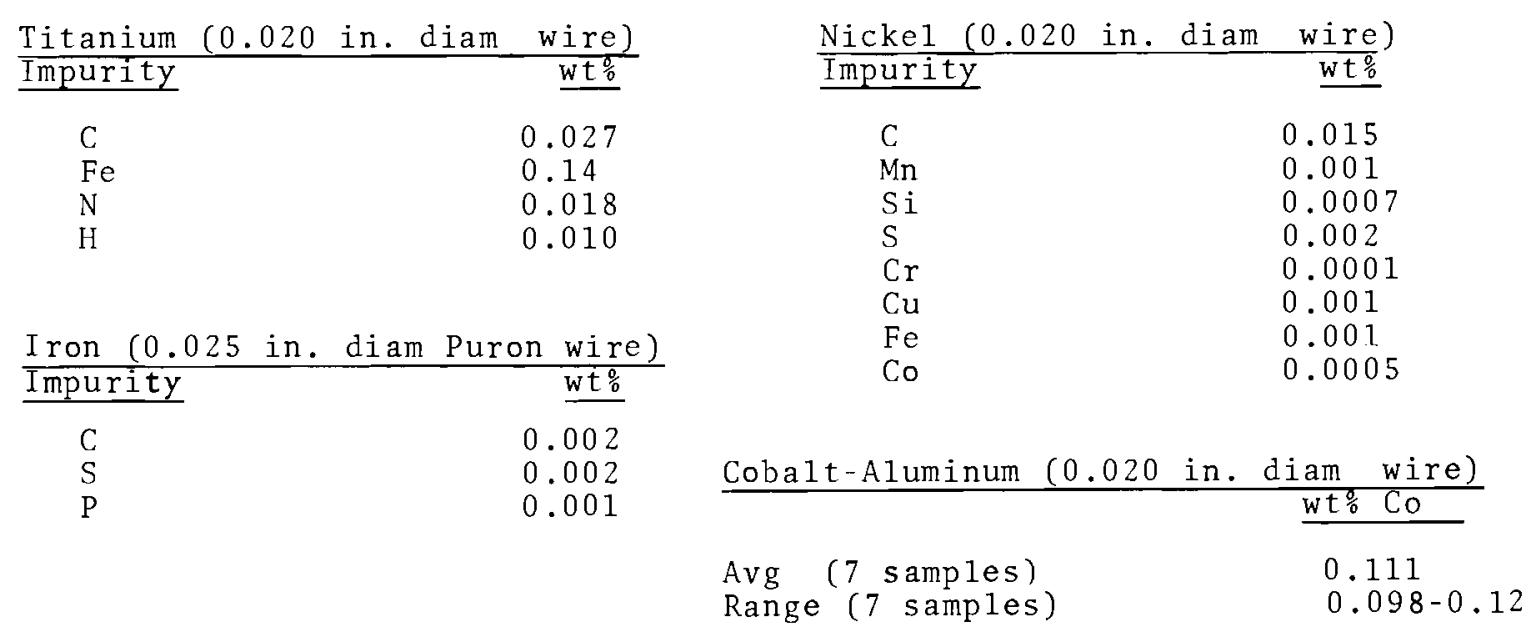

The irradiation histories for quadrants 1 through 140, including insertion cycle, discharge cycle, and effective days at $175 \mathrm{MW}$, are listed in Appendix I.

Beginning with Cycle 47, the rod removal program for the core of the ETR was changed, affecting mainly the flux distribution and intensity in the northwest corner of the core. A diagram of the reactor core, given in Figure 6, shows the location of control rods, fuel elements, and experimental positions. Changes in the rod withdrawal program are given in Table II. (1) 


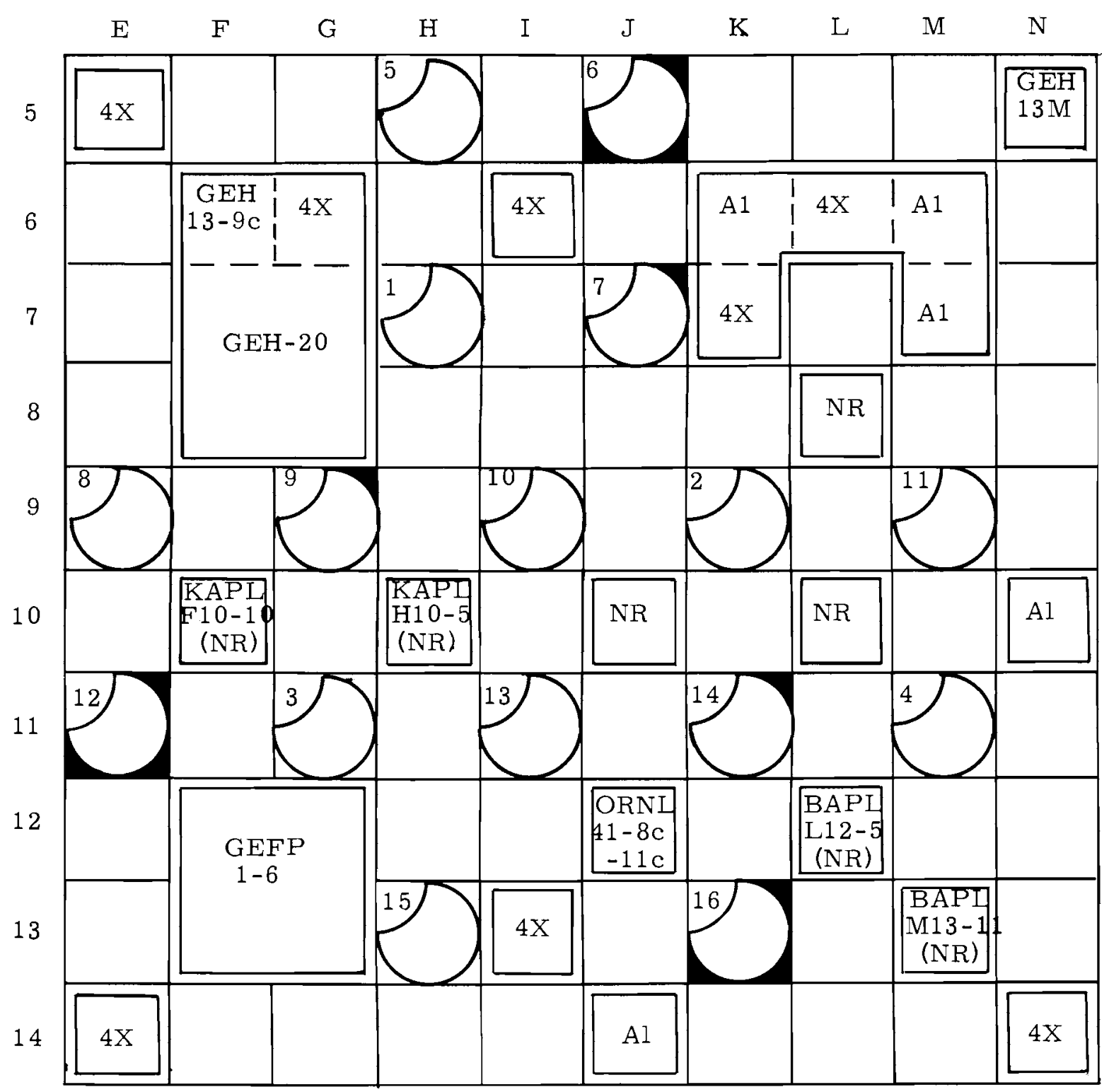

Rod Number
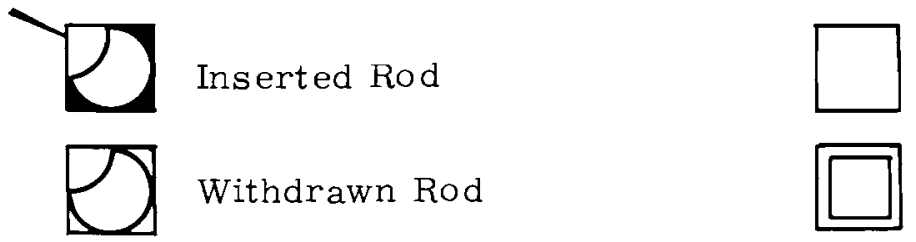

Fuel Element

Experimental Position

FIGURE 6

Diagram of ETR Core Positions 


\section{TABLE II}

\section{CHANGE IN ETR ROD WITHDRAWAL PROGRAM WITH CYCLE 47}

\begin{tabular}{ccc}
$\begin{array}{c}\text { Withdrawa1 } \\
\text { Step }\end{array}$ & \\
\hline 1 & & \\
2 & $\&$ & 3 \\
4 & & \\
5 & & \\
6 & & \\
7 & &
\end{tabular}

$\begin{gathered}\text { Rod Program } \\ \text { Before Cycle } 47\end{gathered}$
$\begin{gathered}1,2,3,4 \\ 10,13 \\ 12 \\ 7,11,15 \\ 5,9,14 \\ 6,8,16\end{gathered}$

Rod Program Starting With Cycle 47

The principal rod withdrawal changes from Table II involved interchanging the withdrawal of rod 12 with 8 and rod 5 with 7 . With the former rod withdrawal program, the core flux distribution at the beginning of the cycle was extremely tilted. That is, the power generation on the east side of the core was comparable with the center region, but the west side was much lower. Of particular importance, the northwest corner containing the G-7 loop had the lowest power generation of any part of the core. This distribution was upset as the control rods were removed during operation; that is, the power generation decreased significantly on the east side and increased greatly on the west side, especially in the northwest corner. Xenon equilibrium occurred with the control rods partially withdrawn in step 6 (rods 5,9 , and 14 on the old program), so that the complete insertion of rod 8 and partial insertion of rod 9 greatly depressed the flux in the southern half of the G-7 loop.

The new rod removal program greatly alleviated the flux tilting situation. Note in Table II that both rods 5 and 8 are removed earlier in the newer program, leaving only rod 9 partially inserted for shim control upon initial xenon equilibrium. Actually, rods 5, 1, 8, and 9 were fully withdrawn throughout most of the duration of many cycles after Cycle 47 .

\section{Counting}

Counting of the dosimeter wires was accomplished at the MTR-ETR counting laboratory under the direction of C. H. Hogg. All gamma analyses were accomplished with a $3 \times 3$-in., right cylindrical, thallium-activated, NaI scintillation crystal. The scintillation spectrometer contained a Nuclear Data Model, 512-channel, pulse-height analyzer. The scintillation 
detector was enclosed in a cubic lead shield having inside dimensions of 32 in. on a side. The normal source-to-detector distance along the cylindrical axis was $10 \mathrm{~cm}$, and the normal channel width was $10 \mathrm{keV} / \mathrm{channel}$. Detailed descriptions of the spectrometer and detector components, source mounting procedures, and data preparation steps are given in the GammaRay Spectrum Catalogue, by Heath. (2)

All pulse-height values were measured relative to that of the 0.57 , 1.06, and $1.77 \mathrm{MeV}$ gamma peaks of $\mathrm{Bi}^{207}$ as defined by standard Heath curves. A least squares procedure was used to fit channel positions, and a computer program was used to shift either the gain or the zero position of the pulse-height scale. Further description of these procedures are given els ewhere. $(3,4)$

An exchange of control flux wires for intercomparison of counting data was made among the nine organizations participating in the Irradiation Effects on Reactor Structural Materials program. (5) The activated samples were taken from the standard $\mathrm{Ti}, \mathrm{Fe}, \mathrm{Ni}$, and $\mathrm{Al}-0.1 \mathrm{wt} \%$ Co wires procured for the program. Satisfactory counting consistency was obtained among the sites after two exchanges, and possible counting errors were reduced to within $10 \%$.

Activated sources on the present program were counted nondestructively, except for the early iron detectors. The $\mathrm{Mn}^{54}$ isotope for the first 50 quadrants, was chemically separated from the iron by ion exchange to improve peak discrimination.

\section{Analys is}

The following nuclear reactions were used on the program: $\operatorname{Fe}^{54}(n, p)$ $\mathrm{Mn}^{54}, \mathrm{Ti}^{46}(\mathrm{n}, \mathrm{p}) \mathrm{Sc}^{46}, \mathrm{Ni}^{58}(\mathrm{n}, \mathrm{p}) \mathrm{Co}^{58}$, and $\mathrm{Co}^{59}(\mathrm{n}, \mathrm{y}) \mathrm{Co}^{60}$. The first three reactions are particulariy useful for long-term irradiations because of the relatively long half-lives of the products. All three of these reactions have drawbacks, however, which limit their accuracy for the fast flux determinations. For example, the cross section for the $\mathrm{Ti}^{46}$ (n, p) Sc${ }^{46}$ reaction has not been measured as a function of energy. A high $\mathrm{Fe}^{59}$ content in irradiated iron specimens occasionally necessitates a chemical separation of the $\mathrm{Mn}^{54}$ isotope. Finally, the $\mathrm{Co}^{58}$ isomers of the $\mathrm{Ni}^{58}$ (n, p) $\mathrm{Co}^{58}$ reaction 
have a high thermal cross-section requiring a burnup correction for long irradiations. To assist in this correction thermal flux at each monitored position was measured by the $\mathrm{Co}^{59}(\mathrm{n}, \mathrm{y}) \mathrm{Co}^{60}$ reaction. Discrepancies in fast flux measurements arising from the above drawbacks usually can be recognized if $\mathrm{Fe}, \mathrm{Ni}$, and $\mathrm{Ti}$ detectors are used concurrently, and advantage can be taken of the relative strong points of each type of detector.

All of the measured specific disintegration rates of the above reactions were corrected to the time of reactor discharge. Half-lives of the product isotopes used for this purpose are given in Table III.

TABLE II I

HALF LIVES USED FOR CORRECTION TO TIME OF DISCHARGE

$\begin{array}{lcc}\text { Isotope } & \text { Half Life, hours } & \begin{array}{c}\text { Percent } \\ \text { Isotopic Abundance } \\ \text { of Parent Isotope }\end{array} \\ \mathrm{Co}^{58} & 1,710 & 100 \\ \mathrm{Co}^{60} & 46,170 & 26.23 \\ \mathrm{Mn}^{54} & 7,536 & 5.82 \\ \mathrm{Sc}^{46} & 2,016 & 7.93\end{array}$

The cross sections determined for the threshold detectors were averaged over a fission spectrum for energies above $1 \mathrm{MeV}$ by the following expression:

$$
\bar{\sigma}=\frac{\int_{0}^{\infty} \sigma(E) \varphi(E) d E}{\int_{E_{L}}^{\infty} \varphi(E) d E}
$$

where $\sigma(\mathrm{E})$ is the reaction cross-section for neutrons with energy $\mathrm{E}$ and $\varphi(E)$ is the associated neutron flux with that energy in the spectrum. The denominator in Equation (1), representing that fraction of neutrons in a Watt $U^{235}$ fission spectrum having energies above $1 \mathrm{MeV}$, was assumed to be 0.692 . In general, the value of $E_{L}$ may be any reference energy.

Unfortunately, cross-sections as a function of energy have either not been measured (in the case of titanium) or are not precisely known for 
many threshold detectors. The technique used to overcome this problem was to irradiate concurrently a number of threshold dosimeters in a reactor neutron environment approximating a fission spectrum (EBR-1). After irradiation, the reaction rate for the detector whose $\bar{\sigma}$ is to be measured was compared with the known $\bar{\sigma}$ for the $\mathrm{Al}^{27}$ (n, $\left.\propto\right) \mathrm{Na}^{24}$ reaction. ${ }^{(6)}$ The values of $\bar{\sigma}$ obtained for the reactions of interest are listed in Table IV.

\section{TABLE IV}

MEASURED VALUES OF FAST NEUTRON CROSS-SECTIONS

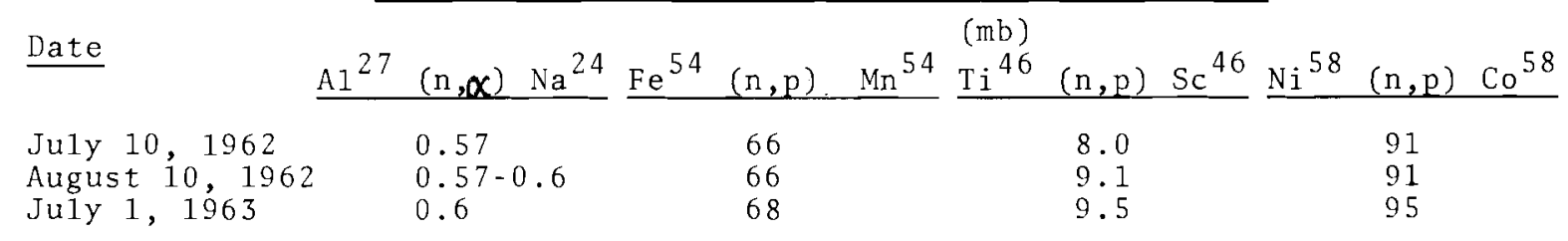

The cross sections given in Table IV were changed during the course of irradiations in the G-7 loop. All of the flux data in this report are normalized to the last set of values given. Fast neutron exposure is then calculated by the general relationship

$$
\varphi t(E>1 \mathrm{MeV})=\int_{0}^{\mathrm{t}} \int_{\mathrm{E}=1 \mathrm{MeV}}^{\infty} \varphi(\mathrm{E}) \mathrm{dE} \mathrm{dt}=\frac{\mathrm{KA}}{\lambda \bar{\sigma} \mathrm{N}^{1}}
$$

where $\varphi$ is the neutron flux integrated over the range indicated

$A$ is the disintegration rate observed in the reaction product

(corrected to time of discharge)

$\lambda$ is the decay constant of the product isotope

$\mathrm{N}$ is the number of atoms of the product isotope.

$\mathrm{K}$ is proportional constant used wherever thermal burnup is significant

One of the difficulties encountered in using threshold monitors for long-term irradiations is the reaction of the product isotopes with thermal neutrons. Whereas the thermal neutron cross sections for $\mathrm{Sc}^{46}$ and $\mathrm{Mn}^{54}$ are relatively low ( 0.25 barns and 30 barns, respectively), the cross section for $\mathrm{Co}^{58}$ is relatively high. If burnout is kept below $50 \%$ and burnup corrections are made, the reaction is still considered useful. (6) The 
relationship derived to correct for $\mathrm{Co}^{58}$ burnout according to the reaction and decay scheme shown in Figure 7 is as follows: ${ }^{(7)}$

$$
\varphi_{f} t=\frac{A \exp \left(\lambda_{2} t_{o}\right)}{N \lambda_{2}}\left[\frac{\alpha \beta t}{\left(\sigma-\frac{\lambda_{1} \sigma_{m}}{\alpha-\beta}\right) \beta\left(1-e^{-\alpha t}\right)+\sigma_{m}^{\alpha}\left(1+\frac{\lambda_{1}}{\alpha-\beta}\right)\left(1-e^{-\beta t}\right)}\right]
$$

where:

$$
\begin{aligned}
& \alpha=\lambda_{2}+\sigma_{2} \varphi \\
& \beta=\lambda_{1}+\sigma_{1} \varphi \\
& \varphi=\text { gross thermal-neutron flux intensity } \\
& \varphi_{\mathrm{f}}=\text { fast-neutron flux intensity } \\
& \mathrm{t}=\text { irradiation time } \\
& \mathrm{t}_{\mathrm{O}}=\text { decay time between the end of irradiation and foil counting } \\
& \mathrm{A}=\text { activity of } \mathrm{Co}^{58} \\
& \mathrm{~N}=\text { number of } \mathrm{Ni}^{58} \text { atoms }=6.95 \times 10^{18} \\
& \sigma=\text { fast-neutron activation cross section for } \mathrm{Ni}^{58} \text { to } \mathrm{Co}^{58}=66 \mathrm{mb} \\
& \sigma_{1}=\text { thermal-neutron absorption cross section of } \mathrm{Co}^{58 \mathrm{~m}}=1.7 \times 10^{4} \mathrm{~b} \\
& \sigma_{2}=\text { thermal-neutron absorption cross section of } \mathrm{Co}^{58}=1650 \mathrm{~b} \\
& \sigma_{\mathrm{m}}=\text { fast-neutron activation cross section for } \mathrm{Ni}^{58}=29 \mathrm{mb} \\
& \lambda_{1}=\text { decay constant for } \mathrm{Co}^{58} \mathrm{~m}=1.83 \mathrm{day}^{-1} \\
& \lambda_{2}=\text { decay constant for } \mathrm{Co}^{58}=9.72 \times 10^{-3} \mathrm{day}^{-1}
\end{aligned}
$$

\section{FAST-NEUTRON EXPOSURE}

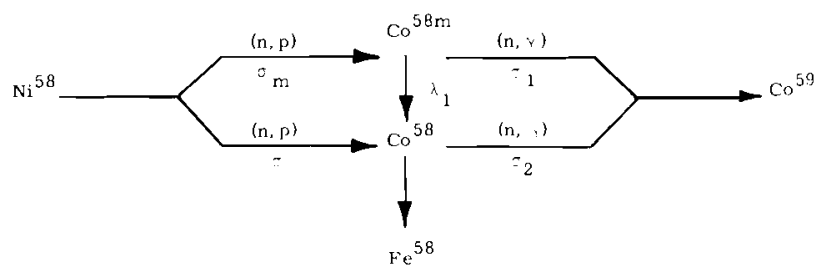

FIGURE 7

Activation and Decay Scheme for Co 58

(See Equation (3) for definition of terms) 
The dependency of mean cross section on neutron flux spectrum over the energy range of interest stresses the importance of measuring actual flux-energy spectra. If actual spectra differ significantly from the assumed fission spectrum, appropriate corrections to $\bar{\sigma}$ are required.

The space-energy distribution of neutrons for the northwest quadrant of the ETR was calculated to determine flux intensity gradients and spectral shifts. ${ }^{(8)}$ These calculations were made with a multigroup, multiregion, transport-theory code 2DXY which uses XY geometry. Eighteen energy groups were used with 16 of the groups above $0.18 \mathrm{MeV}$, thereby giving a detailed study of neutron spectra in the damage-producing energy range. Spatially, the quadrant was analyzed using a $19 \times 19$ grid of inch squares, and materials contained within each square were homogenized. Thus, solutions were obtained in 361 separate zones in 18 energy intervals.

Figure 8 illustrates the portion of the reactor and the loading arrangement in the core which was analyzed for Cycle 47 . The G-7 hot-water loop is shown in Figure 9, where again materials were smeared over $1 \times 1$-in. zones. Solutions were obtained over 36 zones in this facility, with the No. 9 rod, frequently used for shim control, full in and full out of the core.

Suitable neutron-exposure units are necessary for radiation-damage experiments to correlate test data obtained in different reactors. Referring to Equation (1), the value of the specified energy limit $E_{L}$ in the denominator was arbitrarily selected as $1 \mathrm{MeV}$. However, atomic displacements in metal lattices take place at much lower energies. What is really desired is a value of $E_{L}$ such that the integrated neutron flux above $E_{L}$ is proportional to gross-displacement production independent of spectrum. In the following analysis, $E_{L}$ is varied until for a particular material the quantity

$$
D\left(E_{1}\right)=\frac{\int_{0}^{\infty} N(E) \sigma(E) \varphi(E) d E}{\int_{E_{L}}^{\infty} \varphi(E) d E}
$$

is equal for the various spectra in which radiation effects are compared. 


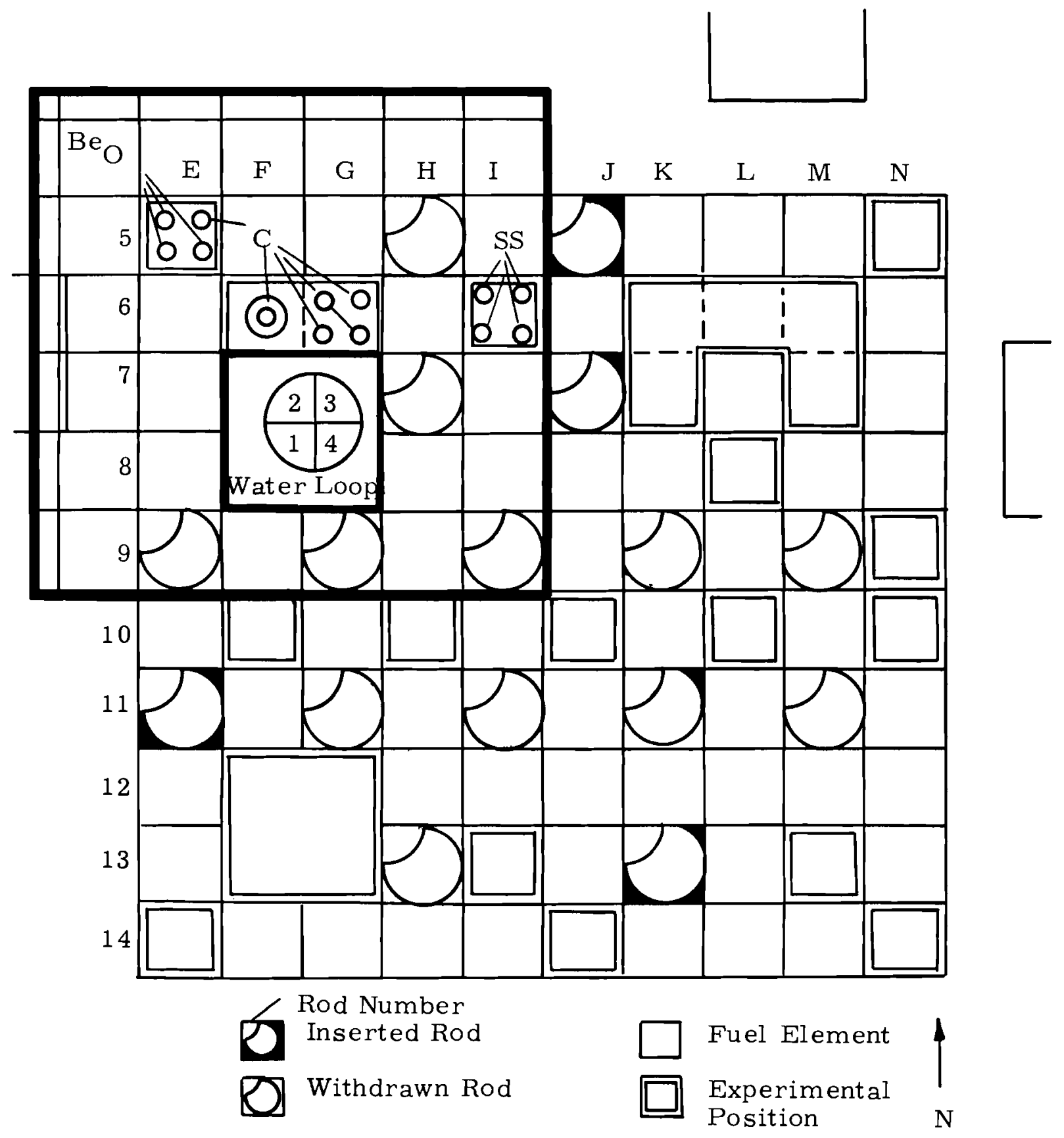

Neg. No. 0630552-4

FIGURE 8

ETR Core - The Northwest Quadrant

Used in the Flux Calculations Lies Inside the Heavy Lines 


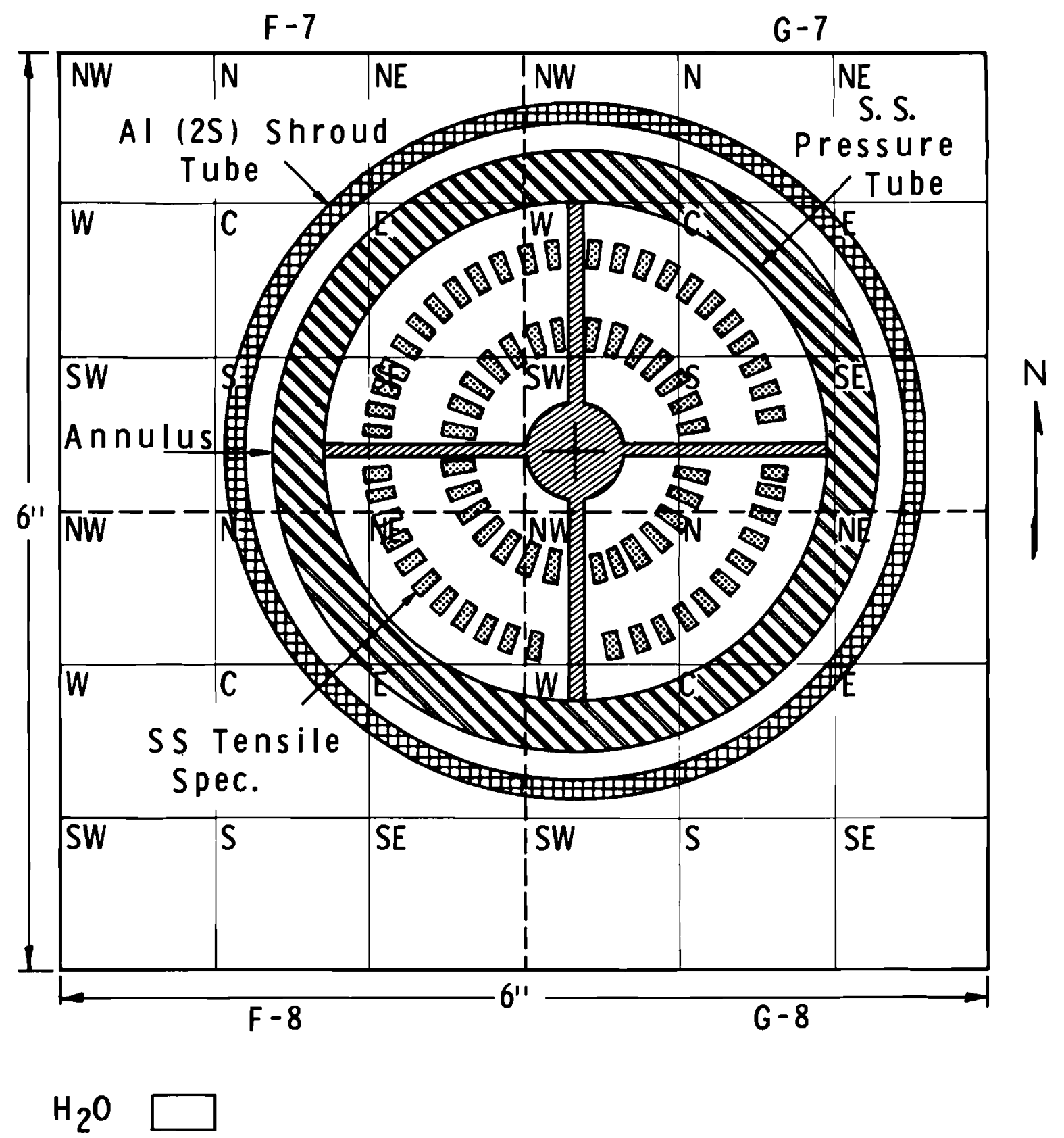

FIGURE 9

Water Loop

0630552-3

ETR Core 
$\mathrm{N}(\mathrm{E})$ is the number of displacements produced by a neutron with energy $\mathrm{E}$, $\sigma(E)$ is the energy-dependent cross section of the material, and $\varphi(E)$ is the neutron spectrum.

Figure 10 shows that the condition required of $\mathrm{E}_{\mathrm{L}}$ is generally satisfied for a wide variety of useful spectra. Included are plots of $\mathrm{D}\left(\mathrm{E}_{\mathrm{L}}\right)$ using a Kinchin and Pease damage model for a Watt $\mathrm{U}^{235}$ fission spectrum, an ETR spectrum, and a graphite moderated reactor spectrum. At about $0.46 \mathrm{MeV}$, the various curves intersect fulfilling the desired conditions for the exposure unit. This method has been found to be relatively insensitive to the specific model relating vacancy production to neutron energy selected.

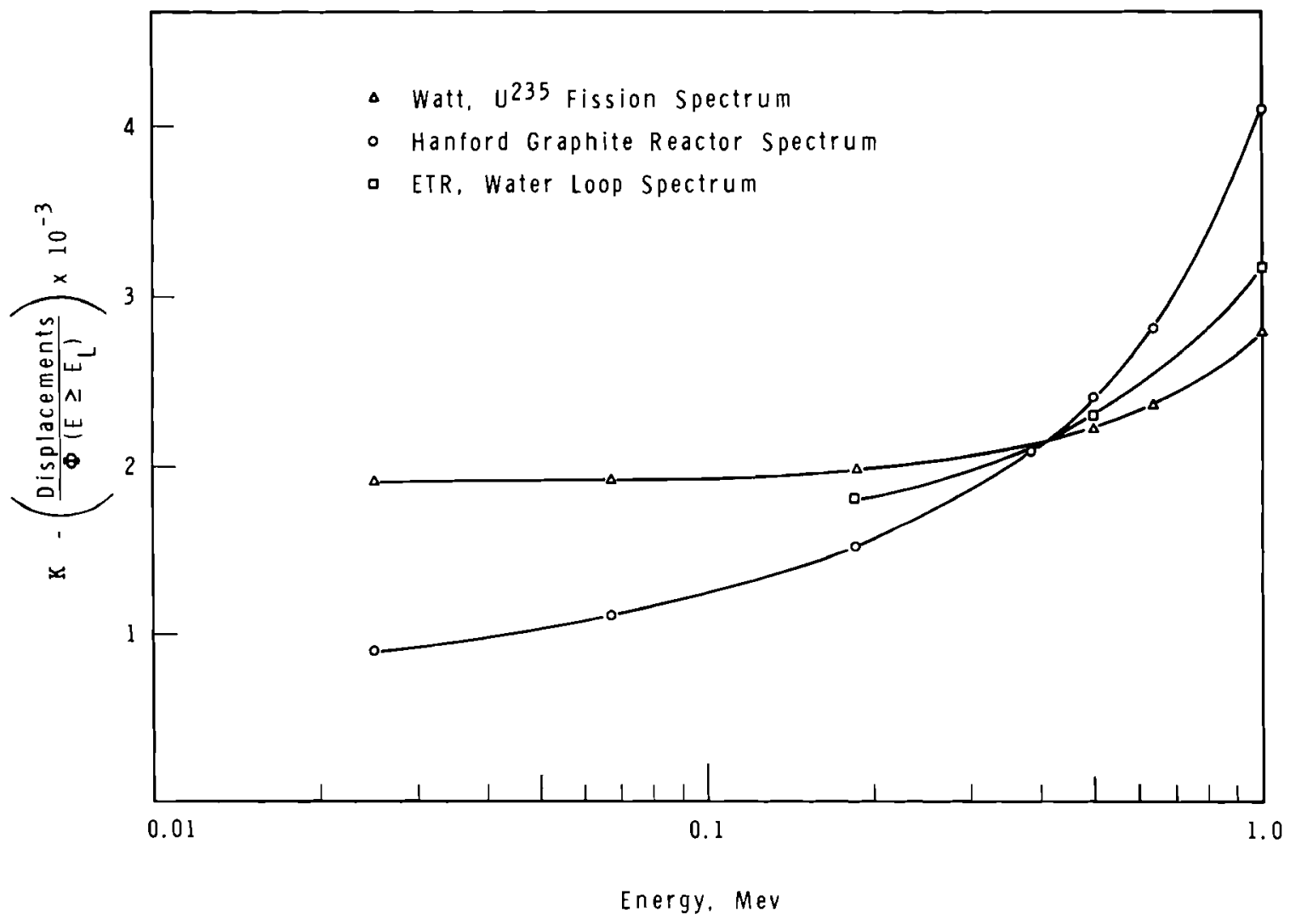

FIGURE 10

Normalization of Displacements in Iron in Various Spectra $0643234-2$ 
The relationship between $\mathrm{E}_{\mathrm{L}}$ and atomic mass for several materials of interest is shown in Figure 11. As expected, lower values of $\mathrm{E}_{\mathrm{L}}$ are necessary for lighter elements and higher values of $\mathrm{E}_{\mathrm{L}}$ for heavier elements. For substances heavier than iron there is little change in $E_{L}$. Based on these results, a convention adopted on the current program is to report exposures for energies above $0.5 \mathrm{MeV}$ as well as above $1 \mathrm{MeV}$.

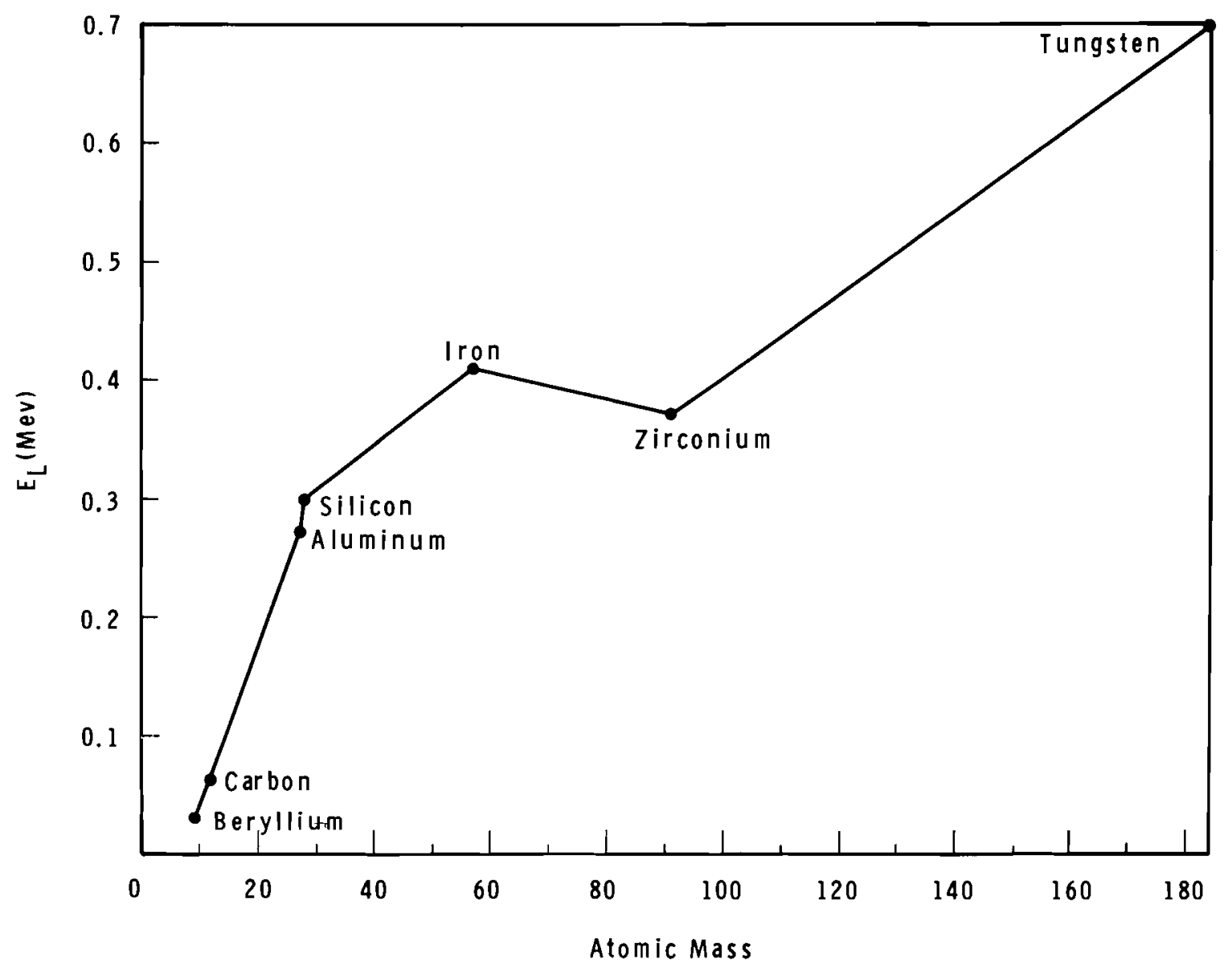

FIGURE 11

Variation of $\mathrm{E}_{\mathrm{L}}$ with Atomic Mass

for Damage Normalization

0641991-6 


\section{RESULTS}

\section{Central Flux}

The specific disintegration rates corrected for time of discharge for all of the central flux dosimeters measured at the ETR-MTR counting laboratories are tabulated in Appendix II. Instantaneous flux and integrated exposure values derived from these disintegration rates are given in Appendix III. The values for fast flux are based on neutron energies greater than $1 \mathrm{MeV}$, and cobalt burnout corrections have been applied to the fluxes determined from nickel.

Ir radiations in the $\mathrm{G}-7$ loop are accomplished at seven, evenlyspaced vertical levels, as mentioned previously. Average values for the measured flux at each of these leveis are given in Table $\mathrm{V}$. The average flux for each monitor was determined for the ETR cycles preceding the change in the control rod withdrawal program (Cycles 45-47) and for cycles following the change (Cycles 48-57). Additional information given in Table $\mathrm{V}$ includes the vertical distances below the top of the core filler piece to the center of each specimen quadrant and to the center of each flux dosimeter. The percent standard deviation of the data for Cycles 48 to 57 and ratios of thermal to fast neutron flux (based on nickel) are also given. The percent standard deviation in the fast flux is about $\pm 10 \%$ with a maximum value of $\pm 15.7 \%$. The standard deviation in thermal flux is somewhat greater near the peak of the flux gradient (levels $E$ and $F$ ). Cycle-to-cycle variations in flux constitutes the greater part of these deviations. 
TABLE $V$

CENTRAL NEUTRON FLUX DISTRIBUTION - G-7 LOOP

\begin{tabular}{|c|c|c|c|c|c|c|}
\hline & $\begin{array}{l}\text { Position } \\
\text { (Level) }\end{array}$ & $\underline{\mathrm{Ni}}$ Fast Flu & $\frac{(\mathrm{E}>1 \mathrm{MeV})}{\underline{\mathrm{Fe}}}$ & ${ }^{13} \mathrm{nv}$ & $\begin{array}{r}1013 \text { nv } \\
\text { A1-0.1 wt: Co } \\
\end{array}$ & $\phi_{\mathrm{Co} /} \phi_{\mathrm{Ni}}$ \\
\hline A & $(2-1 / 4)^{(1)}$ & (2) & $(1-1 / 2)$ & (3) & $(2-1 / 2)$ & \\
\hline & Cycles $45-47(\operatorname{Avg})^{(2)}$ & 1.92 & 1.68 & 2.55 & 3.81 & 1.98 \\
\hline & Cycles 48-57(Avg) (3) & 2.14 & 1.78 & 2.8 & 4.5 & 2.1 \\
\hline & $\pm S^{(4)}(\%)$ & 10.7 & 12.4 & 13.6 & 12.2 & \\
\hline$B$ & (7) & $(6-3 / 4)$ & $(6-1 / 4)$ & $(7-3 / 4)$ & $(7-1 / 4)$ & \\
\hline & Cycles 45-47 (Avg) & 4.4 & 4.23 & 5.33 & 8.57 & 1.95 \\
\hline & Cycles 48-57 (Avg) & 4.93 & 4.65 & 5.86 & 10.72 & 2.18 \\
\hline & $\pm S(\%)$ & 10.1 & 9.5 & 7.2 & 9.8 & \\
\hline $\mathrm{C}$ & $(11-3 / 4)$ & $(11-1 / 2)$ & $(11)$ & $(12-1 / 2)$ & (12) & \\
\hline & Cycles 45-47 (Avg) & 6.77 & 6.48 & 8.01 & 15.4 & 2.28 \\
\hline & Cycles 48-57 (Avg) & 7.62 & 7.13 & 8.1 & 17.83 & 2.34 \\
\hline & $\pm S(\%)$ & 12.9 & 15.7 & 14.5 & 12.5 & \\
\hline $\mathrm{D}$ & $(16-1 / 2)$ & $(16-1 / 4)$ & $(15-3 / 4)$ & $(17-1 / 4)$ & $(16-3 / 4)$ & \\
\hline & Cycles 45-47 (Avg) & 8.52 & 8.14 & 9.29 & 16.21 & 1.9 \\
\hline & Cycles 48-57 (Avg) & 9.65 & 9.43 & 10.3 & 20.89 & 2.16 \\
\hline & $\pm S(\%)$ & 7.7 & 7.5 & 7.8 & 13.7 & \\
\hline E & $(21-1 / 4)$ & (21) & $(20-1 / 2)$ & $(22)$ & $(21-1 / 2)$ & \\
\hline & Cycles 45-47 (Avg) & 9.41 & 9.08 & 10.47 & 22.77 & 2.42 \\
\hline & Cycles 48-57 (Avg) & 10.72 & 10.45 & 11.52 & 26.23 & 2.45 \\
\hline & $\pm S(\%)$ & 11.1 & 10.0 & 9.4 & 18.3 & \\
\hline $\mathrm{F}$ & $(26)$ & $(25-3 / 4)$ & $(25-1 / 4)$ & $(26-3 / 4)$ & $(26-1 / 4)$ & \\
\hline & Cycles 45-47 (Avg) & 9.60 & 9.41 & 10.37 & 22.87 & 2.38 \\
\hline & Cycles 48-57 (Avg) & 10.35 & 10.72 & 10.89 & 25.77 & 2.48 \\
\hline & $\pm S\left(\frac{0}{0}\right)$ & 12.8 & 8.8 & 11.6 & 16.3 & \\
\hline G & $(30-3 / 4)$ & $(30-1 / 2)$ & $(30)$ & $(31-1 / 2)$ & $(31)$ & \\
\hline & Cycles 45-47 (Avg) & 9.05 & 8.48 & 9.2 & 18.1 & 2.00 \\
\hline & Cycles 48-57 (Avg) & 9.26 & 8.88 & 8.75 & 19.9 & 2.15 \\
\hline & $\pm S\left(\frac{\%}{0}\right)$ & 12.2 & 11.3 & 10.2 & 10.8 & \\
\hline
\end{tabular}

(1) Inches from the top of the core filler piece to the nearest $1 / 4$ inch $(A=2-5 / 32$ in.)

(2) Cycles before change in rod withdrawal program

(3) Cycles after change in rod withdrawal program

(4) Percent standard deviation based on Cycles 48-57 
The average values of fast neutron flux for each of the dosimeters are plotted in Figure 12 as a function of vertical distance from the top of the core filler piece. The points for titanium fall considerably above those for nickel and iron, and the curves are fared through the nickel and iron values only. The net results of changing the rod-withdrawal program were to increase the peak flux from approximately 9.6 to $10.7 \times 10^{13} \mathrm{nv}$ and to shift the peak in the flux gradient about 2 in. higher. Flux changes at both the top and bottom irradiation levels were low.

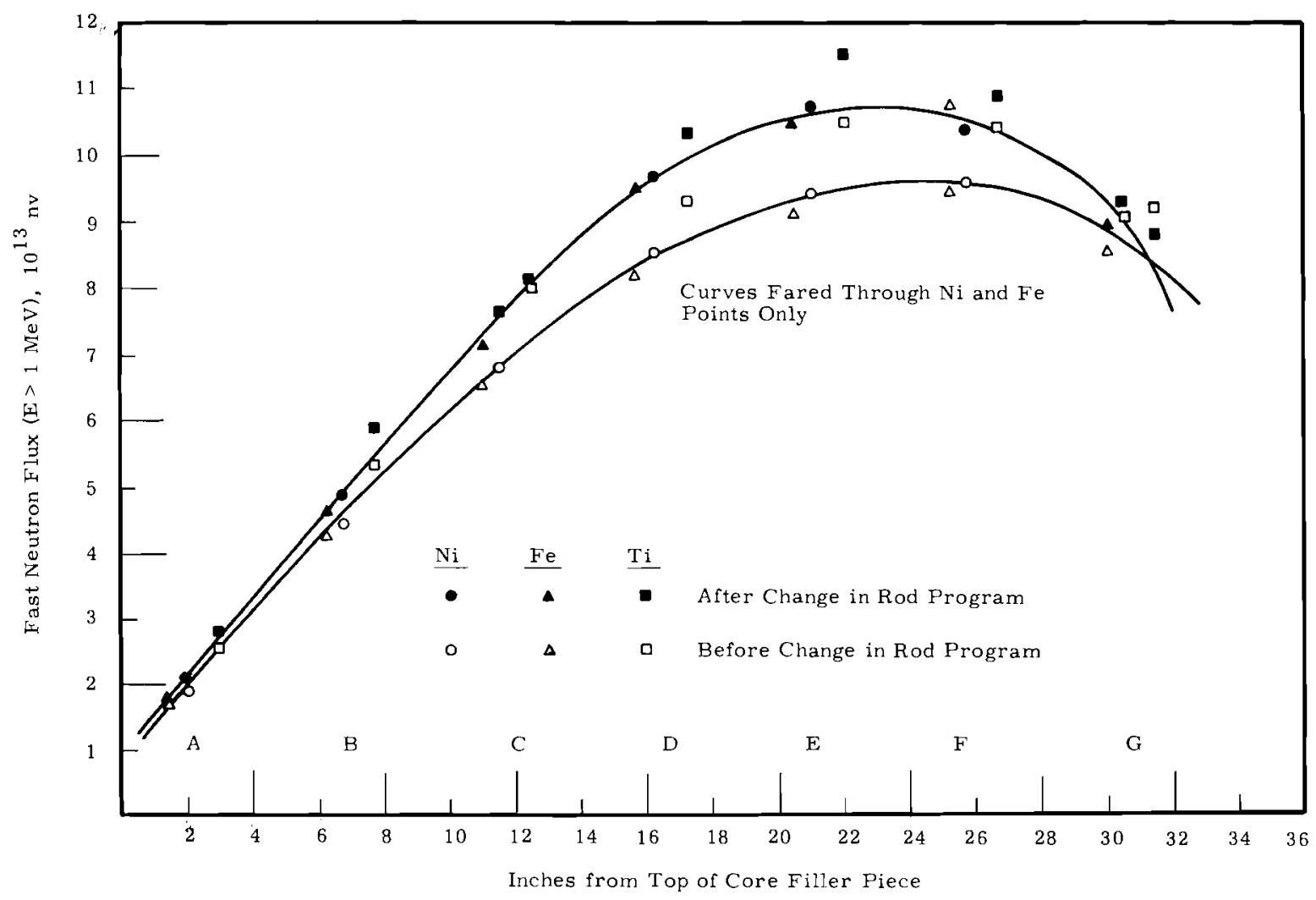

FIGURE 12

Vertical Fast Flux Gradient in the G-7 Hot-Water Loop

Thermal neutron flux is plotted in Figure 13 as a function of vertical distance along the loop centerline. The trends in the flux gradient with change in the rod program are generally similar to those indicated in the fast flux. The flux values for levels B, D, and G are somewhat depressed 
with respect to the other values both before and after the change in the rod program. These effects are attributed to hafnium additions to the $\mathrm{H}-10$ test loop after Cycle 47 .

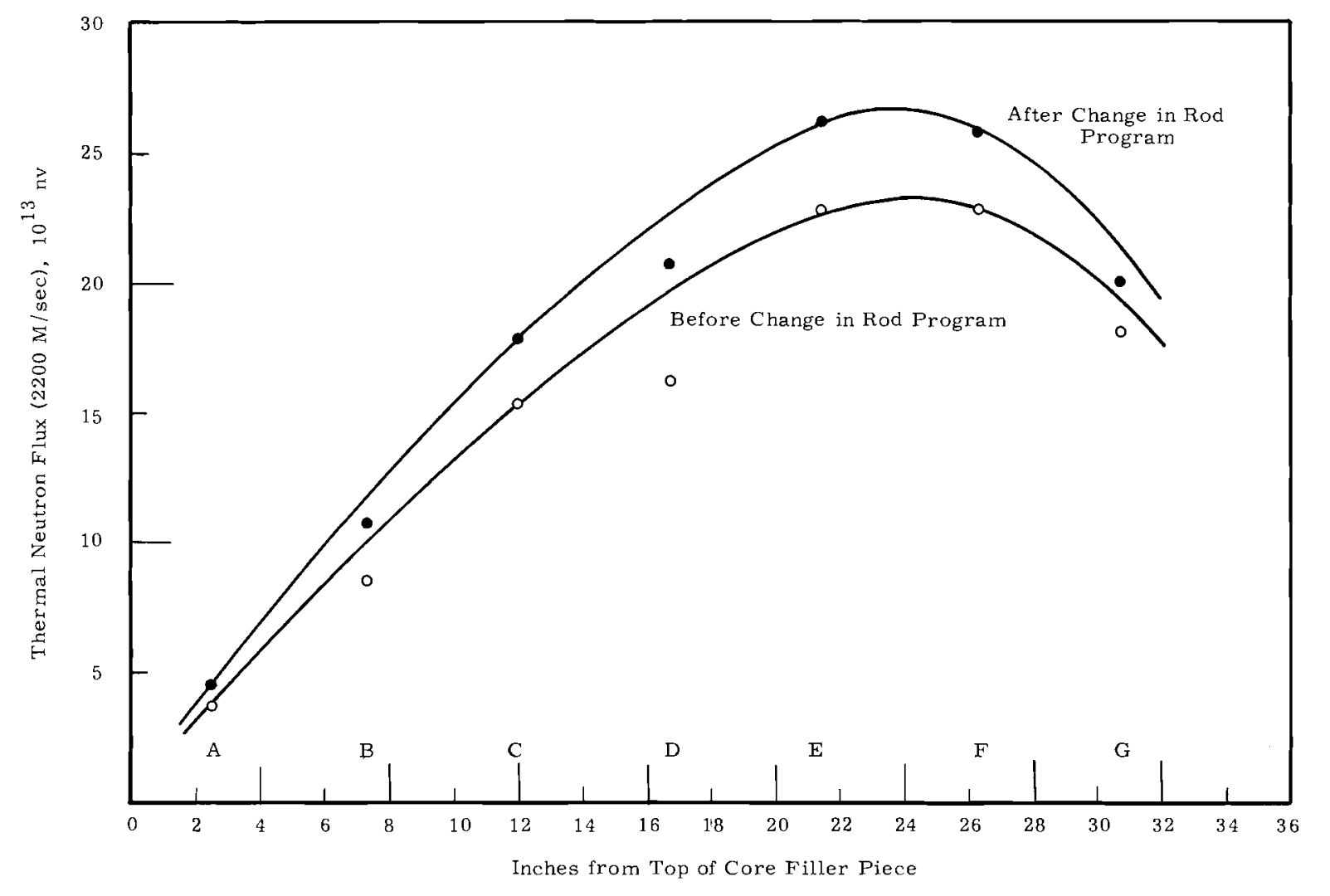

FIGURE 13

Vertical Thermal Flux Gradient in the G-7 Hot-Water Loop

The ratio of thermal to fast neutron flux is plotted in Figure 14 as a function of fast neutron flux. Discounting the points for levels $B, D$, and $G$, for which the thermal flux was shown to be depressed, the ratio increases from about 2 for a fast flux of $2 \times 10^{13} \mathrm{nv}$ to about 2.5 for a fast flux of $11 \times 10^{13} \mathrm{nv}$.

Referring to Figure 2, the flux wires were spaced on $1 / 2-i n$. centers at each irradiation level. Since this vertical separation results in a significantly different flux along the steeper portions of the flux gradient, vertical corrections must be made before data from the three dosimeter materials can be compared. Vertical flux correction factors derived from the average fast flux gradient in Figure 12 for Cycles 48 to 57 are listed in Table VI. 


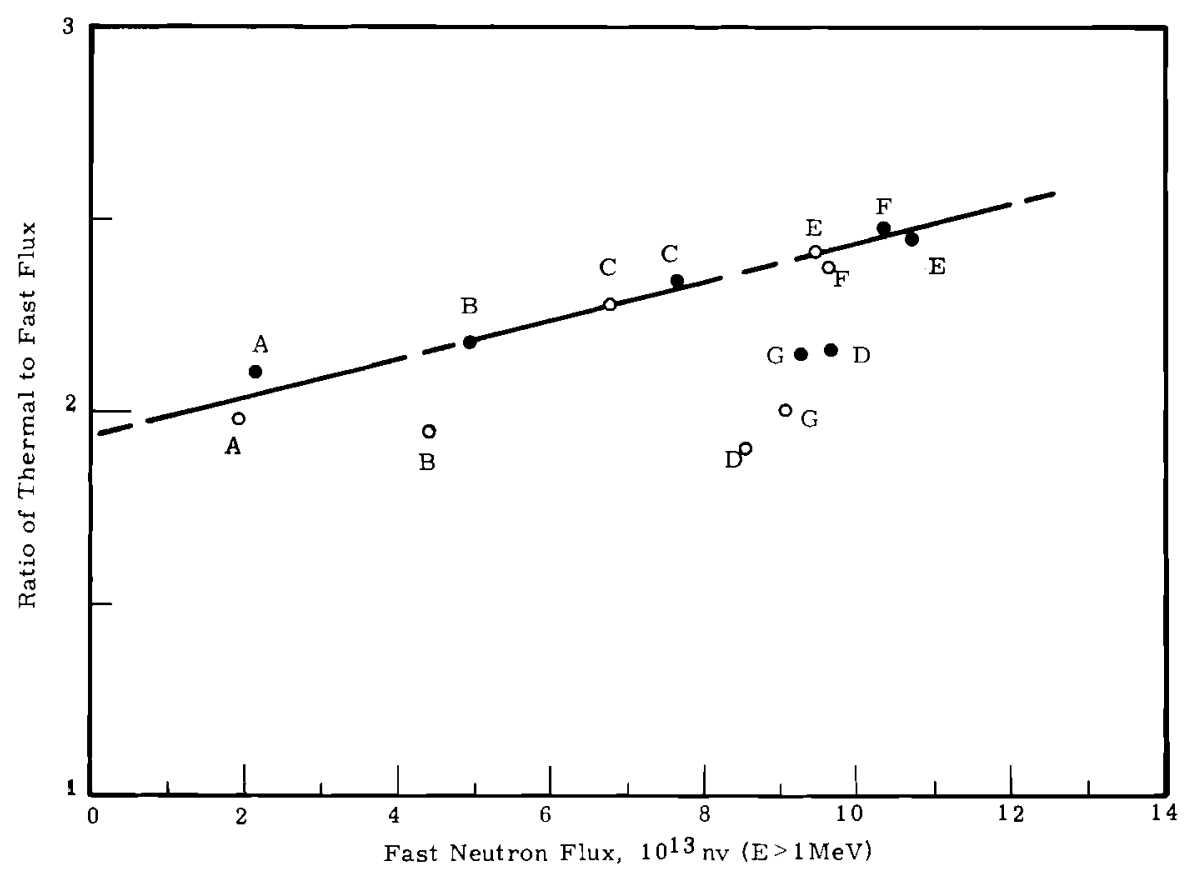

\section{FIGURE 14}

Thermal to Fast Flux Ratio in the G-7 Position

TABLE VI

VERTICAL FLUX CORRECTION FACTORS

Position $\underline{\text { (Leve 1) }}$

\section{A}

B

C

D

E

$\mathrm{F}$

G

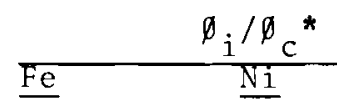

0.79

0.92

0.95

0.98

0.99

1.01

1.05

0.92

1.19

$\underline{\text { Range }}$

$-21 \%$

$+19 \%$

- $8 \%$

88
$+\quad 9 \%$

$\pm 5 \%$

$+2 \%$

$-1 \%$

$-1 \%$
$+\quad 0 \%$

$\begin{array}{llll}1.01 & 1.00 & 0.99 & \pm 1 \% \\ 1.05 & 1.02 & 0.94 & +5 \% \\ & & & \end{array}$

$\emptyset_{i}=$ Flux at monitor position, $\emptyset_{c}=$ flux at centerline of quadrant 
The necessary correction varies from about $\pm 20 \%$ at level $\mathrm{A}$ to practically no correction at level $\mathrm{E}$ to about $\pm 5 \%$ at level $\mathrm{G}$. The average fast flux at each irradiation level for Cycles 48 to 57 after vertical correction of the individual dosimeter measurements are given in Table VII. Also tabulated are the ratios of the dosimeter value to the overall average value for each level, expressed as

$$
\frac{\left|\mathrm{f}_{\mathrm{Fe}}^{-1} \sum_{\mathrm{i}} \varphi_{\mathrm{Fe}}\right|_{j}}{\frac{1}{3}\left\langle\mathrm{f}_{\mathrm{Fe}}^{-1} \sum_{\mathrm{i}} \varphi_{\mathrm{Fe}}+\mathrm{f}_{\mathrm{Ni}}^{-1} \sum_{\mathrm{i}} \varphi_{\mathrm{Ni}}+\mathrm{f}_{\mathrm{Ti}}^{-1} \sum_{\mathrm{i}} \varphi_{\mathrm{Ti}}\right\rangle_{j}}
$$

where $f_{F e}, f_{N i}, f_{T i}$ are vertical correction factors

$\varphi_{\mathrm{Fe}}, \varphi_{\mathrm{Ni}}, \varphi_{\mathrm{Ti}}$ are fast flux measurements derived from iron, nickel, and titanium, respectively

$i=$ cycles summed over (48 to 57 )

$\mathrm{j}$ = irradiation level $(A, B, \ldots, G)$.

These ratios indicate both the internal consistency of each monitor and the relative accuracy among the three monitors. On the average, the spread in flux measurement at each irradiation level is within $\pm 5 \%$. Whereas the iron dosimeters tend to be about $2 \%$ low, the titanium monitors tend to be about $3 \%$ high from the average of all values for a given level.

TABLE VII

RATIO OF DOSIMETER FLUX MEASUREMENTS AFTER VERTICAL CORRECTION

\begin{tabular}{|c|c|c|c|c|}
\hline $\begin{array}{l}\text { Position } \\
\text { (Leve1) } \\
\end{array}$ & $\emptyset_{\mathrm{Avg}}\left(10^{13} \mathrm{nv}\right)$ & ${ }^{\emptyset} \mathrm{Fe}^{/ \phi} \mathrm{Avg}$ & $\emptyset_{\mathrm{Ni}} / \emptyset_{\mathrm{Avg}}$ & $\emptyset_{\mathrm{Ti}} / \phi_{\mathrm{Avg}}$ \\
\hline A & 2.31 & 0.98 & 1.00 & 1.02 \\
\hline B & 5.15 & 0.98 & 0.98 & 1.04 \\
\hline $\mathrm{C}$ & 7.67 & 0.98 & 1.01 & 1.00 \\
\hline D & 9.83 & 0.98 & 0.99 & 1.03 \\
\hline$E$ & 10.94 & 0.97 & 0.98 & 1.05 \\
\hline $\mathrm{F}$ & 10.62 & 1.00 & 0.97 & 1.04 \\
\hline \multirow[t]{2}{*}{ G } & 8.86 & 0.96 & 1.00 & 1.05 \\
\hline & Average & 0.98 & 0.99 & 1.03 \\
\hline
\end{tabular}


The ratio of the corrected flux for each level to the overall average flux for that level is plotted for each ETR cycle in Figure 15. The expression that applies is

$$
\frac{\left(\varphi^{\prime} \mathrm{Avg}^{\prime}\right)_{i j}}{\frac{1}{n_{i}} \sum_{i}\left(\varphi^{\prime} \mathrm{Avg}^{\prime}\right)_{j}}
$$

where $\varphi^{\prime}$ Avg is the corrected flux averaged for iron, nickel, and titanium

$$
\begin{aligned}
n_{i} & =\text { number of cycles summed over (48 to } 57) \\
i & =\text { ETR cycle } \\
j & =\text { irradiation level }(A, B, \ldots, G) .
\end{aligned}
$$

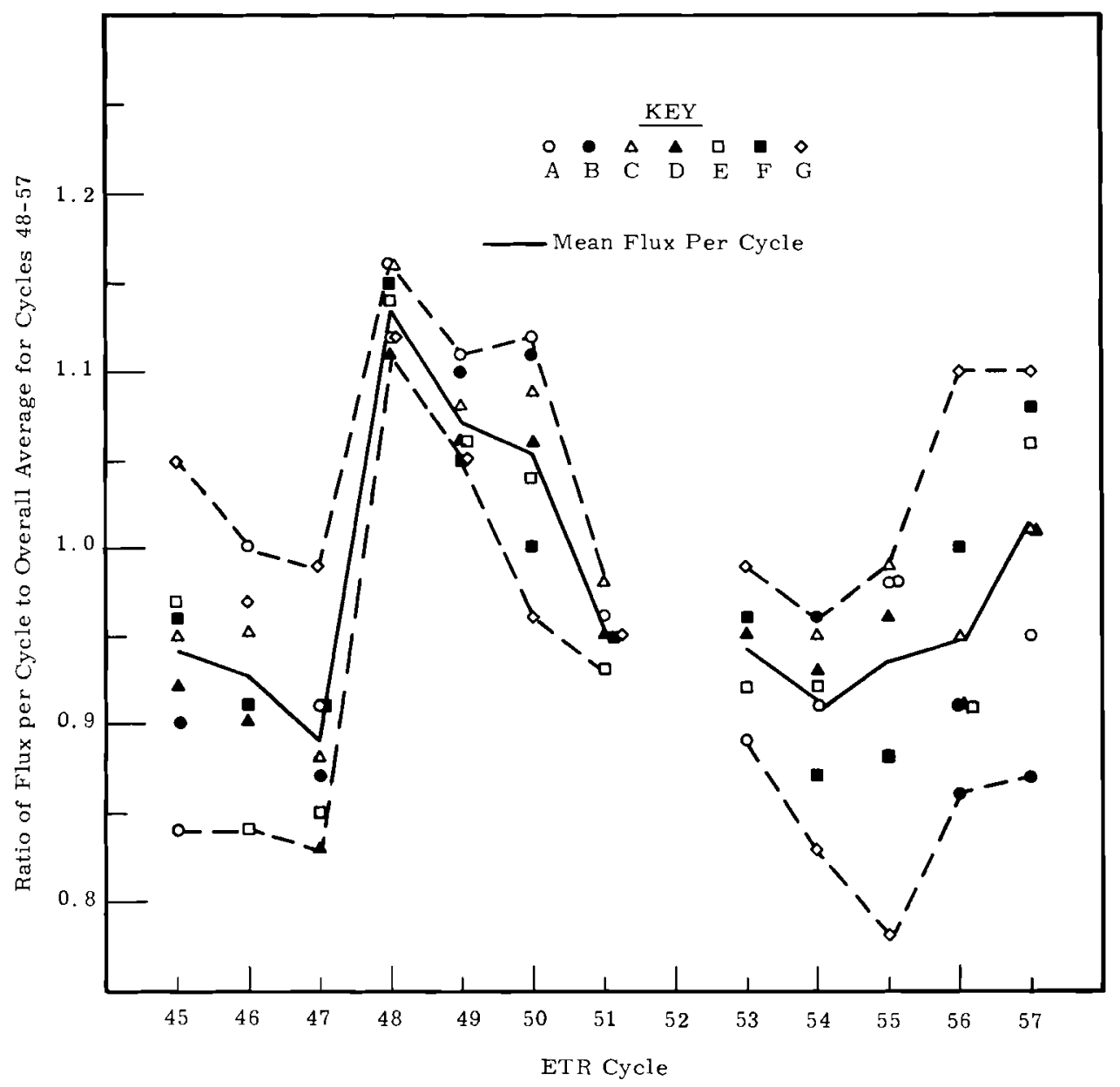

FIGURE 15

Cyclic Flux Variation Along the Centerline of the G-7 Loop 
The curve in Figure 15 connecting the means of the values for each cycle represents the cycle-to-cycle shift in flux intensity in the G-7 loop. The abrupt increase in mean flux resulting from the change in rod program after Cycle 47 is clearly indicated. A maximum positive deviation in mean flux of about $14 \%$ occurs for Cycle 48 and a maximum ne gative deviation of about $8.5 \%$ occurs for Cycle 54 . Dispersion in the values about the mean for each cycle is a measure of the deviation of the flux gradient for that cycle from the gradient averaged over all of the cycles. For example, the dispersion for Cycles 48, 49, and 51 is relatively small indicating that, aside from differences in mean flux intensity, the flux gradient curves are closely approximated by the average gradient curve (plotted from the values given in Table VII). Departures from this reference curve are great for Cycles 45,50,55,56, and 57 where the dispersion about the mean is high.

Typical departures from the reference gradient curve are illustrated schematically in Figure 16. In insert $A$ the flux intensity is raised equally for each exposure level. This condition is closely represented by Cycles 48 , 49, and 51 in Figure 15. In insert $B$ the flux is translated relative to the

A. Flux-Intensity Shift

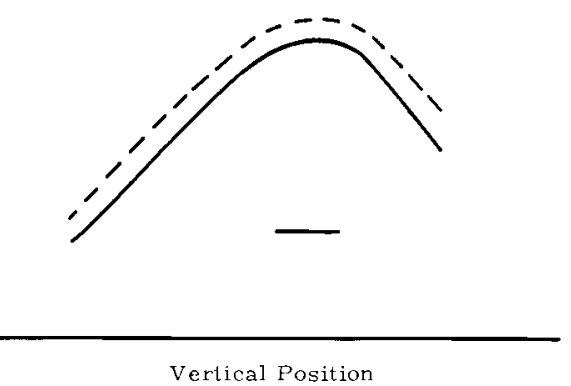

C. Flux Tilting

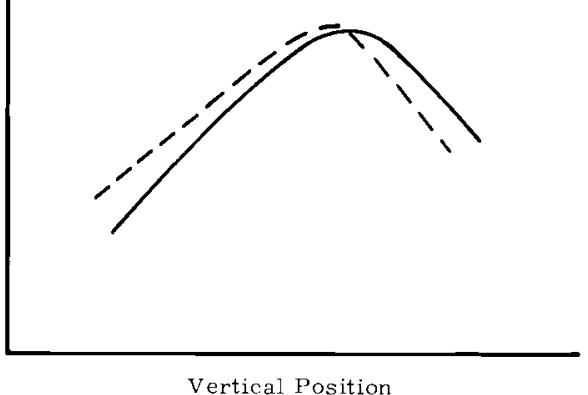

B. F'lux Displacement

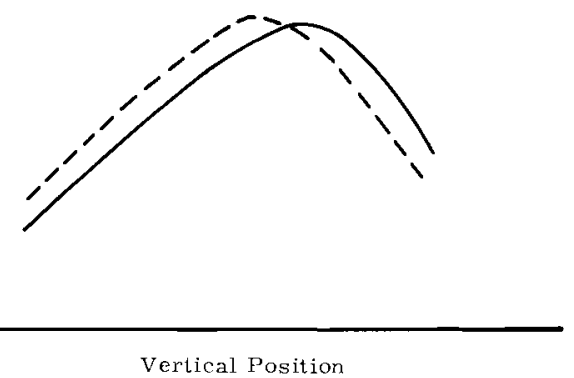

D. Gradient Flattening or Bowing

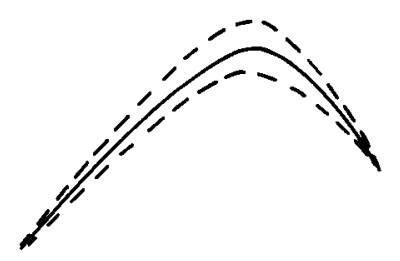

Vertical Position

FIGURE 16

Schematic Fluctuations in Flux Gradient 
centerline of the core position, and in insert $C$ the flux gradient is rotated. The shifts represented by inserts $A, B$, and $C$ can be brought about by either a simple translation or rotation of the axis system. Insert $D$ represents the case where the curvature of the flux gradient is either increased or decreased.

An examination of the data plotted in Figure 15 shows that values for level D are not greatly displaced from the mean curve. Consequently, the ratios calculated by Equation (6) have been normalized to the value for level $D$, and are listed in Table VIII. The effect of this step is to superimpose all of the gradient curves for the various ETR cycles at a point representing level D. The values listed in Table VIII then represent displacements from the reference curve by a combination of steps $B, C$, or D in Figure 16 but not step A. The extremes in these displacements amount to about $\pm 20 \%$ at most.

TABLE VIII

RELATIVE VERTICAL FLUX INTENSITIES

\begin{tabular}{|c|c|c|c|c|c|c|c|c|}
\hline \multirow[b]{2}{*}{ Cycle } & \multicolumn{7}{|c|}{$\begin{array}{l}\text { Position (Level) } \\
\left(\phi \phi \phi_{\mathrm{Avg}}\right)_{\mathrm{i}}\end{array}$} & \multirow[b]{2}{*}{ Range } \\
\hline & $\mathrm{A}$ & $\mathrm{B}$ & $\mathrm{C}$ & $\mathrm{D}$ & $E$ & $\mathrm{~F}$ & $\mathrm{G}$ & \\
\hline 45 & 0.91 & 0.98 & 1.03 & 1.00 & 1.05 & 1.04 & 1.14 & $\begin{array}{l}-9 \% \\
+14 \%\end{array}$ \\
\hline 46 & 1.11 & 1.06 & 1.06 & 1.00 & 0.94 & 0.99 & 1.08 & $\begin{array}{l}-6 \% \\
+11 \%\end{array}$ \\
\hline 47 & 1.10 & 1.05 & 1.06 & 1.00 & 1.02 & 1.10 & 1.19 & $\begin{array}{r}0 \\
+198\end{array}$ \\
\hline 48 & 1.05 & 1.01 & 1.05 & 1.00 & 1.03 & 1.04 & 1.01 & $\begin{array}{l}-0 \\
+5 \%\end{array}$ \\
\hline 49 & 1.05 & 1.04 & 1.02 & 1.00 & 1.00 & 0.99 & 0.99 & $\begin{array}{r}-1 \% \\
+\quad 5 \%\end{array}$ \\
\hline 50 & 1.06 & 1.05 & 1.03 & 1.00 & 0.98 & 0.94 & 0.91 & $\begin{array}{r}\quad 9 \% \\
+\quad 6 \% \\
\end{array}$ \\
\hline 51 & 1.01 & 1.01 & 1.03 & 1.00 & 0.98 & 1.00 & 1.00 & $\begin{array}{r}2 \% \\
+\quad 3 \%\end{array}$ \\
\hline 52 & - - & - & -- & - - & - - & - & -- & $\cdots$ \\
\hline 53 & 0.94 & $\cdots$ & $\cdots$ & 1.00 & 0.97 & 1.01 & 1.04 & $\begin{array}{l}-\quad 6 \% \\
+\quad 4 \%\end{array}$ \\
\hline 54 & 0.98 & 1.03 & 1.02 & 1.00 & 0.99 & 0.94 & 0.89 & $\begin{array}{r}-11 \% \\
+\quad 3 \%\end{array}$ \\
\hline 55 & 1.02 & 1.02 & 1.03 & 1. 00 & 1.02 & 0.92 & 0.81 & $\begin{array}{r}-19 \% \\
+\quad 3 \%\end{array}$ \\
\hline 56 & 0.94 & 1.00 & 1.04 & 1.00 & 1.00 & 1.10 & 1.21 & $\begin{array}{r}-6 \% \\
+21 \%\end{array}$ \\
\hline 57 & 0.94 & 0.86 & 1.00 & 1.00 & 1.05 & 1.09 & 1.09 & $\begin{array}{r}-14 \% \\
+9 \%\end{array}$ \\
\hline $\begin{array}{c}\text { Flux } \\
\left.10^{13} \mathrm{nv}\right)\end{array}$ & 2.31 & 5.15 & 7.67 & 9.83 & 10.94 & 10.62 & 8.86 & \\
\hline
\end{tabular}


Representative deviations from the reference flux gradient are plotted in Figure 17. The upper set of curves represent flux tilting as indicated by case $\mathrm{C}$ in Figure 16. For Cycle 50 the gradient tilts so as to increase the flux in level $A$ and decrease the flux in level $G$. Tilting in the opposite sense occurs for Cycle 45. The lower part of Figure 16 shows examples of gradient flattening and bowing. The flux gradient for Cycle 47 is flatter and the gradient for Cycle 54 is more bowed than the reference curve. Considerable flux displacement (Case B, Figure 15) occurs as well in Cycle 54. All of the gradients listed in Table VIII for the various reactor operation cycles represent a combination of all of the modes of displacement illustrated in Figure 16. These fluctuations could undoubtedly be explained with the detailed knowledge of fuel power densities, control-rod movements, and materials surrounding the $G-7$ position.
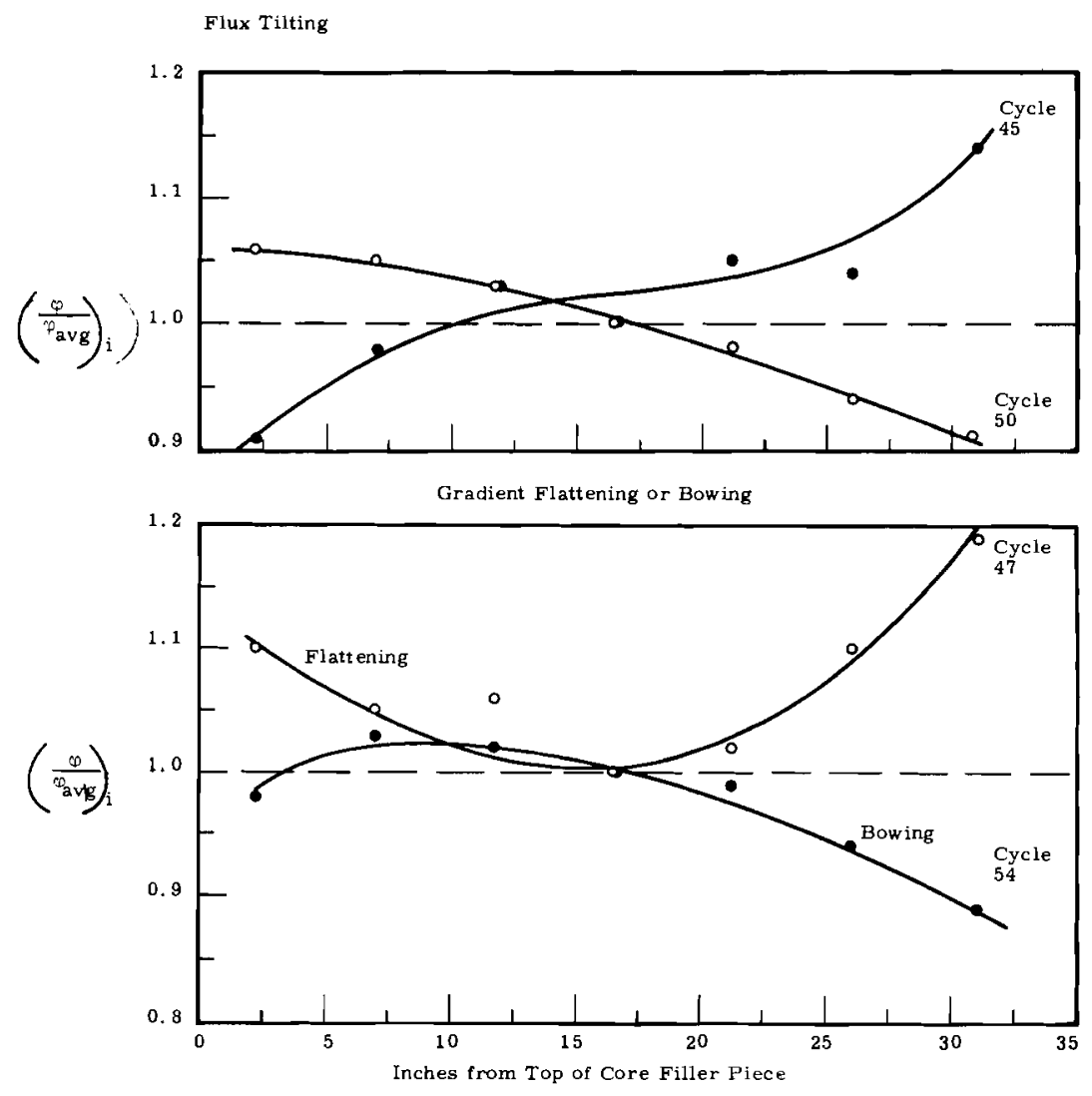

FIGURE 17

Representative Deviations from the Reference Flux Gradient 


\section{Quadrant Flux}

Disintegration data for the quadrant dosimeters are presented in Appendix IV. Some dosimeters among the lower-numbered quadrants were lost while developing hot-cell techniques for removing the wires from the capillary tubing. Most of the wires stored after analysis at the ETR-MTR counting laboratories were eventually shipped to Hanford for recounting at the $200-\mathrm{W}$ counting laboratories. Whereas the initial analysis at NRTS was accomplished two to four half-lives removed from discharge, the counting at Hanford was accomplished eight to ten half-lives removed. Consequently, these latter data are less accurate in the case of nickel and titanium whose isotopes of interest have shorter half-lives than those causing strong interference peaks.

Referring to Appendix IV, the HAPO specific disintegration rates for nickel are generally lower than the PPCo rates by about $5 \%$; however, variations among some sets of dosimeters are as high as $\pm 15 \%$. The Co ${ }^{58}$ peak for the nickel wires counted at HAPO was barely discernable above the background caused by $\mathrm{Co}^{60}$ interference. Furthermore, relative differences are magnified by extrapolating the specific activities over ten half-lives to time of discharge.

Relative variations in the PPCo and HAPO analyses of the titanium dosimeters are high due to interference from impurity isotopes after long decay periods. The HAPO data are generally higher than the PPCo data by about $10 \%$, except for the later quadrants where agreement is within $\pm 3 \%$.

Relative counting accuracy is best represented by both the Al-Co dosimeters and the iron dosimeters for quadrants beyond No. 26 (counted nondestructively). Agreement in specific disintegration rates among these monitors is within $\pm 3 \%$. Differences in some of the iron dosimeters exceed this range because of $\mathrm{Co}^{60}$ contamination picked up in the hot cells, and PPCo values for the first 26 quadrants are about $20 \%$ low due to chemical solution losses.

Neutron flux values for $\mathrm{E}>1 \mathrm{MeV}$ and an assumed fission spectrum were derived from the data in Appendix IV and are tabulated in Appendix V. 
With some exceptions, the scatter among the three quadrant dosimeters after correction for vertical flux gradient is within $\pm 8 \%$. About $\pm 3 \%$ of this error can be attributed to error in assumed cross sections.

Quadrant flux variations from the loop centerline flux are plotted in Figures 18 and 19. In these plots, differences between quadrant and centerline flux at each irradiation level are plotted as a function of fast flux. Consequently, a line plotted through the data points starting from the origin represents a composite percent variation for the various irradiation levels. Each of the points on these plots are averaged values for the

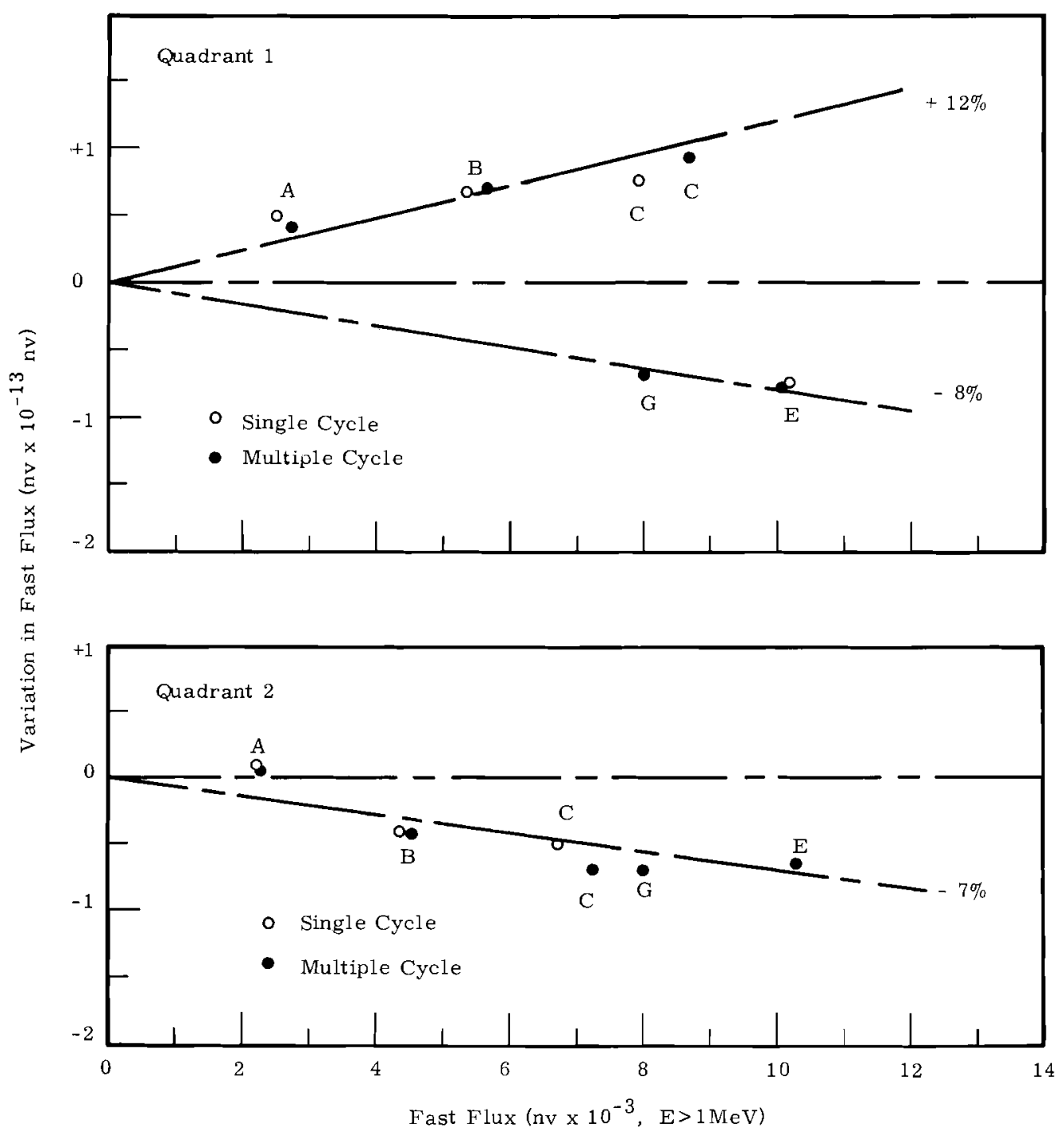

FIGURE 18

Variations in Flux for Quadrants 1 and 2 Relative to Loop Centerline Flux 


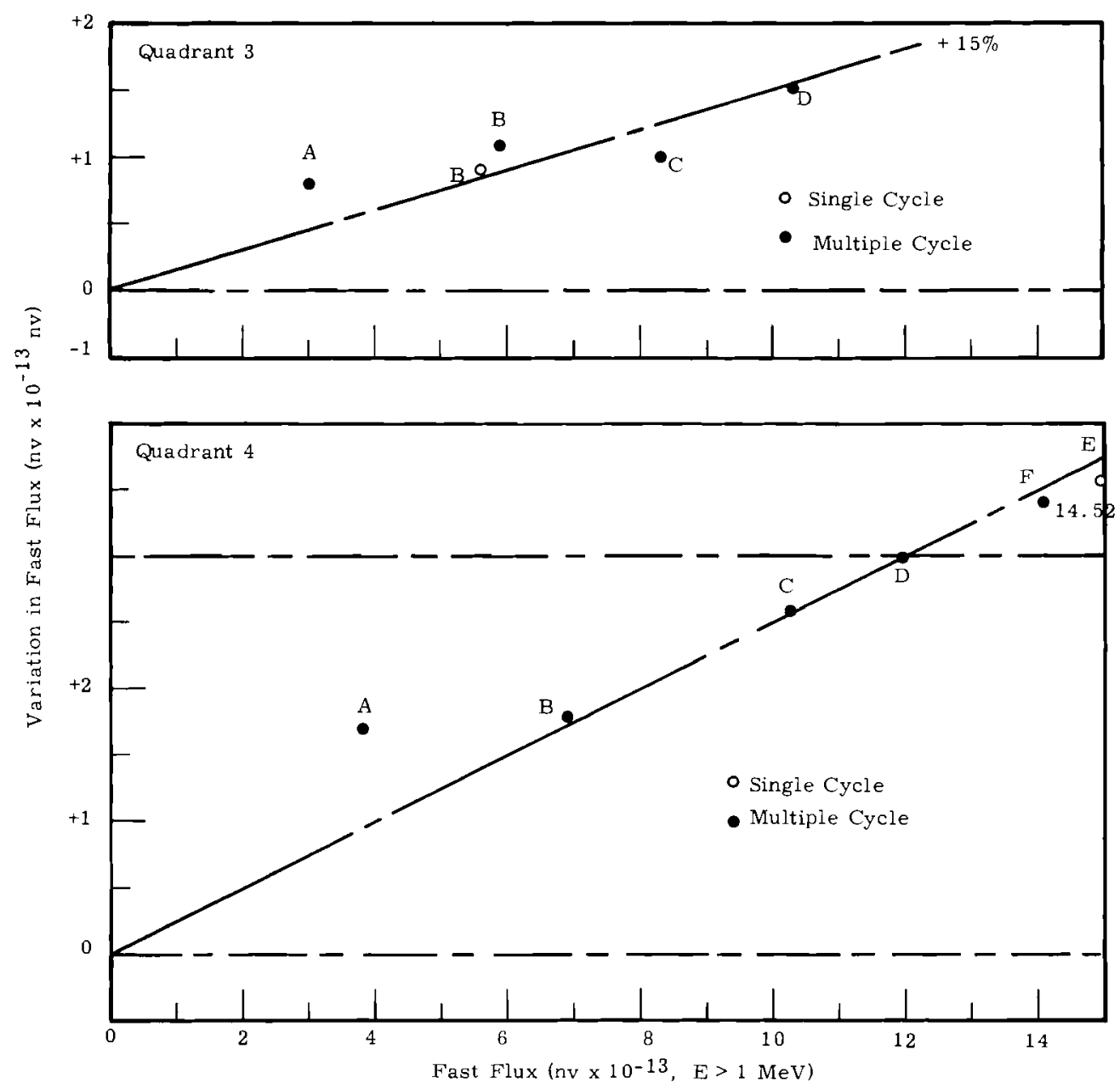

FIGURE 19

Variations in Flux for Quadrants 3 and 4 Relative to Loop Centerline Flux several quadrants irradiated in a particular position. Quadrants irradiated for a single cycle were treated separately from those irradiated several cycles to determine consistency in both sets of flux data. In the case of multicycle irradiations, the average quadrant flux is compared to a timeaveraged flux at the centerline, expressed as

$$
\left[\frac{\varphi^{\prime} q}{\frac{1}{t} \sum_{i} \varphi^{\prime} c^{t} i}\right]_{j}
$$

where

$$
\begin{aligned}
& \varphi_{\mathrm{q}}^{\prime}=\text { vertically normalized quadrant flux } \\
& \varphi_{\mathrm{c}}^{\prime}=\text { vertically normalized centerline flux }
\end{aligned}
$$




$$
\begin{aligned}
& t=\text { total irradiation time } \\
& t_{i}=\text { effective irradiation time for cycle } i \\
& i=\text { irradiation cycle } \\
& j=\text { irradiation level. }
\end{aligned}
$$

Referring to Figure 18, the points for quadrant 1 fall not on one but two lines representing both a positive and negative deviation from the centerline flux. The quadrant flux is about $10 \%$ higher than the centerline flux at levels $A, B$, and $C$ in the upper part of the loop and about $8 \%$ lower than the centerl ine flux for levels $\mathrm{E}$ and $\mathrm{G}$ near the bottom of the loop. This divergence in relative flux with vertical position cannot be explained by shim rod movements which would cause an opposite effect. This behavior is discussed later.

Subsequent plots for quadrants 2, 3, and 4 in Figures 18 and 19 are constructed with single lines representing the best fit through the points and exhibit, respectively, $-7 \%,+15 \%$, and $+25 \%$ deviations between quadrant and centerline flux. The plots show satisfactory agreement between singlecycle and multicycle flux measurements.

\section{Spectrum Effects}

Neutron flux spectra calculated by transport theory at three adjacent zones in the center of the G-7 loop facility are shown in Figure 20. (Refer also to Figure 9 to locate positions.) Effective nickel-activation cross sections and relative intensities of the integrated spectra for neutrons with energies above $0.5 \mathrm{MeV}$ and above $1 \mathrm{MeV}$ (normalized to the loop centerline) are presented in Table IX. From the data in Table IX the crosssection values do not differ by more than $7 \%$; however, there is a $300 \%$ variation in the flux intensity over the three positions. 


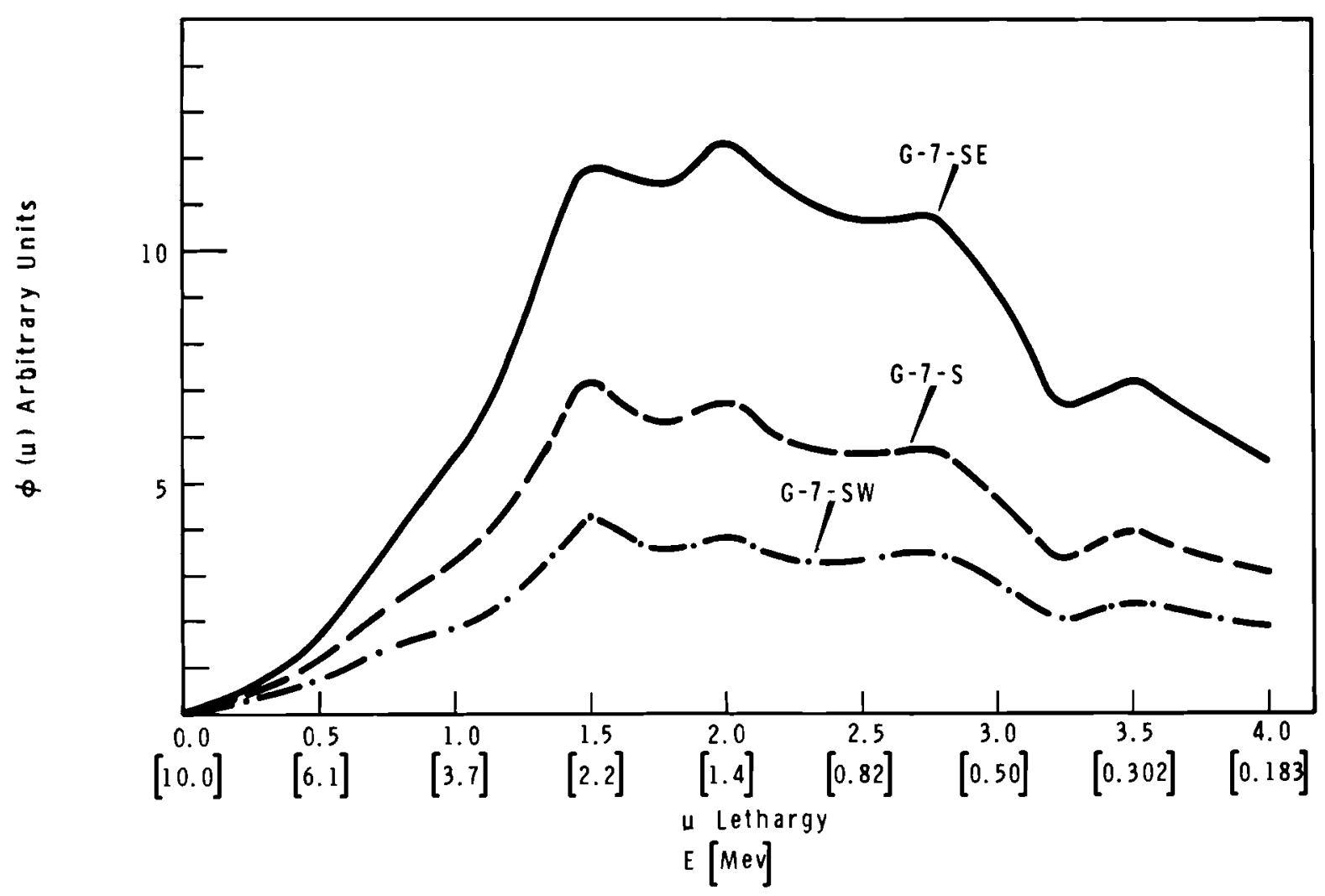

FIGURE 20

Flux Spectra and Relative Intensities in ETR Water Loop

\section{TABLE IX}

RELATIVE MONITOR CROSS SECTIONS AND INTENSITY FACTORS

$\frac{\text { Position }}{\text { G-7 SE }}$
G-7 S
G-7 SW

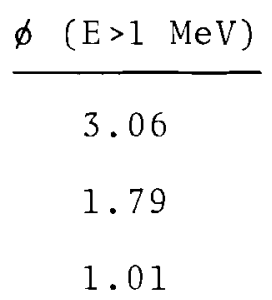

$\varnothing(E>0.5 \mathrm{MeV})$

4.22

$\frac{\bar{\sigma}_{\mathrm{Ni}}(\mathrm{E}>1 \mathrm{MeV})}{138}$

2.47

146

1.40 


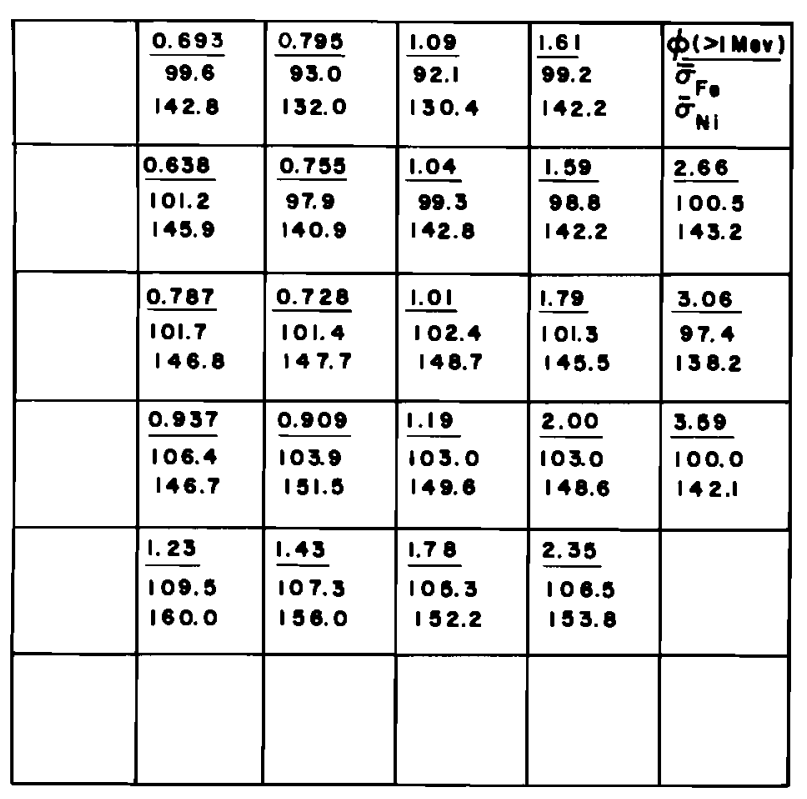

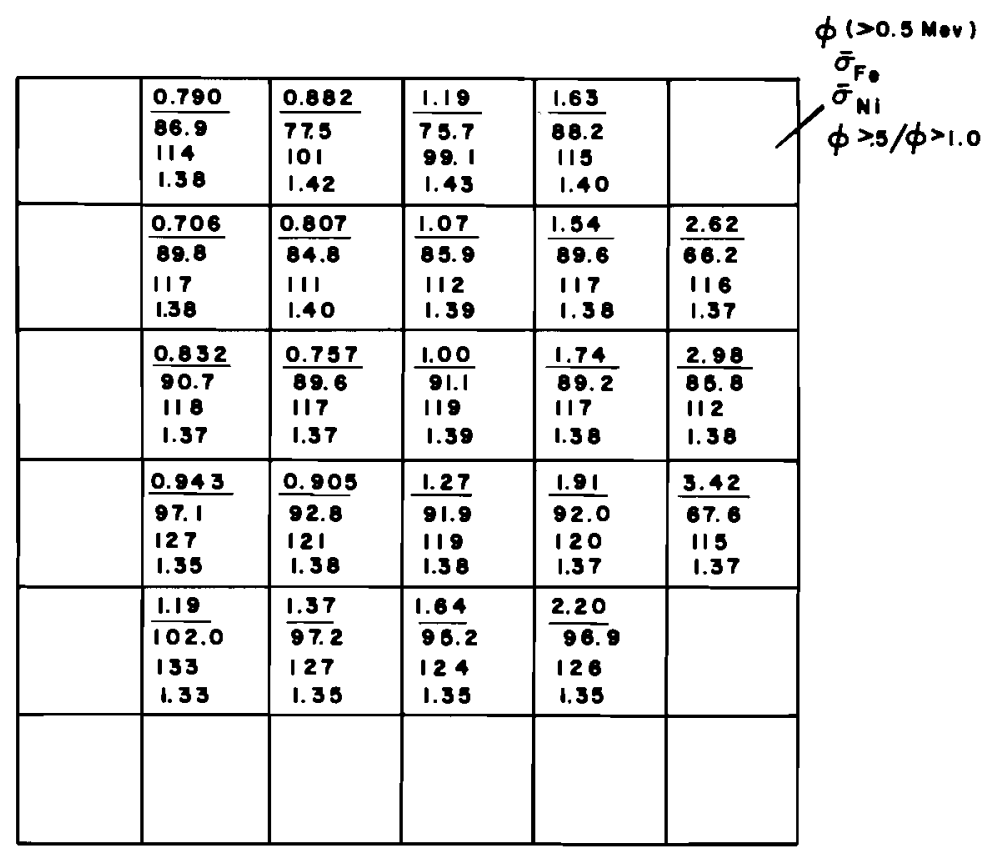


Relative monitor cross sections and flux intensity factors (normalized to loop centerline) are presented in Figures 21, 22, and 23 for the following respective conditions: $\mathrm{E}>1 \mathrm{MeV}$, shim rod out; $\mathrm{E}>0.5 \mathrm{MeV}$, shim rod out; and $\mathrm{E}>0.5 \mathrm{MeV}$, shim rod in. Additionally, the ratio of $\varphi(\mathrm{E}>0.5$ $\mathrm{MeV})$ to $\varphi(E>1 \mathrm{MeV})$ is given in Figure 22. Flux isopleths, constructed from these grids, are illustrated in Figures 24, 25, and 26.

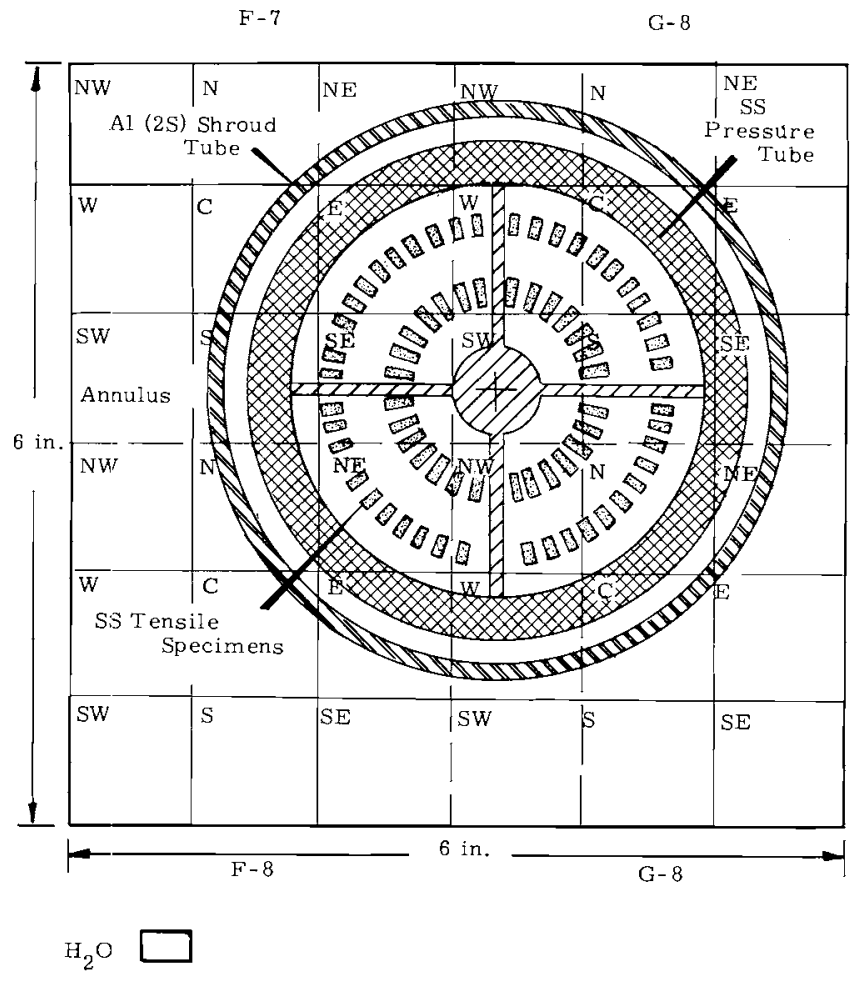

FIGURE 21

Relative Monitor Cross Sections and Flux Intensity Factors ( $\mathrm{E}>1 \mathrm{MeV}$, Shim Out)

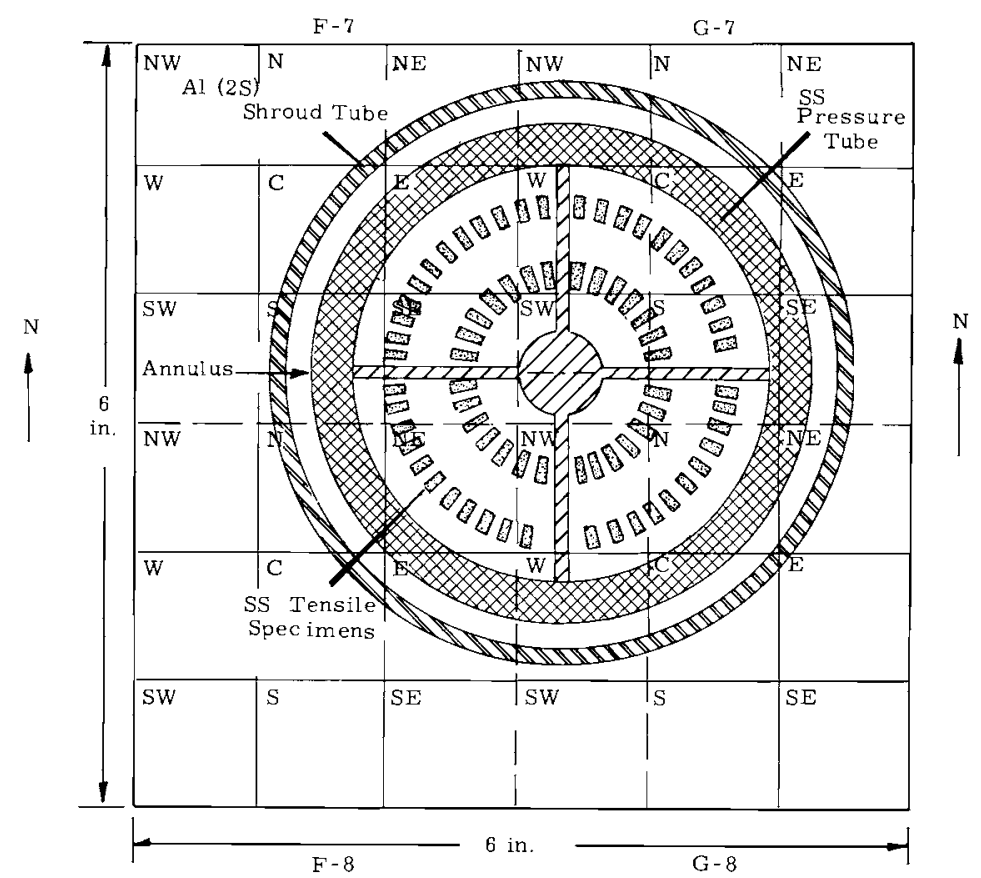

$\mathrm{H}_{2} \mathrm{O} \square$
FIGURE 22

Relative Monitor Cross Sections and Flux Intensity Factors ( $\mathrm{E}>0.5 \mathrm{MeV}$, Shim Out)

The isopleths for neutron flux above $1 \mathrm{MeV}$ energy plotted in Figure 24 are based on the replacement of No. 9 control rod in position G-9 with fuel. The flux gradient in quadrant 3 and 4 is quite steep and runs generally from east to west. The effect of the fuel in positions F-9 and G-9 is reflected by a strong bending of the flux contours in quadrant 1 from a northsouth to an east-west direction. Hence the flux at the loop centerline and the quadrant 1 monitor lie on about the same isopleth. Flux levels are lowest in quadrant 2 and decrease in a northwesterly direction. 


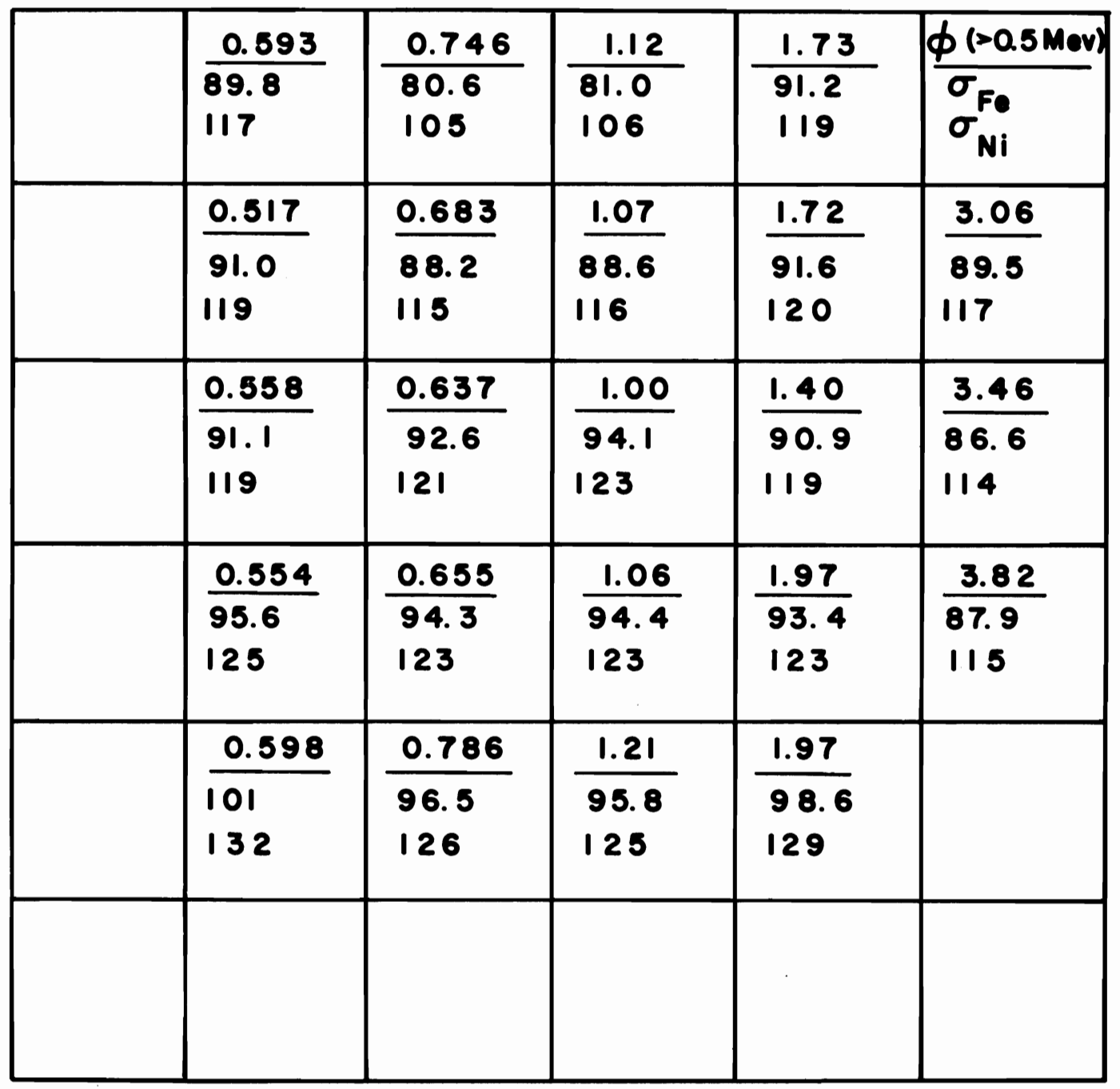


BNWL-89

F-7

G-7

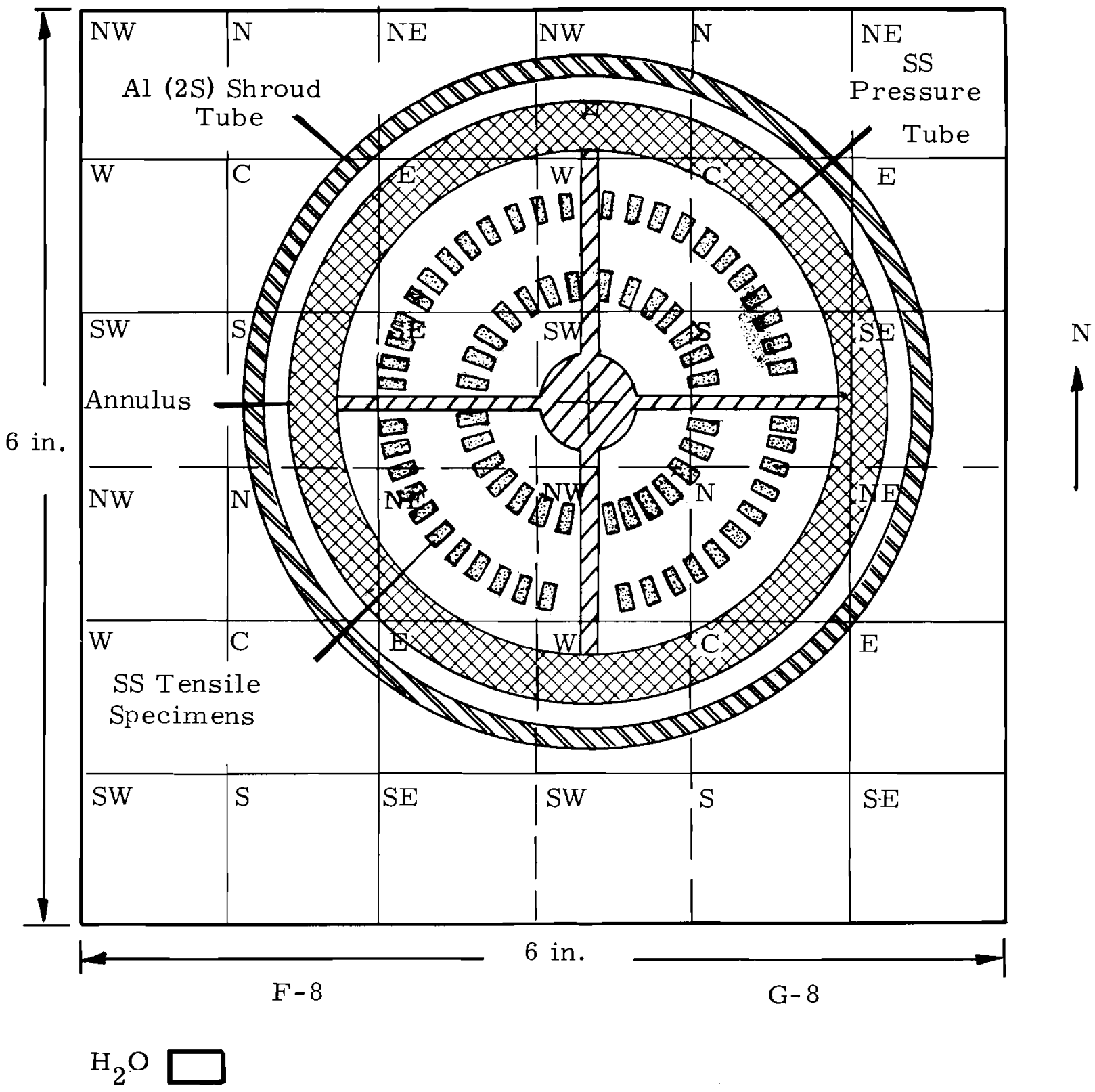

FIGURE 23

Relative Monitor Cross Sections and Flux Intensity Factors ( $\mathrm{E}>0.5 \mathrm{MeV}$, Shim In) 


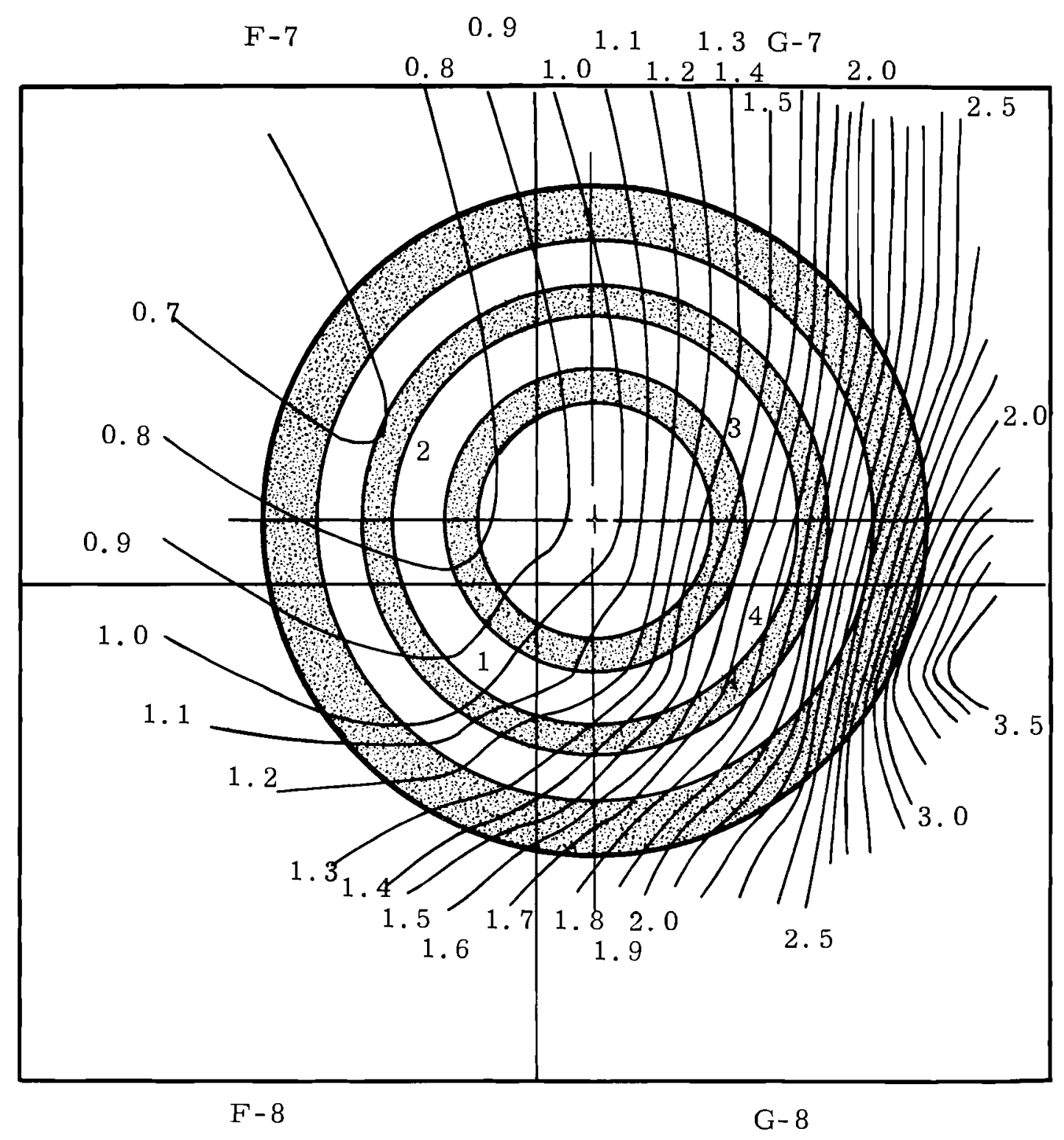

FIGURE 24

Flux Isopleths G-7 Loop

(E >1 MeV, Shim Out) 
Flux isopleths are plotted in Figure 25 for neutron energies greater than $0.5 \mathrm{MeV}$ also with fuel in the G-9 position. Flux contours in this plot are essentially the same as in Figure 24 , and the ratio of $\varphi(E>0.5 \mathrm{MeV})$ to $\varphi(\mathrm{E}>1 \mathrm{MeV})$ from Figure 22 is nearly constant throughout the loop cross section.

$\mathrm{F}-7$

G-7

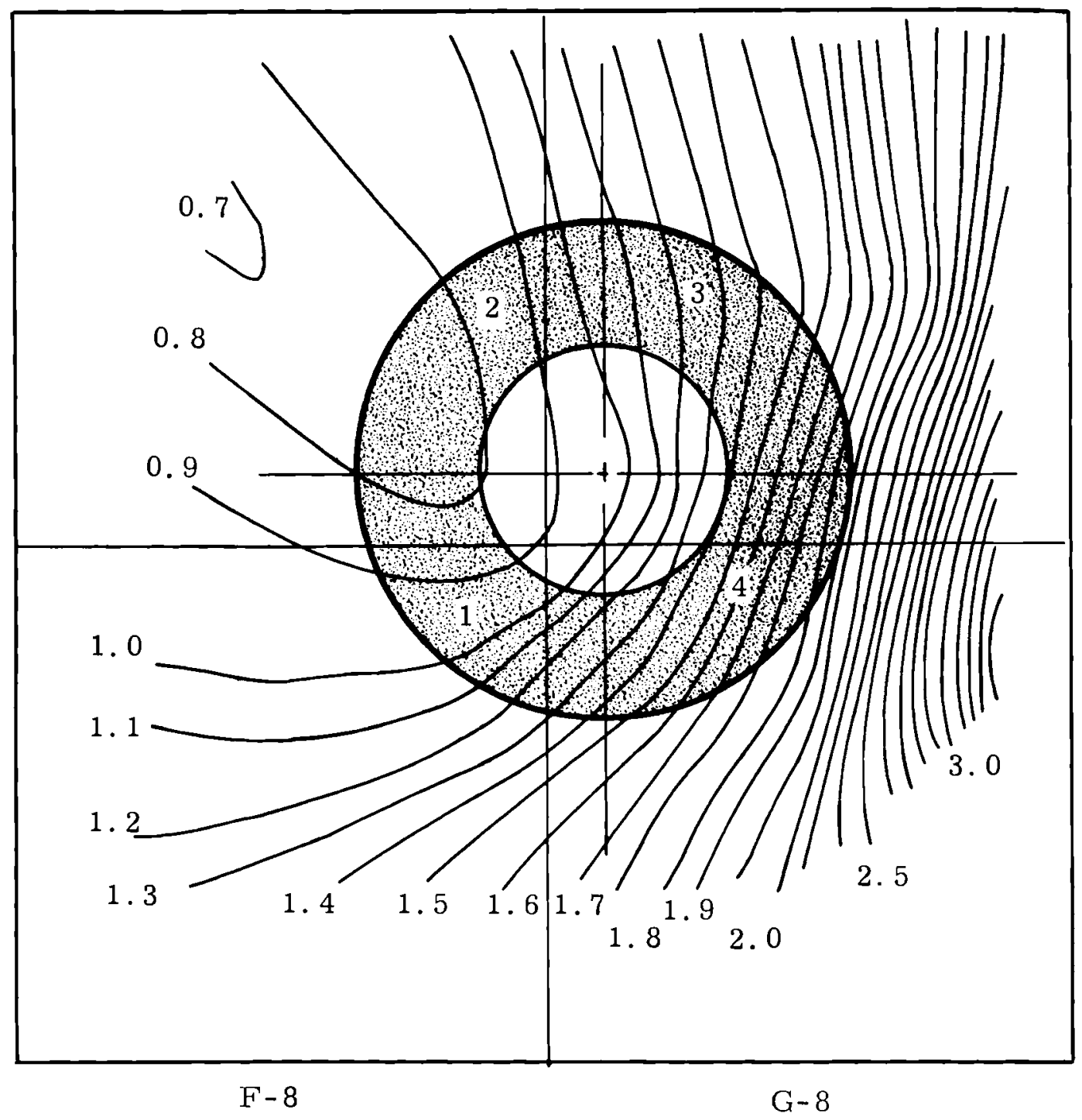

FIGURE 25

Flux Isopleths G-7 Loop

(E $>0.5 \mathrm{MeV}$, Shim Out) 
Changes to the flux contours brought about by inserting the $G-7$ control rod are illustrated in Figure $26(\mathrm{E}>0.5 \mathrm{MeV})$. The contour directions are generally north-south throughout the loop with the gradient becoming less steep in traversing from east to west. The largest change in flux intensities occurs in quadrant 1 .

F -7

$\mathrm{G}-7$

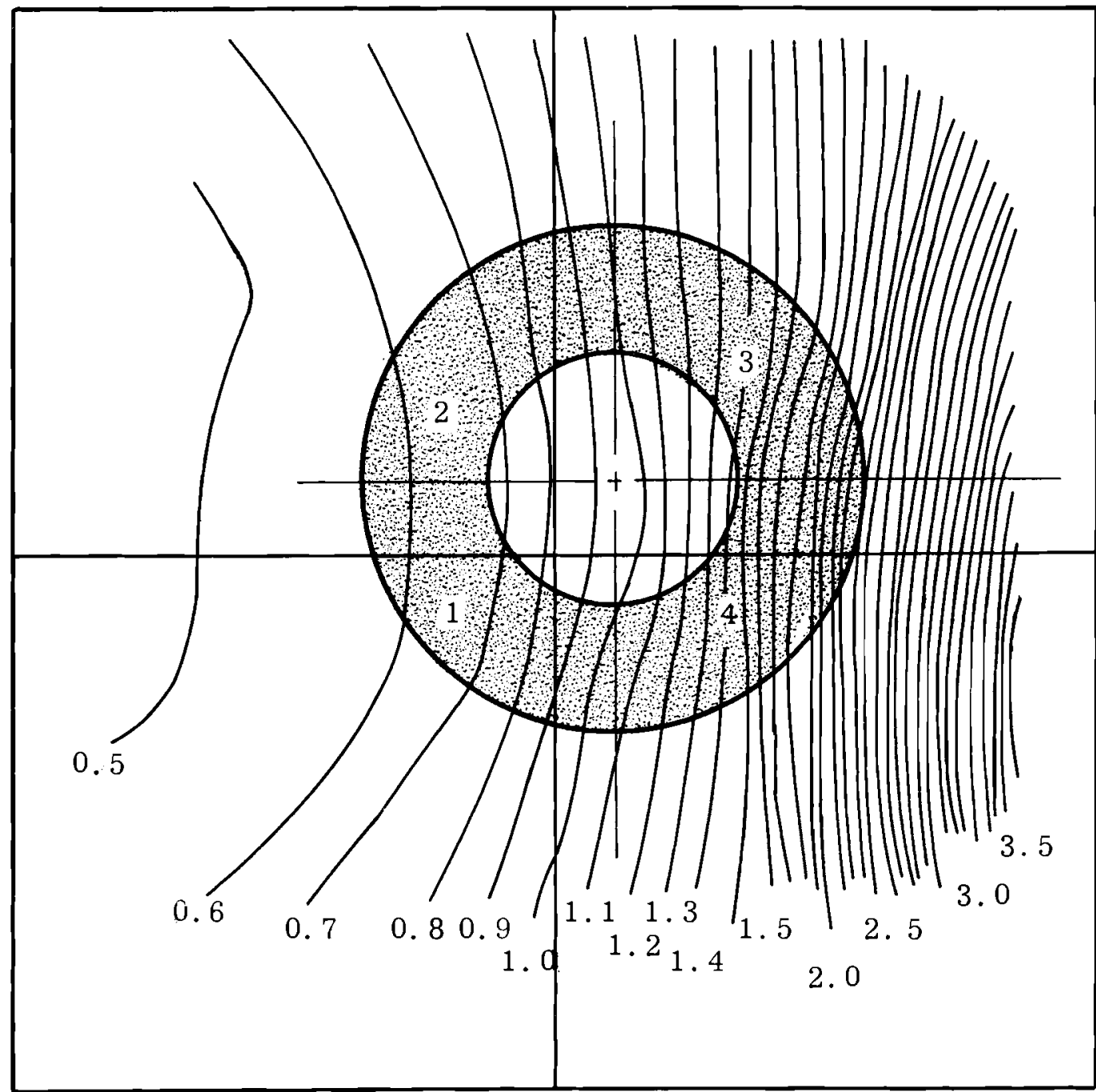

F-8

$G-8$

FIGURE 26

Flux Isopleths G-7 Loop

( $\mathrm{E}>0.5 \mathrm{MeV}$, Shim In) 
The percent deviations between quadrant and loop centerline fluxes plotted in Figures 18 and 19 and the general appearance of the contour maps in Figures 24, 25, and 26 were used to construct reference flux isopleths in Figures 27 and 28. Separate plots are presented for levels A, B, and C and for levels D, E, F, and $G$ corresponding to the separate deviations for quadrant 1 shown in Figure 18. The most noticeable difference between these derived flux rnaps and those based on transport theory is the large reduction in flux gradient.

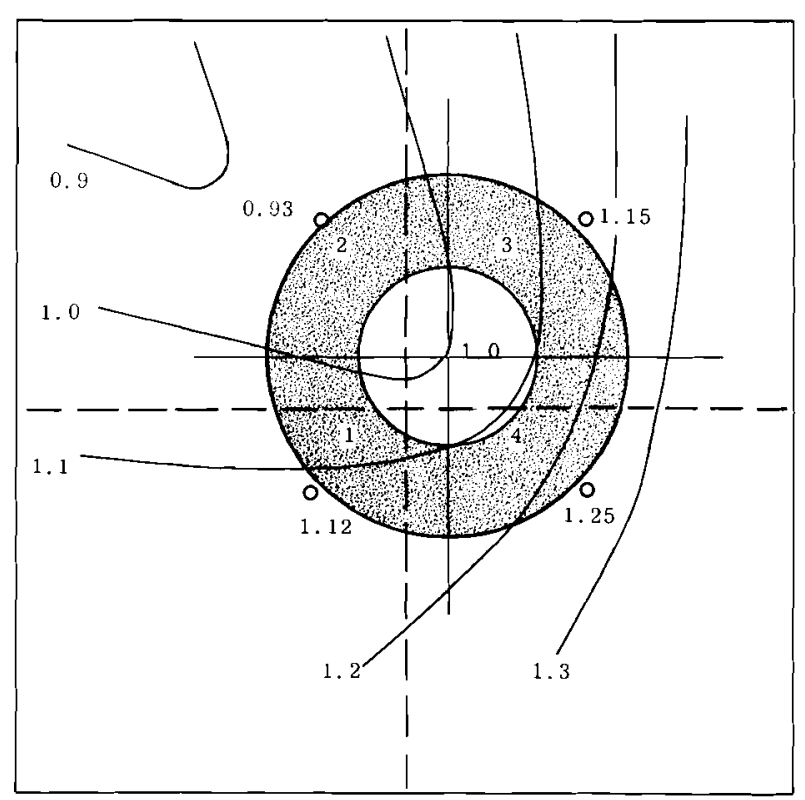

FIGURE 27

Reference Flux Isopleths from Flux Measurements Levels A, B, C

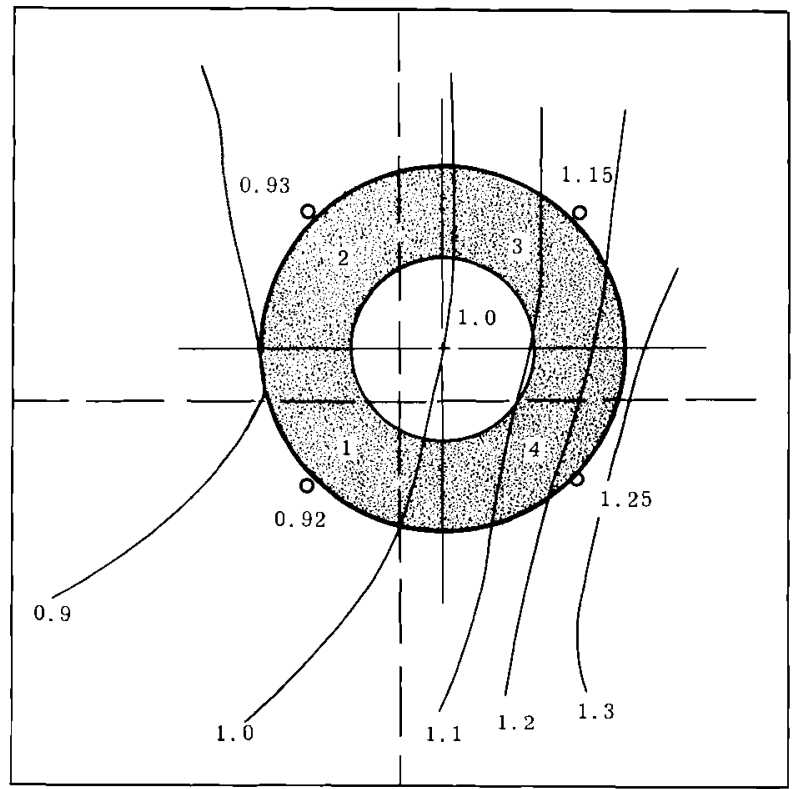

FIGURE 28

Reference Flux Isopleths frorn Flux Measurements Levels D, E, F, G

The flux map in Figure 27 is similar to that in Figure 24, showing an upward bending of flux lines indicating added fuel south of the loop. The flux map in Figure 28 for the lower loop irradiation levels corresponds to Figure 26, showing a straightening of flux lines indicative of added poison south of the loop. These effects are opposite from those expected from normal control rod withdrawals, and suggests that fuel loadings and shim control in adjacent test facilities have an overriding influence on the flux distribution. 
Relative quadrant flux intensities for the different conditions represented in Figures 24 through 28 are listed in Table X. The relative flux intensities given for each quadrant include the quadrant monitor flux, the maximum and minimum quadrant fluxes, and the average flux integrated over the area taken up by specimens. The percent range of the flux about the monitor position is also given.

Referring to Table $X$ the range of quadrant flux about the flux at the monitor position is high for the calculated cases, approaching $\pm 40 \%$ for quadrant 3. Such a high variation in flux would necessitate close positioning between flux monitors and specimens to arrive at adequate estimates of exposure. Fortunately, the range of flux for the flux maps derived from actual measurements is much lower, the maximum deviations being about $+19 \%$ for quadrant 2 (levels $\mathrm{A}, \mathrm{B}$, and C) and $-18 \%$ for quadrant 4 (levels $D, E, F$, and G). Use of the derived flux maps permits estimating specimen flux to within about $\pm 3 \%$ from knowledge of its position in the quadrant. Use of the bulk average flux as an estimate of flux for all specimens in the quadrant would result in a possible $\pm 10 \%$ error, which is not much greater than the variation among three detectors at a single position. Finally, the average between the quadrant monitor and the central monitor flux gives a value which does not vary from the bulk average flux (for the specimen positions) by more than about $3 \%$ 。

The greatest usefulness of the average central monitor flux listed in Table VII and the quadrant variations plotted in Figures 18 and 19 is in estimating the flux for specific quadrant irradiations. If these estimates do not vary considerably more than the $\pm 8 \%$ scatter among dosimeters, then considerable expense and effort in monitoring the many loop irradiation positions might be saved. 
$\underline{\text { TABLE }} \underline{X}$

CALCULATED QUADRANT FLUXES RELATIVE TO LOOP CENTERLINE

\begin{tabular}{|c|c|c|c|c|c|c|}
\hline \multirow{2}{*}{\multicolumn{2}{|c|}{ Case and Quadrant }} & \multicolumn{5}{|c|}{ Quadrant Flux (Relative to Center) } \\
\hline & & $\begin{array}{c}\text { At } \\
\text { Monitor }\end{array}$ & Maximum & Minimum & $\begin{array}{c}\frac{?}{y} \\
\text { Range* } \\
\end{array}$ & $\begin{array}{c}\text { Bulk } \\
\text { Averag } \\
\end{array}$ \\
\hline \multicolumn{7}{|c|}{ Calculated (Shim Out) } \\
\hline \multirow[t]{4}{*}{$\mathrm{E}>1 \mathrm{MeV}$} & -1 & 0.95 & 1.40 & 0.77 & $\begin{array}{l}+48 \\
-19\end{array}$ & 0.95 \\
\hline & 2 & 0.75 & 0.98 & 0.70 & $\begin{array}{l}+31 \\
-7\end{array}$ & 0.80 \\
\hline & 3 & 1.48 & 2.00 & 0.95 & $\begin{array}{l}+35 \\
-36\end{array}$ & 1.15 \\
\hline & 4 & 1.85 & 2.10 & 1.10 & $\begin{array}{l}+14 \\
-40\end{array}$ & 1.59 \\
\hline \multirow[t]{4}{*}{$\mathrm{E}>0.5 \mathrm{MeV}$} & -1 & 0.99 & 1.45 & 0.77 & $\begin{array}{l}+46 \\
-22\end{array}$ & 0.99 \\
\hline & 2 & 0.79 & 1.08 & 0.74 & $\begin{array}{l}+37 \\
-\quad 6\end{array}$ & 0.85 \\
\hline & 3 & 1.45 & 2.00 & 1.01 & $\begin{array}{l}+38 \\
-30\end{array}$ & 1.37 \\
\hline & 4 & 1.85 & 2.00 & 1.20 & $\begin{array}{l}+8 \\
-35\end{array}$ & 1.57 \\
\hline
\end{tabular}

Calculated (Shim In)

\begin{tabular}{|c|c|c|c|c|c|c|}
\hline \multirow[t]{4}{*}{$E>0.5 \mathrm{MeV}$} & -1 & 0.65 & 1.08 & 0.58 & $\begin{array}{l}+66 \\
-11\end{array}$ & 0.74 \\
\hline & 2 & 0.65 & 1.01 & 0.58 & $\begin{array}{r}+55 \\
-11\end{array}$ & 0.73 \\
\hline & 3 & 1.60 & 2.30 & 0.99 & $\begin{array}{r}+44 \\
-38\end{array}$ & 1.45 \\
\hline & 4 & 1.80 & 2.30 & 1.00 & $\begin{array}{l}+28 \\
-44\end{array}$ & 1.57 \\
\hline
\end{tabular}

* Relative to quadrant monitor

Derived

\begin{tabular}{|c|c|c|c|c|c|c|}
\hline \multirow[t]{4}{*}{ Levels A } & $A, B, C,-1$ & 1.12 & 1.17 & 0.99 & $\begin{array}{r}+5 \\
-13\end{array}$ & 1.07 \\
\hline & 2 & 0.93 & 1.11 & 0.93 & $\begin{array}{l}+19 \\
-\quad 0\end{array}$ & 0.95 \\
\hline & 3 & 1.15 & 1.25 & 1.00 & $\begin{array}{l}+9 \\
-13\end{array}$ & 1.11 \\
\hline & 4 & 1.25 & 1.26 & 1.08 & $\begin{array}{l}+1 \\
-14\end{array}$ & 1.16 \\
\hline \multirow[t]{4}{*}{ Leve1s } & $D, E, F, G-1$ & 0.92 & 1.05 & 0.90 & $\begin{array}{l}+14 \\
+\quad 2\end{array}$ & 0.96 \\
\hline & 2 & 0.93 & 0.99 & 0.90 & $\begin{array}{l}+6 \\
-\quad 3\end{array}$ & 0.96 \\
\hline & 3 & 1.15 & 1.25 & 0.99 & $\begin{array}{l}+9 \\
-14\end{array}$ & 1.10 \\
\hline & 4 & 1.25 & 1.28 & 1.03 & $\begin{array}{l}+2 \\
-18\end{array}$ & 1.15 \\
\hline
\end{tabular}


Reference quadrant fluxes are listed in Table XI for the seven irradiation levels. These values are based upon the variation of each point plotted in Figures 18 and 19 rather than the average obtained from a plot through the points. These reference fluxes are compared with measured values for a number of quadrants listed in Table XII. The quadrants listed contained tensile specimens and received all or a substantial portion of their irradiation during Cycles 48 to 56 (for which the average central flux in Table XI applies).

$\underline{\text { TABLE XI }}$ CALCULATED REFERENCE QUADRANT FLUXES

Irradiation
Leve1

A

B

$\mathrm{C}$

D

E

F

G

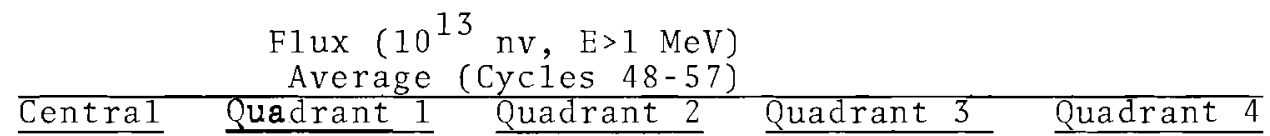

2.31

2.75

2.40

4.80

7.05

9.15

10.20

9.85

8.05
2.95

6.10

8.60

10.30

12.60

12.20

10.20
3.40

6.50

0.60

12.30

13.60

13.20

11.10

Referring to Table XII, quadrants having more than a $\pm 10 \%$ variation between measured and calculated flux are noted. Nearly all of these quadrants are located in the top or bottom irradiation positions where large deviations are normal or in quadrants 3 or 4 where flux gradients are steep. In only 2 out of 39 quadrants does the variation exceed $20 \%$.

Two corrections to the flux data are desired after the various corrections for position and tests for consistency described above have been accomplished. These consist of a correction for the actual ETR neutron spectrum and a normalization of the flux to an energy limit of $0.5 \mathrm{MeV}$ for correlation with damage models. The first correction can be accomplished by using the effective cross sections listed in Table IX and Figure 21 for the loop 
TABLE XII

COMPARISONS BETWEEN MEASURED AND CALCULATED VALUES*

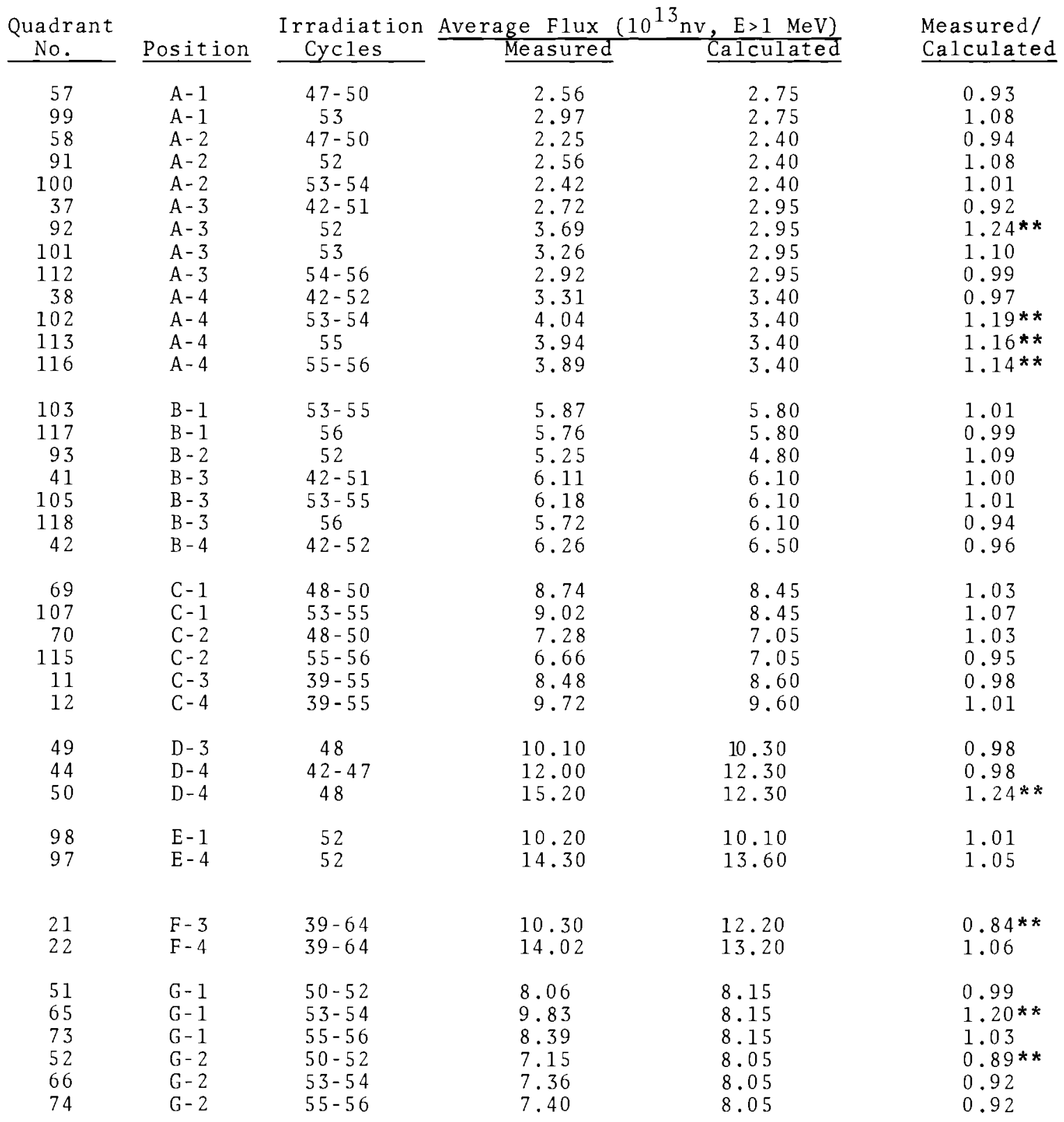

*Based on best two out of three dosimeter values and normalized vertically. ** Greater than $\pm 10 \%$ variation. 
centerline. Since the variation in neutron cross section is small among the quadrant positions and the actual flux gradient is much smaller than the calculated gradient, no additional XY corrections are considered necessary. The expression that applies is

$$
(\varphi \bar{\sigma})_{F}=(\varphi \bar{\sigma})_{E}
$$

or alternately,

$$
\frac{\varphi_{\mathrm{E}}}{\varphi_{\mathrm{F}}}=\frac{\bar{\sigma}_{\mathrm{F}}}{\bar{\sigma}_{\mathrm{E}}}
$$

where $\varphi_{F}, \bar{\sigma}_{F}$ refers to a fission spectrum

and $\varphi_{E}, \bar{\sigma}_{\mathrm{E}}$ refers to an ETR spectrum

The ratio $\varphi_{\mathrm{E}} / \varphi_{\mathrm{F}}$ for nickel becomes

$$
\frac{(95)}{(0.692)(148.9)}=0.924
$$

and for iron

$$
\frac{(68)}{(0,692)(102.4)}=0.960
$$

These corrections are significant for precise correlations and indicate that a fission-spectrum assumption for the G-7, hot-water loop position is generally satisfactory but approximate for fluxes above $1 \mathrm{MeV}$. The factor required to convert from the energy limit of $1.0 \mathrm{MeV}$ to $0.5 \mathrm{MeV}$ can be found from Figure 22. Again, this factor, amounting to 1.39 at the central position, is nearly constant throughout the loop cross section. The ETR spectrum departs from a fission spectrum sharply at energies below $1 \mathrm{MeV}$. The ratio of flux above $0.5 \mathrm{MeV}$ to that above $1 \mathrm{MeV}$ in a fission spectrum is 1.25 , thus a fission spectrum assumption would introduce a larger error at the lower energies. 


\section{$\underline{\text { DISCUSSION }}$}

At the time irradiations of structural materials were begun in the ETR G-7, hot-water loop (and since that time), the general accuracy of flux measurement in test reactors had beer. generally quoted as $\pm 20 \%$. The actual error could be considerably greater, perhaps a factor of 2, depending upon experimental control in the chain of events separating the actual placement of the detectors to the final analysis of the data. The overall error includes contributions from the type of detector selected, the techniques employed in counting specific gamma activity, physical constants used in reducing the data to neutron exposure, and the methods applied to the data to correlate neutron damage in irradiated specimens. These sources of error are neither all inclusive nor mutually exclusive.

A well-conducted monitoring program should initially provide sufficient experimental control and measured data to statistically analyze the variance of flux data in the test facility. Only by such an analysis can an adequate appraisal of mechanical or physical properties changes in test specimens be obtained. Although the present program has provided considerable amounts of flux data and repetitive activation analyses, certain important gaps exist in the data which limit the application of statistical methods. The present analysis is almost entirely empirical, more from expediency than intent, and is perhaps even more limited in application. However, the characterization of flux distribution and variations due to reactor operating variables determined from the study are valuable for checking the consistency in measured data and for planning future $11 \mathrm{xx}$ investigations.

The repetitive counting measurements of the activated detectors revealed that excellent accuracy in activation analysis can be obtained even after long intervals if the gamma ray peaks of interest can be clearly distinguished. If the peak being measured is occluded by background interference from impurities or contaminants, the error may increase from $\pm 3 \%$ to as high as $\pm 100 \%$.

Selection of an optimum radioactive decay time before counting depends upon the relative half-lives of interfering isotopes and the isotope of interest. 
Counting errors inherent in the detector can be greatly reduced if highpurity materials with short half-lived residual impurities can be obtained. A desirable step prior to using the material for flux detectors is to subject a representative sample to gamma spectroscopy following a short neutron exposure. By this procedure, the optimum holding time after discharge for optimum peak discrimination can be determined.

In the present study, the greatest reliability in flux measurement was obtained with iron detectors counted nondestructively. Iron detectors subjected to chemical isotopic separation gave values as much as $20 \%$ lower than companion samples counted nondestructively. Titanium detectors also gave good reproducibility, but the flux values were consistently higher than those for nickel and iron due to errors in assumed cross section. The lack of data for activation cross section as a function of neutron energy for titanium makes this material unreliable for absolute flux measurements.

Flux values measured from nickel dosimeters were often erratic, particularly after long exposures where corrections of the thermal neutron burnout of cobalt are expectantly inaccurate. A contributing factor in the erratic response of nickel is the thermal neutron flux perturbation caused by adjacent experiments and from materials inserted into the loop. The relatively smooth variation in fast flux compared to a deviating gradient in thermal flux along the loop centerline are illustrated in Figures 13 and 14, respectively.

The distribution of fast flux in the G-7 loop was comprehensively delineated by both cycle-to-cycle measurements along the loop centerline and by multigroup, neutron-transport calculations. The maximum cyclical variation in mean flux intensity was only about +14 and $-8 \%$. However, flux variations in levels $A$ (top) and $G$ (bottom) due to flux bowing and tilting of the centerline gradient (cosine distribution) were as much as $\pm 20 \%$.

Changes in the flux distribution throughout the loop can be attributed to control rod movements, specific fuel neutron generation, the degree of moderation in empty core positions, and the nature of surrounding irradiation experiments. Neutron transport calculations for the GEH-20, hot-water loop considered only the northwest sector of the ETR core and did not include 
the F-10 and H-10 KAPL loops or the No. 7 control rod only two or three positions removed. A possible influence of surrounding experiments on flux distribution is indicated by the vertical flux gradient in quadrant 1. As shown in Figures 18, 27, and 28, the flux intensity in the upper positions $A, B$, and $C$ relative to the centerline was generally higher than in the lower loop positions. Since the opposite effect would be predicted from known movements of the No. 9 control rod, some overriding influences from positions outside the boundary selected for analysis are suspect.

Another limitation of the multigroup calculations of flux distribution is the assumption that all fuel elements have the same composition. In actual practice small amounts of boron are added to the fuel in the ETR, and the boron composition generally increases from the periphery to the core of the reactor. This has the net effect of augmenting control rod movements in leveling the core flux distribution. This inhomogeneity in the fuel accounts for the flatter measured flux distribution across the GEH-20 loop cross section (Figures 27 and 28) compared to the distributions calculated from transport theory (Figures 24, 25, and 26).

The above comparisons between calculated and measured flux topography suggest three desirabie refinements: (1) extending the calculations over a larger core area about the position of interest, (2) inserting greater detail concerning materials and fuel compositions and (3) extending the calculation from two to three dimensions. An estimate of the three-dimensional flux distribution is provided from the data in Table XI. Any advances along these lines requires a considerable amount of detailed data and a continual free exchange of information between the investigator, the reactor operator, and the various irradiation test sponsoring agencies.

The attempts to calculate fluxes at the quadrant monitors from known centerline flux and derived cross-section aistribution factors were moderately successful. In many cases the agreement between calculated and measured values was better than the agreement among the three dosimeters at a given position. In other cases the discrepancy between measured and calculated flux was as high as $24 \%$. Discrepancies were largest in levels $\mathrm{A}$ and $\mathrm{G}$ (at the loop extremes) and in quadrants 3 and 4 (where the horizontal gradient 
is steepest) which are affected most by control rod programs and adjacent experiments. A more extensive characterization of the flux topography and topology in these regions as a function of reactor loadings and operation is needed.

The results above indicate that attempts to extrapolate flux over a distance exceeding about 1 in. from a monitored position may be subject to considerable error without detailed knowledge of the surrounding flux environment. However, the incentive to develop such a capability is large considering the expense and manpower normally invested in flux measurements on a comprehensive irradiation program. A selective cutback in monitoring flux for several of the quadrant positions appears to be justified with the continued measurement of loop centerline flux and application of derived spatial coefficients.

In addition to improving flux monitoring accuracy in a given test reactor, there is the urgent requirement for correlating irradiation data obtained from different reactors having varying physical characteristics. One of the biggest drawbacks in applying currently available data to design problems is the excessive scatter that results when the data are plotted on a common neutron exposure scale. The results of this study show that neutron spectrum corrections would provide a 4 to $8 \%$ improvement in the calculated neutron exposure for the ETR. The amount of correction for other reactors would increase with the degree of moderation.

Better correlations of irradiation damage data are achievable if greater percentages of the neutrons causing damage are included in exposure calculations. Recent studies ${ }^{(9)}$ have shown that an energy cutoff of about $0.5 \mathrm{MeV}$ for structural metals gives less scatter in irradiation damage observed in different reactors than a $1.0 \mathrm{MeV}$ energy limit. The flux of neutrons having an energy greater than $0.5 \mathrm{MeV}$ in the GEH-20 loop was found to be approximately 1.4 times greater than neutrons having energies above $1.0 \mathrm{MeV}$. 
In summary, the flux variations from various causes in the GEH-20 loop are given below:

Source

1. Gamma radiation counting

2. Scatter among dosimeters

3. Vertical gradient (within 2 in.)

4. Horizontal gradient $(1-1 / 2$ in. radius about the loop centerline)

5. Cycle-to-cycle variation (Position D)

6. Cycle-to-cycle variation (Position A)

7. Cycle-to-cycle variation (Position G)

8. Errors in assumed cross sections

9. Spectrum correction ( $\mathrm{E}>1 \mathrm{MeV})$

$\quad$ Percent Variation
\pm 3 to about \pm 15
\pm 8
$=1$ (Position E) to
\pm 20 (Position A)
+28
-10
+14
$-\quad 8$
+15
-20
+12
-28
+3
-2
-8 (nickel)

It is not possible to state unambiguously the composite error in flux measurement in the present study short of a statistical analys is of variance. However, an estimate of $\pm 20 \%$ seems too high in view of the extensive measurements made to account for variations listed in 2 through 7 above. Combining items 1, 2, and 8 and making some allowance for compensating errors, an estimate of $\pm 10 \%$ error in measured flux seems appropriate. Calculated estimates of quadrant flux from the average centerline flux over Cycles 48 to 57 are considered accurate to within $\pm 20 \%$.

The deviations in flux measured by the three dosimeter materials (namely, iron, nickel, and titanium) were large compared to the variation in specific activation measurements. Improvement in this scatter, however, will require a better knowledge of neutron activation cross sections, improved characterization of detector materials, and more precise detector placement 
in the reactor. Furthermore, the use of a universal, spectrum-independent, damage unit is promising but not sufficiently tested Future flux investigations in the G-7 hot-water loop should be planned with these aims in mind.

\section{ACKNOWLEDGEMENTS}

The authors are grateful for the efforts and collaboration of C. H. Hogg and his colleagues at the MTR-ETR counting laboratory and of W. H. Zimmer and T. R. Garland at the Hanford, 200-W counting laboratory. The assistance of J. H. Johnson and J. Berger in coordinating the irradiation program at the ETR and the help given by J. A. Ulseth in analyzing the flux data are greatly appreciated. Thanks also goes to Dr. H. H. Yoshikawa for many helpful discussions. 


\section{REFERENCES}

1. R. E. Oswald. Phillips Petroleum Company, Idaho Falls, Idaho. Letter to D. R. de Boisblanc, "ETR Control Rod Withdrawal ProgramREO-7-62A," July 23, 1962.

2. R. L. Heath. Scintillation Spectrometry-Gamma-Ray Spectrum Catalogue, 2nd ed., vol. I, IDO-16880. Phillips Petroleum Company, Arco, Idaho, August 1964.

3. R. G. Helmer, R. L. Heath, D. D. Metcalf, and G. A. Cazier. A Linear Least-Squares Fitting Program for the Analysis of Gamma-Ray Spectra Including a Gain-Shift Routine, IDO-17015. Phillips Petroleum Company, Arco, Idaho, September 1964.

4. R. L. Heath, R. G. Helmer, L. A. Schmittroth, and G. A. Casier. Generation of Detector Response Curves for Gamma-Ray Scintillation Spectrometers, IDO-17017. Phillips Petroleum Company, Arco, Idaho, 1964.

5. H. H. Yoshikawa and W. H. Zimmer. Fast Neutron Dosimetry: Intercalibration of Counting Facilities, HW-81871. General Electric Company, Richland, Washington, April, 1964.

6. C. H. Hogg and L. D. Weber. "Fast-Neutron Dosimetry at the MTR-ETR Site, "Symposium on Radiation Effects and Neutron Dosimetry, Am. Soc. Test and Mater. STP No. 341, pp. 133-140, 1962.

7. W. C. Morgan. FOILS: A Program for Computing Neutron Exposures from Foil-Activation Data, HW-81367. General Electric Company, Richland, Washington, April, 1964.

8. R. E. Dahl. Measuring and Correlating Neutron Exposure in Graphite, HW-79793. General Electric Company, Richland, Washington, December, 1963.

9. R. E. Dahl and H. H. Yoshikawa. "Neutron Exposure Correlation for Irradiation Damage Studies," Nuc.Sci. and Eng., vol.21, pp. 312-318, March, 1965. 
APPENDIX I

IRRADIATION HISTORIES FOR GEH-20 QUADRANTS 1 THROUGH 141

\begin{tabular}{|c|c|c|c|c|c|}
\hline Quadrant & Insertion & Reactor & Discharge & End of & Effective \\
\hline Number & Cycle & Start Up & Cycle & Cycle & Days at $175 \mathrm{MW}$ \\
\hline 1 & 39 & $8-20-61$ & 40 & $10-2-61$ & 28.9 \\
\hline 2 & 39 & $8-20-61$ & 40 & $10-2-61$ & 28.9 \\
\hline 3 & 39 & $8-20-61$ & 41 & $11-12-61$ & 52.5 \\
\hline 4 & 39 & $8-20-61$ & 41 & $11-12-61$ & 52.5 \\
\hline 5 & 39 & $8-20-61$ & 40 & $10-2-61$ & 28.9 \\
\hline 6 & 39 & $8-20-61$ & 40 & $10-2-61$ & 28.9 \\
\hline 7 & 39 & $8-20-61$ & 41 & $11-12-61$ & 52.5 \\
\hline 8 & 39 & $8-20-61$ & 41 & $11-12-61$ & 52.5 \\
\hline 9 & 39 & $8-20-61$ & 44 & $3-18-62$ & 118.2 \\
\hline 10 & 39 & $8-20-61$ & 44 & $3-18-62$ & 118.2 \\
\hline 11 & 39 & $8-20-61$ & 55 & $6-23-63$ & 342.4 \\
\hline 12 & 39 & $8-20-61$ & 55 & $6-23-63$ & 342.4 \\
\hline 13 & 39 & $8-20-61$ & 40 & $10-2-61$ & 28.9 \\
\hline 14 & 39 & $8-20-61$ & 40 & $10-2-61$ & 28.9 \\
\hline 15 & 39 & $8-20-61$ & 41 & $11-12-61$ & 52.5 \\
\hline 16 & 39 & $8-20-61$ & 41 & $11-12-61$ & 52.5 \\
\hline 17 & 39 & $8-20-61$ & $*$ & -- & -- \\
\hline 18 & 39 & $8-20-61$ & $*$ & -- & - - \\
\hline 19 & 39 & $8-20-61$ & 47 & $8-6-62$ & 193.4 \\
\hline 20 & 39 & $8-20-61$ & 47 & $8-6-62$ & 193.4 \\
\hline 21 & 39 & $8-20-61$ & $63 * *$ & $5-31-64$ & 522.6 \\
\hline 22 & 39 & $8-20-61$ & $63 * *$ & $5-31-64$ & 522.6 \\
\hline 23 & 39 & $8-20-61$ & $*$ & -- & - - \\
\hline 24 & 39 & $8-20-61$ & * & - - & - \\
\hline 25 & 39 & $8-20-61$ & 42 & $1-2-62$ & 76.9 \\
\hline 26 & 39 & $8-20-61$ & 42 & $1-2-62$ & 76.9 \\
\hline 27 & 39 & $8-20-61$ & $*$ & - & - - \\
\hline 28 & 39 & $8-20-61$ & $*$ & - - & - \\
\hline 29 & 41 & $10-14-61$ & 41 & $11-12-61$ & 23.6 \\
\hline 30 & 41 & $10-14-61$ & 41 & $11-12-61$ & 23.6 \\
\hline 31 & 41 & $10-14-61$ & 41 & $11-12-61$ & 23.6 \\
\hline 32 & 41 & $10-14-61$ & 41 & $11-12-61$ & 23.6 \\
\hline 33 & 41 & $10-14-61$ & $*$ & - & $\ldots$ \\
\hline 34 & 41 & $10-14-61$ & $*$ & - - & - - \\
\hline 35 & 45 & $4-11-62$ & 45 & $5-6-62$ & 23.1 \\
\hline 36 & 45 & $4-11-62$ & 45 & $5-6-62$ & 23.1 \\
\hline 37 & 42 & $11-25-61$ & 51 & $12-26-62$ & 203.5 \\
\hline 38 & 42 & $11-25-61$ & 52 & $2-17-63$ & 223.9 \\
\hline 39 & 45 & $4-11-62$ & 45 & $5-6-62$ & 23.1 \\
\hline
\end{tabular}

* Irradiation still in progress. **Excluding Cycle 61 . 


\section{APPENDIX I (Cont'd)}

\begin{tabular}{|c|c|c|c|c|c|}
\hline Quadrant & Insertion & Reactor & Discharge & End of & Effective \\
\hline Number & Cycle & $\underline{\text { Start Up }}$ & Cycle & Cycle & Days at $175 \mathrm{MW}$ \\
\hline 40 & 45 & $4-11-62$ & 45 & $5-6-62$ & 23.1 \\
\hline 41 & 42 & $11-25-61$ & 51 & $12-26-62$ & 203.5 \\
\hline 42 & $" 1$ & " & 52 & $2-17-63$ & 223.9 \\
\hline 43 & $"$ & " & 47 & $8-6-62$ & 140.9 \\
\hline 44 & $"$ & $":$ & $"$ & 11 & 11 \\
\hline 45 & $"$ & $"$ & 42 & $1-2-62$ & 24.4 \\
\hline 46 & " & $"$ & $" i$ & 1 & \\
\hline 47 & $"$ & $"$ & : & $"$ & $"$ \\
\hline 48 & $\because$ & $"$ & $"$ & $n$ & $"$ \\
\hline $\begin{array}{l}49 \\
50\end{array}$ & $\begin{array}{l}48 \\
11\end{array}$ & $\begin{array}{c}8-24-62 \\
" 1\end{array}$ & $\begin{array}{l}48 \\
" 1\end{array}$ & $\begin{array}{c}9-17-62 \\
" 1\end{array}$ & 13.5 \\
\hline $\begin{array}{l}51 \\
52\end{array}$ & $\underbrace{50}_{i:}$ & $11-8-62$ & 52 & $2-17-63$ & $\begin{array}{l}54.1 \\
" 1\end{array}$ \\
\hline 53 & 46 & $5-9-62$ & 46 & $6-11-62$ & 28.6 \\
\hline 54 & $"$ & $"$ & $"$ & $"$ & \\
\hline 55 & $n$ & $n$ & 1: & $"$ & $"$ \\
\hline 56 & $"$ & $n$ & $n$ & $\therefore$ & $"$ \\
\hline 57 & 47 & $7-8-62$ & 50 & $11-26-62$ & 65.5 \\
\hline 58 & $"$ & $"$ & $"$ & " & $\because:$ \\
\hline 59 & $"$ & $"$ & $"$ & "1 & " \\
\hline 60 & $"$ & $"$ & ". & $"$ & $"$ \\
\hline $\begin{array}{l}61 \\
62\end{array}$ & 45 & $4-11$ " -62 & 45 & $\begin{array}{c}5-6-62 \\
" 1\end{array}$ & 23.1 \\
\hline $\begin{array}{l}63 \\
64\end{array}$ & $\begin{array}{l}46 \\
" 1\end{array}$ & $\begin{array}{c}5-9-62 \\
" \prime\end{array}$ & 46 & $6-11-62$ & 28.6 \\
\hline $\begin{array}{l}65 \\
66\end{array}$ & 53 & $2-27-63$ & 54 & $5-13-63$ & 44.7 \\
\hline $\begin{array}{l}67 \\
68\end{array}$ & 47 & $\begin{array}{c}7-8-62 \\
i\end{array}$ & 47 & $\begin{array}{c}8-6-62 \\
n\end{array}$ & 23.5 \\
\hline $\begin{array}{l}69 \\
70\end{array}$ & 48 & $\begin{array}{c}8-24-62 \\
n\end{array}$ & 50 & $11-26-62$ & 42.0 \\
\hline 71 & $"$ & " & 49 & $10-15-62$ & 28.9 \\
\hline 72 & " & 11 & $"$ & " & \\
\hline $\begin{array}{l}73 \\
74\end{array}$ & 55 & $5-2 \underset{11}{2}-63$ & 56 & $\begin{array}{c}8-4-63 \\
" 1\end{array}$ & 48.1 \\
\hline 75 & 51 & $12-5-62$ & 52 & $2-17-63$ & 41.0 \\
\hline 76 & $"$ & i: & 51 & $12-26-62$ & 20.6 \\
\hline 77 & $1:$ & ': & 52 & $2-17-63$ & 41.0 \\
\hline 78 & $1:$ & 13 & 51 & $12-26-62$ & 20.6 \\
\hline 79 & 49 & $9-26-62$ & $*$ & $\ldots$ & - - \\
\hline 80 & $"$ & " & * & - - & - - \\
\hline
\end{tabular}

* Irradiation still in progress. 
APPENDIX I (Cont'd)

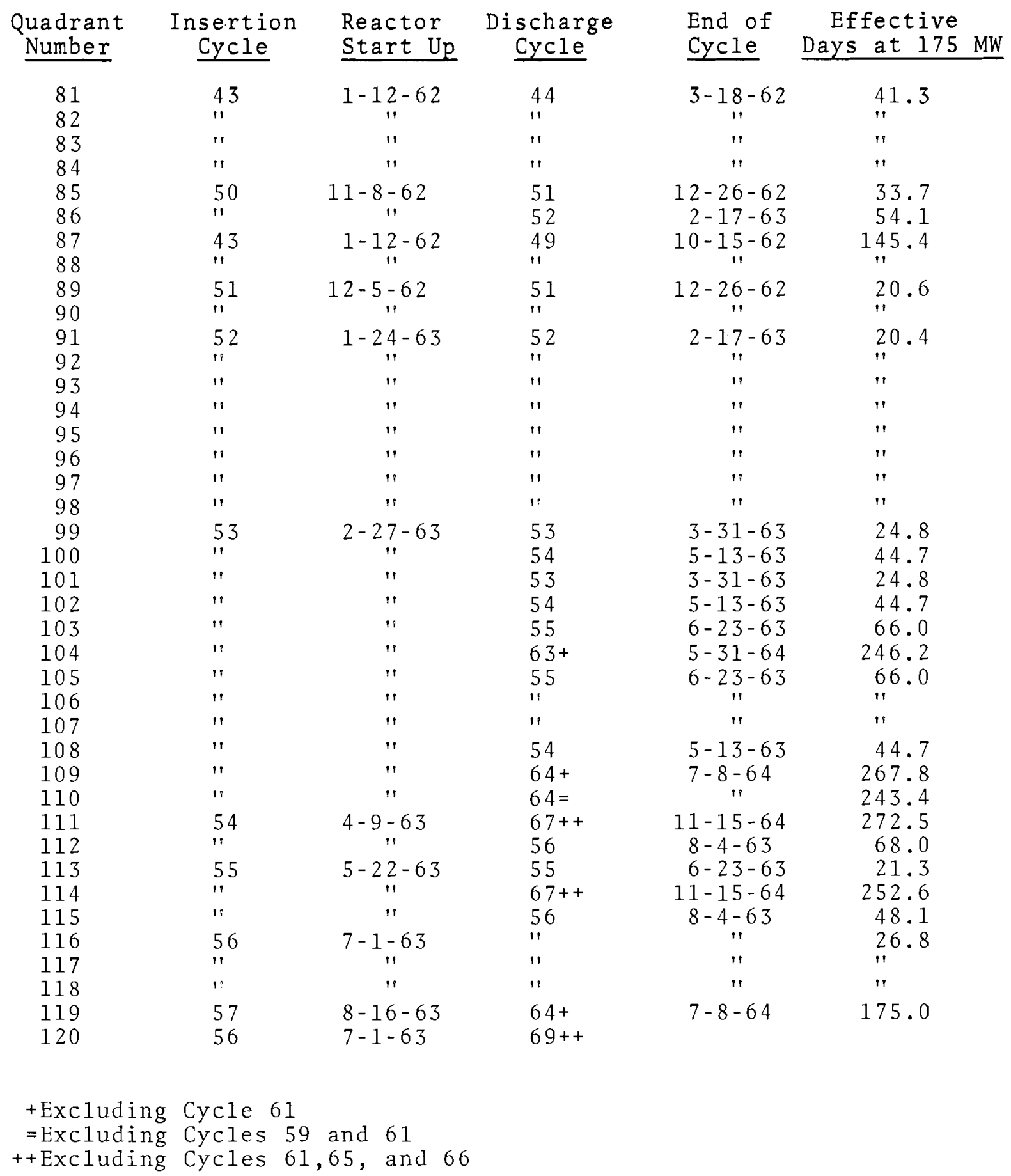




\section{APPENDIX I (Cont'd)}

\begin{tabular}{|c|c|c|c|c|c|}
\hline $\begin{array}{l}\text { Quadrant } \\
\text { Number }\end{array}$ & $\begin{array}{c}\text { Insertion } \\
\text { Cycle }\end{array}$ & $\begin{array}{l}\text { Reactor } \\
\text { Start Up } \\
\end{array}$ & $\begin{array}{c}\text { Discharge } \\
\text { Cycle }\end{array}$ & $\begin{array}{l}\text { End of } \\
\text { Cycle }\end{array}$ & $\begin{array}{r}\text { Effective } \\
\text { Days at } 175 \mathrm{MW} \\
\end{array}$ \\
\hline 121 & 56 & $7-1-63$ & $67++$ & $11-15-64$ & 231.3 \\
\hline 122 & 57 & $8-16-63$ & $64++$ & $7-8-64$ & 175.0 \\
\hline 123 & 56 & $7-1-63$ & 58 & $10-25-63$ & 68.1 \\
\hline 124 & 57 & $8-16-63$ & 58 & $10-25-63$ & 41.3 \\
\hline 125 & $"$ & " & 57 & $9-13-63$ & 22.3 \\
\hline 126 & $"$ & $"$ & 59 & $12-8-63$ & 65.7 \\
\hline 127 & $"$ & $"$ & 60 & $1-19-64$ & 94.1 \\
\hline 128 & $"$ & $"$ & $63+$ & $5-31-64$ & 153.4 \\
\hline 129 & $"$ & $"$ & $*++$ & - - & - \\
\hline 130 & 62 & $3-9-64$ & $68 x$ & & \\
\hline 131 & $"$ & " & $68 x$ & & \\
\hline 132 & 64 & $6-10-64$ & 64 & $7-8-64$ & 21.6 \\
\hline 133 & 65 & $7-19-64$ & 65 & $8-16-64$ & 18.7 \\
\hline 134 & $"$ & " & $" 1$ & " & \\
\hline 135 & 58 & $10-3-63$ & $63+$ & $5-31-64$ & 131.1 \\
\hline 136 & 59 & $11-8-63$ & 60 & $1-19-64$ & 52.8 \\
\hline 137 & 64 & $6-10-64$ & 64 & $7-8-64$ & 21.6 \\
\hline 138 & $" 1$ & 11 & $" 1$ & i" & $" 1$ \\
\hline 139 & 65 & $7-19-64$ & 65 & $8-16-64$ & 18.7 \\
\hline 140 & 59 & $11-18-63$ & $*++$ & - - & $\ldots$ \\
\hline 141 & " & 11 & $64+$ & $7-8-64$ & 133.7 \\
\hline \multirow{3}{*}{\multicolumn{6}{|c|}{$\begin{array}{l}\text { * Irradiation still in progress } \\
+ \text { Excluding Cycle } 61 \\
++ \text { Excluding Cycles } 61.65\end{array}$}} \\
\hline & & & & & \\
\hline & & & & & \\
\hline
\end{tabular}




\section{APPENDIX II}

\section{SPECIFIC ACTIVITIES OF CENTRAL MONITORS}

\begin{tabular}{|c|c|c|c|c|c|}
\hline \multirow[b]{2}{*}{ Cyc $1 \mathrm{e}$} & \multirow{2}{*}{$\begin{array}{c}\text { Irradiation } \\
\text { Leve } 1 \\
\end{array}$} & \multicolumn{4}{|c|}{$\mathrm{d} / \mathrm{s} / \mathrm{mg}$ at Discharge } \\
\hline & & $\mathrm{Fe}\left(10^{4}\right)$ & $\mathrm{Ni}\left(10^{6}\right)$ & $\mathrm{Ti}\left(10^{4}\right)$ & A $1-0.1$ wt: Co $\left(10^{6}\right)$ \\
\hline 45 & $\begin{array}{l}\text { A } \\
\text { B } \\
C \\
D \\
E \\
F \\
\text { G }\end{array}$ & $\begin{array}{c}4.58 \\
12.6 \\
20.0 \\
26.6 \\
30.0 \\
29.3 \\
25.4\end{array}$ & $\begin{array}{r}3.35 \\
8.84 \\
14.3 \\
17.9 \\
21.7 \\
21.5 \\
17.6\end{array}$ & $\begin{array}{c}5.10 \\
10.9 \\
17.0 \\
19.7 \\
22.7 \\
22.2 \\
18.5\end{array}$ & $\begin{array}{l}0.68 \\
1.64 \\
2.90 \\
2.91 \\
4.30 \\
4.23 \\
3.28\end{array}$ \\
\hline 46 & $\begin{array}{l}\text { A } \\
B \\
C \\
D \\
E \\
F \\
G\end{array}$ & $\begin{array}{r}7.0 \\
17.5 \\
26.0 \\
32.0 \\
34.0 \\
37.0 \\
33.0\end{array}$ & $\begin{array}{r}4.8 \\
10.5 \\
15.3 \\
20.0 \\
20.0 \\
20.5 \\
16.9\end{array}$ & $\begin{array}{r}8.3 \\
17.0 \\
25.0 \\
28.0 \\
32.0 \\
30.0 \\
24.0\end{array}$ & $\begin{array}{l}0.92 \\
2.01 \\
3.8 \\
-- \\
5.15 \\
5.0 \\
4.0\end{array}$ \\
\hline 47 & $\begin{array}{l}A \\
B \\
C \\
D \\
E \\
F \\
G\end{array}$ & $\begin{array}{r}5.4 \\
13.0 \\
20.0 \\
24.0 \\
27.0 \\
29.0 \\
27.0\end{array}$ & $\begin{array}{r}3.4 \\
7.4 \\
11.4 \\
13.6 \\
15.0 \\
15.9 \\
15.8\end{array}$ & $\begin{array}{r}6.3 \\
13.0 \\
19.0 \\
23.0 \\
27.0 \\
27.0 \\
22.0\end{array}$ & $\begin{array}{l}0.76 \\
1.6 \\
2.8 \\
3.15 \\
4.6 \\
4.85 \\
3.9\end{array}$ \\
\hline 48 & $\begin{array}{l}\text { A } \\
B \\
C \\
D \\
E \\
F \\
G\end{array}$ & $\begin{array}{r}3.8 \\
9.6 \\
15.5 \\
20.0 \\
23.0 \\
23.0 \\
19.0\end{array}$ & $\begin{array}{l}2.44 \\
4.8 \\
6.5 \\
7.8 \\
8.0 \\
7.9 \\
7.1\end{array}$ & $\begin{array}{r}4.9 \\
9.8 \\
14.5 \\
17.0 \\
19.0 \\
19.0 \\
15.0\end{array}$ & $\begin{array}{l}0.54 \\
1.22 \\
2.2 \\
-- \\
3.3 \\
3.3 \\
2.3\end{array}$ \\
\hline 49 & $\begin{array}{l}\text { A } \\
\text { B } \\
\text { C } \\
\text { D } \\
\text { E } \\
\text { F } \\
\text { G }\end{array}$ & $\begin{array}{r}4.2 \\
11.0 \\
17.0 \\
22.0 \\
25.0 \\
24.0 \\
20.0\end{array}$ & $\begin{array}{l}2.6 \\
5.3 \\
7.0 \\
8.4 \\
8.2 \\
8.1 \\
7.4\end{array}$ & $\begin{array}{r}5.3 \\
11.0 \\
-1 \\
19.0 \\
21.0 \\
20.0 \\
16.0\end{array}$ & $\begin{array}{l}0.61 \\
1.4 \\
2.1 \\
2.5 \\
3.5 \\
3.1 \\
2.7\end{array}$ \\
\hline
\end{tabular}




\section{APPENDIX II (cont'd)}

\begin{tabular}{|c|c|c|c|c|c|}
\hline \multirow[b]{2}{*}{ Cycle } & \multirow{2}{*}{$\begin{array}{c}\text { Irradiation } \\
\text { Level } \\
\end{array}$} & \multicolumn{4}{|c|}{$\mathrm{d} / \mathrm{s} / \mathrm{mg}$ at Discharge } \\
\hline & & Fe $\left(10^{4}\right)$ & $\mathrm{Ni}\left(10^{6}\right)$ & $\operatorname{Ti}\left(10^{4}\right)$ & $\mathrm{A} 1-0.1$ wt: Co $\left(10^{6}\right)$ \\
\hline \multirow[t]{7}{*}{50} & A & 3.61 & 2.31 & 4.63 & 0.946 \\
\hline & B & 9.03 & 4.59 & 9.24 & 2.29 \\
\hline & C & 14.1 & 6.18 & 13.3 & 4.09 \\
\hline & $\mathrm{D}$ & 17.5 & 7.54 & 16.0 & 4.89 \\
\hline & $E$ & 19.1 & 7.66 & 17.4 & 5.95 \\
\hline & F & 18.7 & 7.19 & 16.1 & 5.78 \\
\hline & $\mathrm{G}$ & 15.3 & 6.55 & 12.3 & 3.83 \\
\hline \multirow{7}{*}{51} & A & 4.8 & 3.23 & 5.20 & - - \\
\hline & B & 13.4 & 6.60 & 11.10 & - \\
\hline & C & 21.0 & 9.00 & 17.00 & - - \\
\hline & D & 26.0 & 9.10 & 20.0 & - - \\
\hline & E & 31.0 & - - & 22.0 & - - \\
\hline & $\mathrm{F}$ & 30.0 & 9.10 & 21.0 & - \\
\hline & G & 25.0 & 8.30 & 16.0 & -- \\
\hline \multirow[t]{7}{*}{53} & A & 6.25 & - - & -- & -- \\
\hline & B & - - & - - & - & - - \\
\hline & C & 15.8 & 7.22 & 16.6 & -- \\
\hline & D & 32.4 & 11.2 & 29.4 & - - \\
\hline & E & 31.5 & 10.7 & 32.0 & - - \\
\hline & $\mathrm{F}$ & 36.8 & 10.2 & 29.7 & - - \\
\hline & $\mathrm{G}$ & 31.3 & 11.2 & 22.4 & -- \\
\hline \multirow[t]{7}{*}{54} & A & 4.6 & 2.7 & 11.0 & - - \\
\hline & B & 13.0 & 5.7 & 12.0 & - - \\
\hline & C & 20.0 & 7.7 & 16.0 & - - \\
\hline & D & 26.0 & 8.4 & 20.0 & - - \\
\hline & $\mathrm{E}$ & 28.0 & 8.9 & 22.0 & - - \\
\hline & $F$ & 27.0 & 8.6 & 19.0 & - - \\
\hline & $\mathrm{G}$ & 22.0 & 7.7 & -- & -- \\
\hline \multirow[t]{7}{*}{55} & A & 4.85 & 3.46 & 6.07 & -- \\
\hline & $\mathrm{B}$ & 12.9 & 6.69 & 13.2 & -- \\
\hline & C & 20.4 & 9.90 & 19.1 & - - \\
\hline & D & 25.6 & 10.5 & 22.7 & - - \\
\hline & $\mathrm{E}$ & 28.3 & 11.7 & 25.8 & -- \\
\hline & $\mathrm{F}$ & 27.3 & 9.98 & -- & -- \\
\hline & $\mathrm{G}$ & 21.6 & - & 12.3 & -- \\
\hline
\end{tabular}


APPENDIX II (Cont'd)

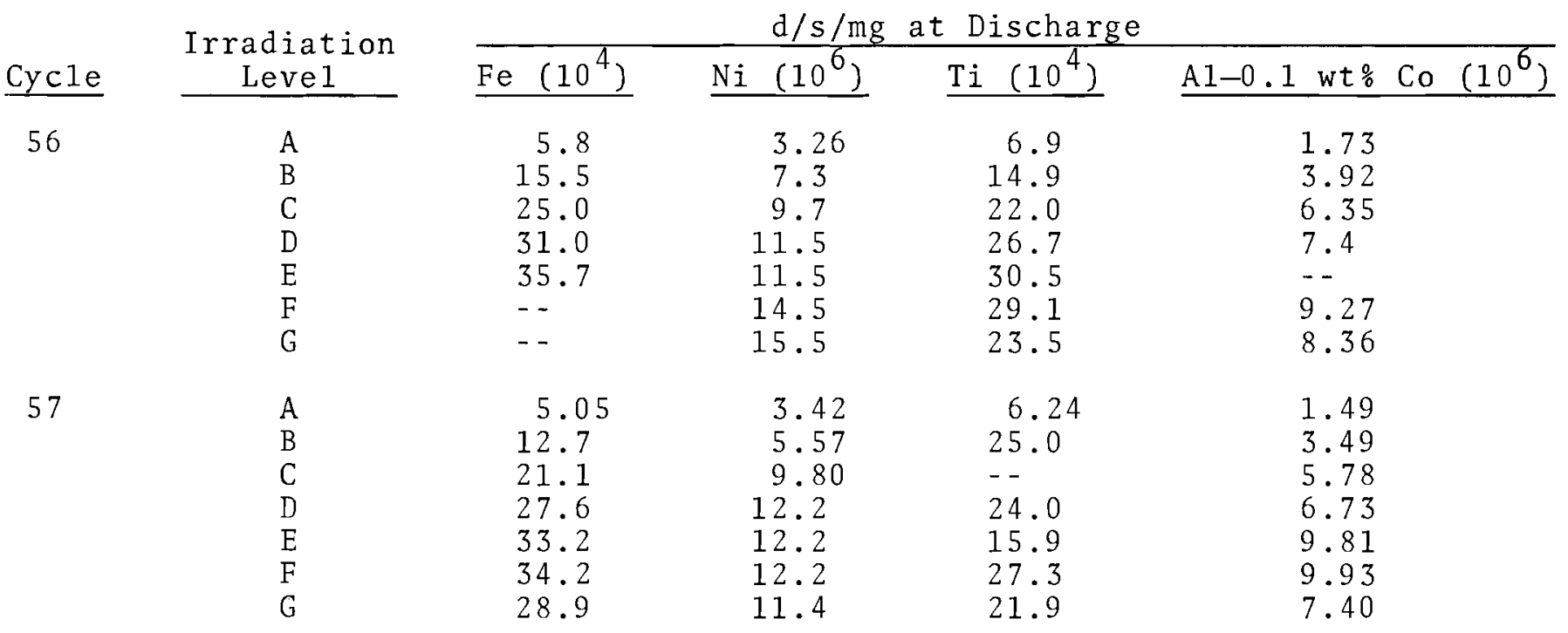


APPENDIX III

CENTRAL MONITOR FLUX DATA (FISSION SPECTRUM, E $>1$ MeV)

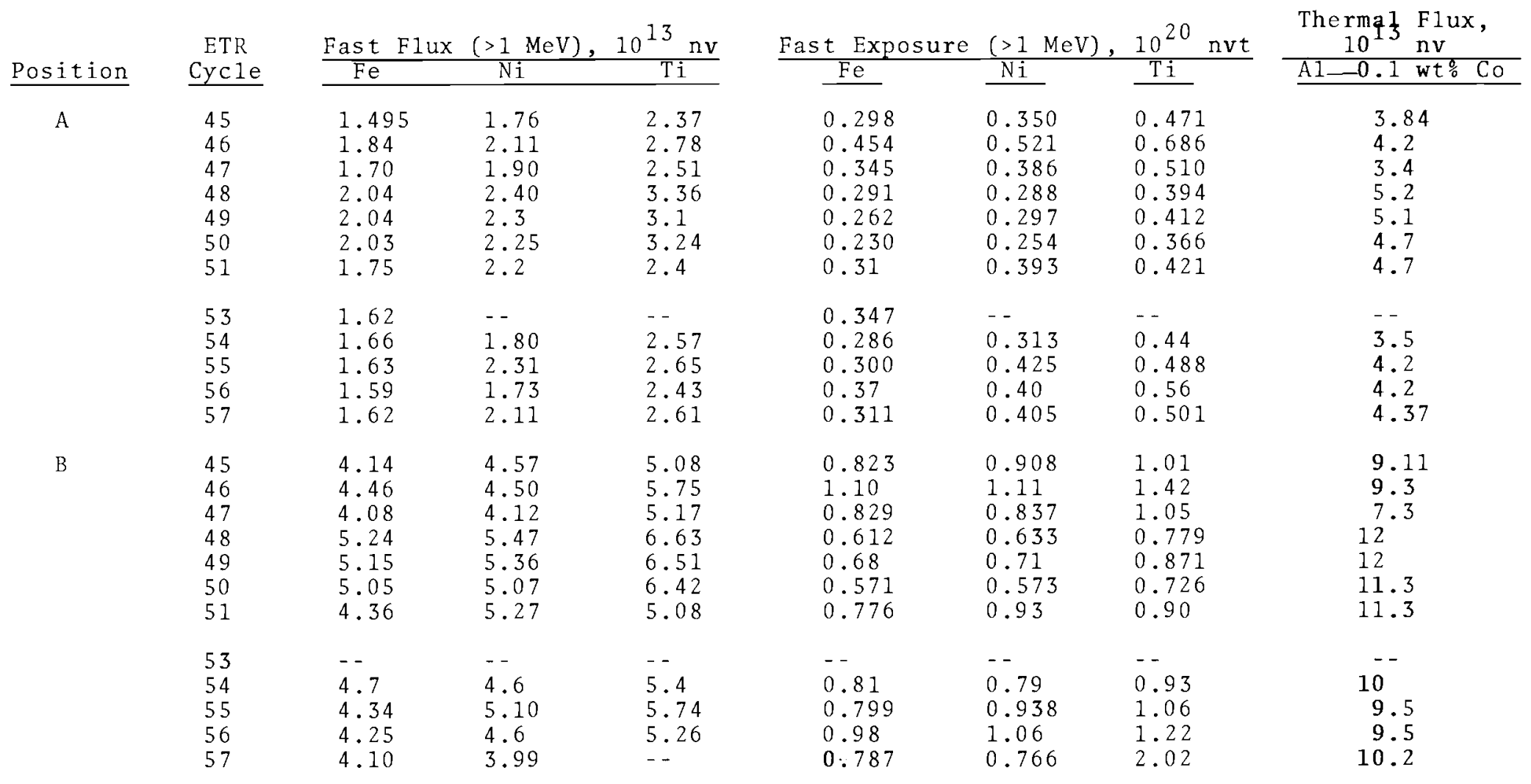


$\underline{\text { APPENDIX III (Cont'd) }}$

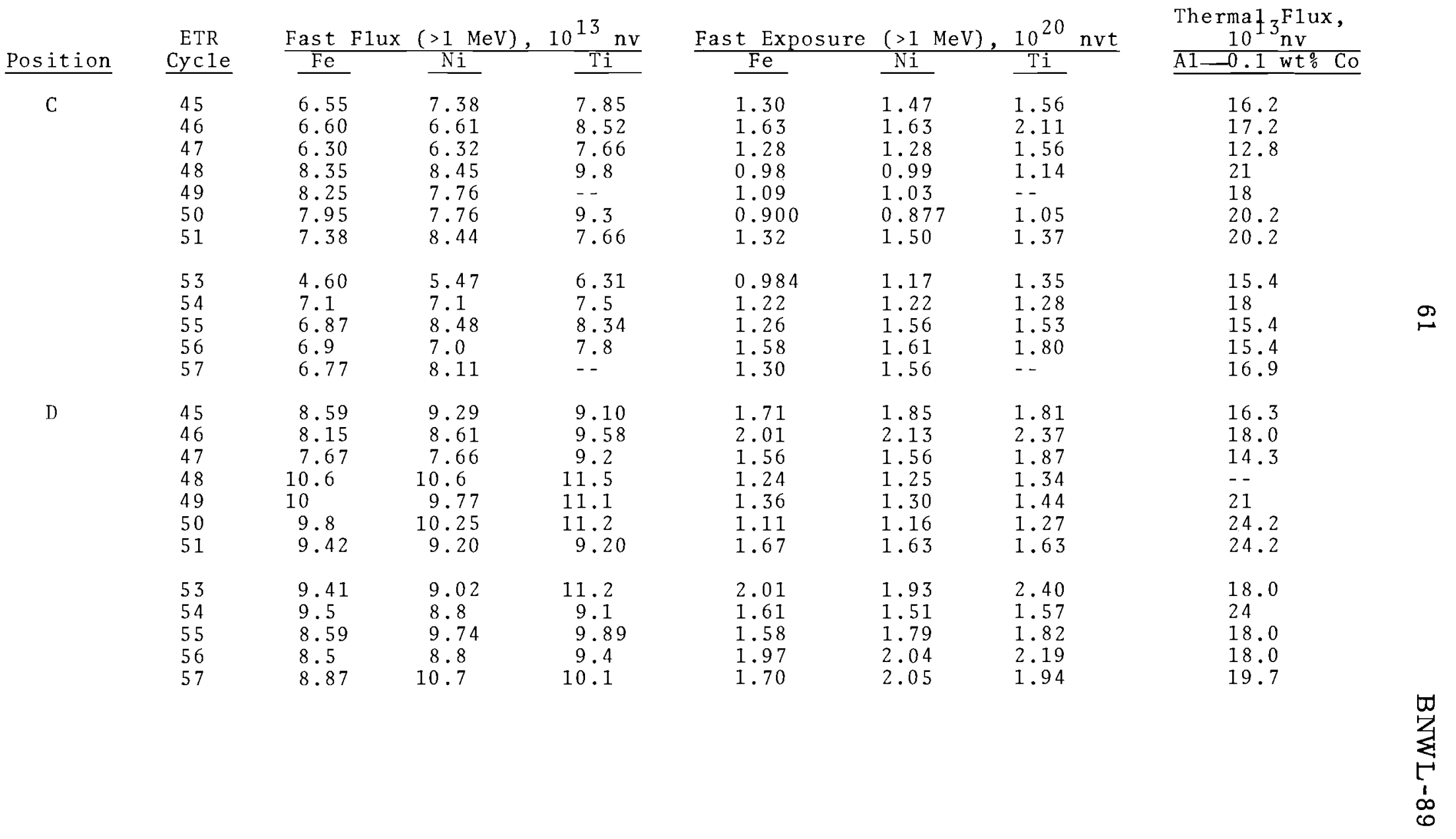


APPENDIX III (Cont'd)

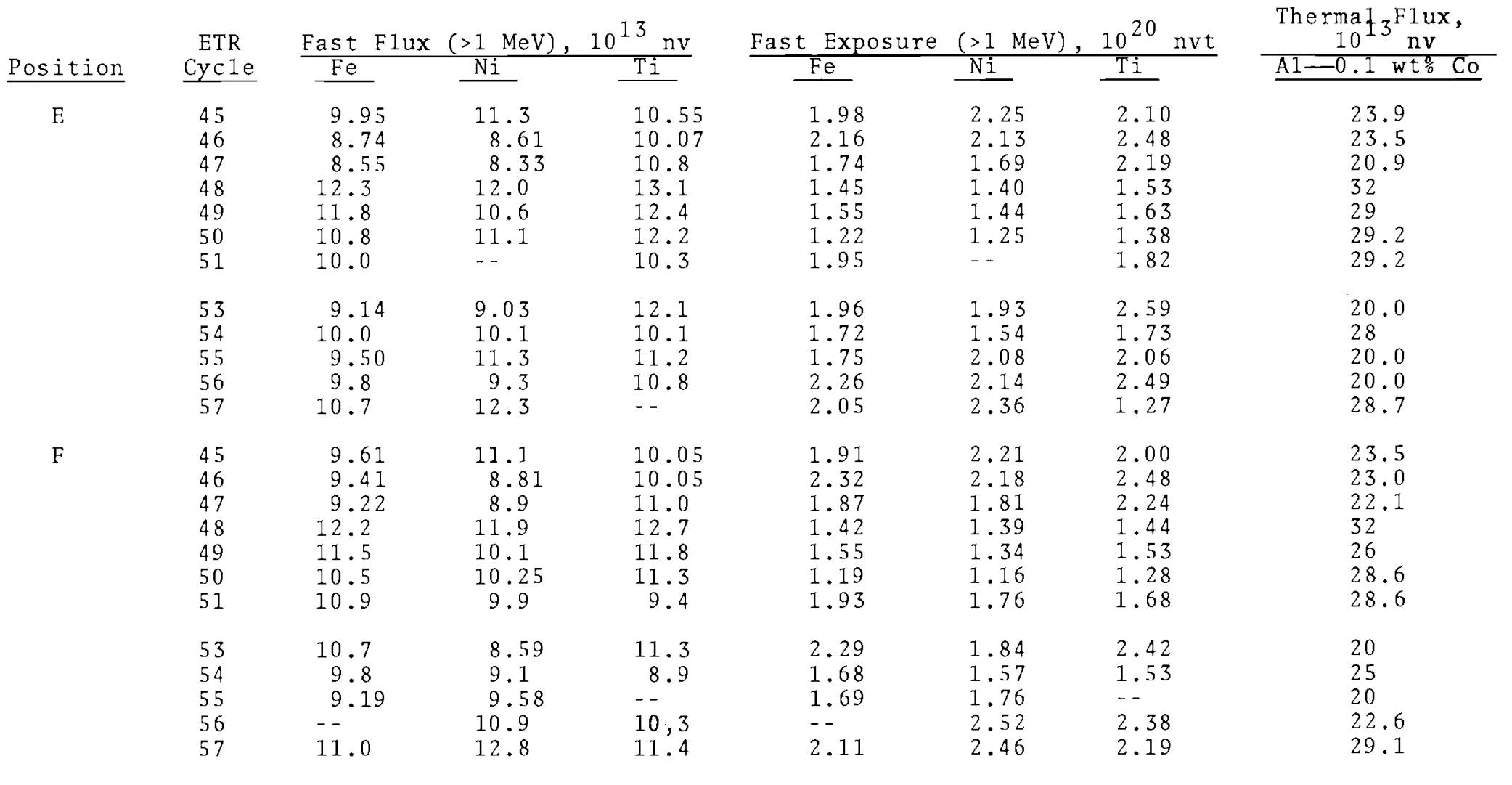


APPENDIX III (Cont'd)

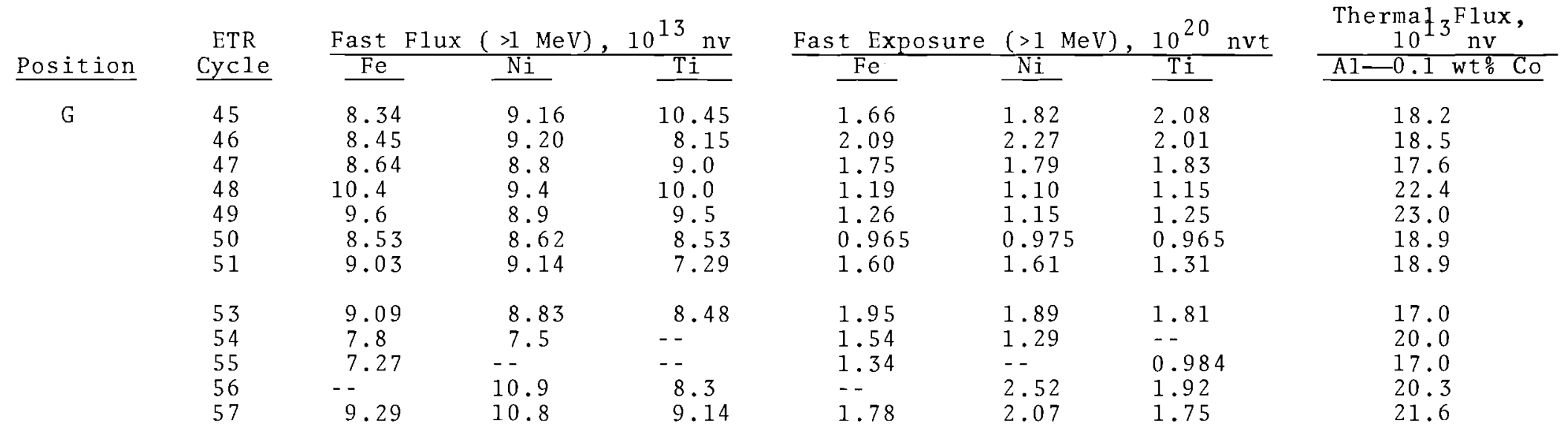


APPENDIX IV

SPECIFIC ACTIVITIES FOR QUADRANT DOSIMETERS

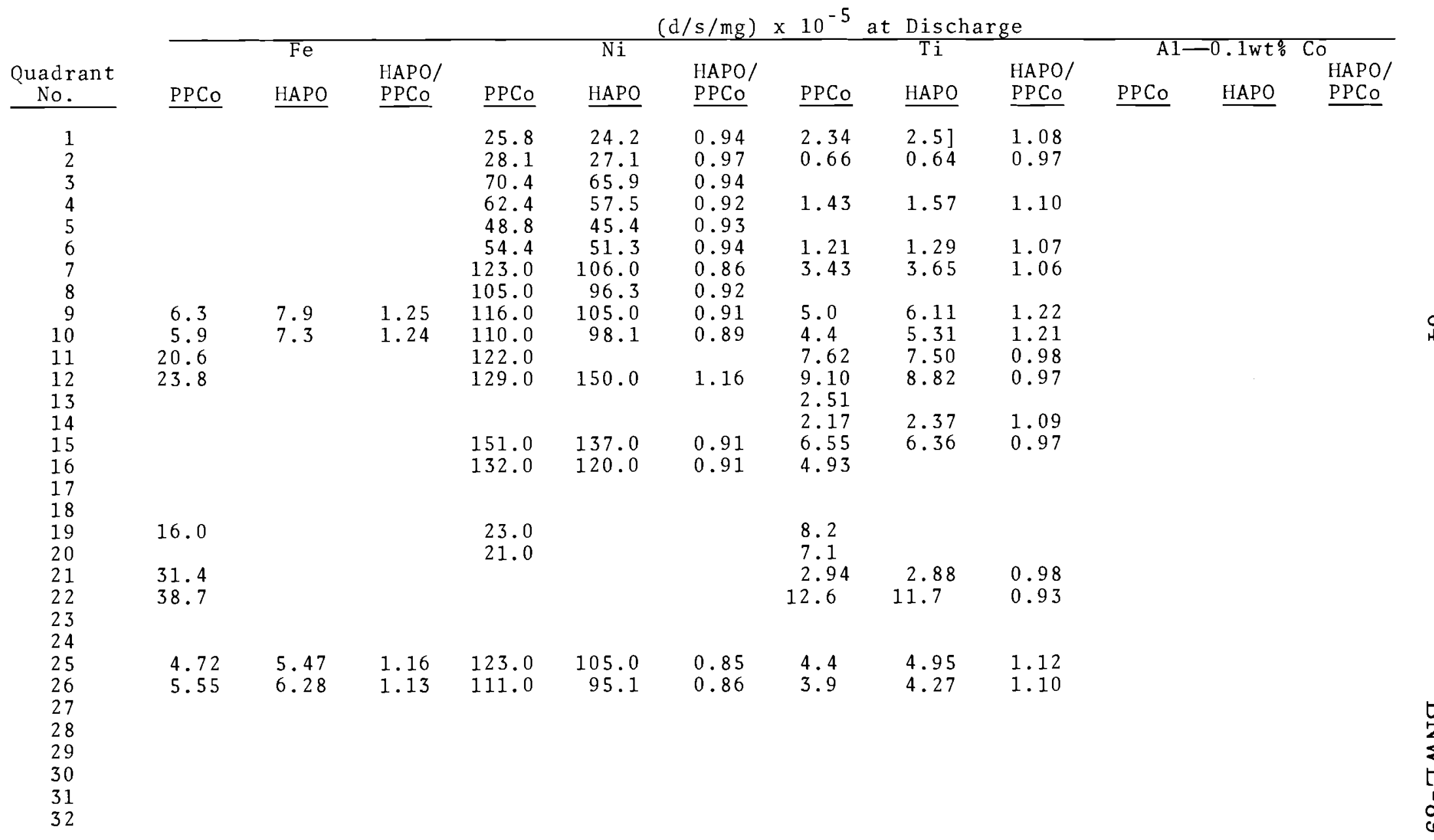


APPENDIX IV (Cont'd)

\begin{tabular}{|c|c|c|c|c|c|c|c|c|c|c|c|c|}
\hline \multirow[b]{3}{*}{$\begin{array}{l}\text { Quadran } \\
\text { No. } \\
\end{array}$} & \multicolumn{12}{|c|}{$(\mathrm{d} / \mathrm{s} / \mathrm{mg}) \times 10^{-5}$} \\
\hline & \multicolumn{2}{|r|}{$\mathrm{Fe}$} & \multirow[b]{2}{*}{$\begin{array}{l}\text { HAPO/ } \\
\text { PPCo }\end{array}$} & \multicolumn{3}{|c|}{$\mathrm{Ni}$} & \multicolumn{3}{|c|}{$\mathrm{Ti}$} & \multicolumn{3}{|c|}{$\mathrm{A} 1-0.1$ wt: $\mathrm{Co}$} \\
\hline & ${ }^{t}$ PPCo & HAPO & & $\underline{\mathrm{PPCO}}$ & $\underline{\text { HAPO }}$ & $\begin{array}{l}\text { HAPO/ } \\
\text { PPCo }\end{array}$ & PPCo & $\underline{\mathrm{HAPO}}$ & $\begin{array}{l}\text { HAPO / } \\
\text { PPCo }\end{array}$ & PPCo & $\underline{\text { HAPO }}$ & $\begin{array}{l}\text { HAPO } \\
\text { PPCo } \\
\end{array}$ \\
\hline $\begin{array}{l}33 \\
34\end{array}$ & & & & & & & & & & & & \\
\hline 35 & 0.57 & 0.56 & 0.98 & 42.0 & & & 075 & 0.88 & 1.17 & & & \\
\hline 36 & 0.49 & 0.45 & 0.92 & & & & 0.60 & 0.675 & 1.12 & & & \\
\hline 37 & 5.80 & 5.80 & 1.00 & 78.0 & & & 1.45 & & & & & \\
\hline 38 & 7.35 & 7.25 & 0.99 & 84.0 & & & 2.15 & & & & & \\
\hline 39 & 1.20 & 1.29 & 1.08 & 79.0 & & & 1.36 & 1.59 & 1.17 & & & \\
\hline 40 & 1.07 & 1.05 & 0.98 & 65.0 & 57.8 & 0.89 & & & & & & \\
\hline 41 & 11.70 & 12.10 & 1.03 & 127.0 & 143.0 & 1.13 & 4.20 & 4.50 & 1.07 & & & \\
\hline 42 & 14.7 & 15.4 & 1.05 & 117.0 & 137.0 & 1.17 & 5.10 & 5.33 & 1.04 & & & \\
\hline 43 & 16.6 & 16.4 & 0.99 & 148.0 & & & 7.80 & 9.05 & 1.16 & & & \\
\hline 44 & 18.5 & & & 169.0 & & & 8.90 & 9.50 & 1.07 & & & \\
\hline 45 & 0.628 & 0.635 & 1.01 & 33.0 & 30.5 & 0.92 & & & & & & \\
\hline 46 & 0.555 & 0.551 & 0.99 & 31.0 & 25.7 & 0.83 & 0.62 & 0.677 & 1.09 & & & \\
\hline 47 & 1.35 & 1.33 & 0.99 & 62.0 & 56.8 & 0.92 & 1.72 & 1.51 & 1.06 & & & \\
\hline 48 & 1.20 & 1.21 & 1.01 & 57.0 & 52.6 & 0.92 & 1.25 & 1.31 & 1.05 & & & \\
\hline 49 & 1.87 & 1.82 & 0.97 & 75.0 & & & 1.51 & & & 24.9 & 25.0 & 1.00 \\
\hline 50 & 2.85 & 2.81 & 0.99 & 109.0 & & & 2.29 & 2.30 & 1.00 & & & \\
\hline 51 & 5.70 & 5.90 & 1.04 & 103.0 & & & 3.60 & 3.63 & 1.01 & 82.0 & 81.5 & 0.99 \\
\hline 52 & 5.20 & 5.14 & 0.99 & 106.0 & 99.7 & 0.94 & 3.13 & 3.17 & 1.01 & 71.1 & 71.1 & 1.00 \\
\hline 53 & 0.63 & 0.621 & 0.99 & 37.0 & & & 0.66 & & & 11.4 & & \\
\hline 54 & 0.72 & 0.696 & 0.97 & 41.0 & & & 0.75 & & & 13.0 & 13.1 & 1.00 \\
\hline 55 & 1.48 & 1.44 & 0.97 & 68.0 & & & 1.28 & & & 22.6 & 22.7 & 1.00 \\
\hline 56 & 1.66 & 1.62 & 0.97 & 74.0 & & & 1.45 & & & 24.9 & 25.0 & 1.00 \\
\hline 57 & 1.64 & 1.64 & 1.00 & 57.0 & & & 1.50 & & & 29.0 & & \\
\hline 58 & 1.42 & 1.38 & 0.99 & 51.0 & & & 1.30 & 1.39 & 1.07 & 30.0 & 32.3 & 1.08 \\
\hline 59 & 4.30 & 4.29 & 1.00 & 94.0 & & & 3.20 & 3.34 & 1.04 & 74.0 & 72.8 & 0.99 \\
\hline 60 & 3.40 & 3.36 & 0.99 & 85.0 & & & & 2.63 & & 61.0 & 61.5 & 1.01 \\
\hline 61 & 1.83 & 2.03 & 1.13 & 92.0 & 79.9 & 0.87 & 1.96 & 2.22 & 1.13 & & 34.0 & \\
\hline 62 & 1.51 & 1.61 & 1.07 & 90.0 & & & 1.49 & 1.56 & 1.05 & & 28.0 & \\
\hline 63 & 2.20 & & & 8.5 & & & 1.80 & & & & & \\
\hline 64 & 3.20 & & & 10.7 & & & 2.35 & & & & & \\
\hline 65 & 6.30 & 6.15 & 0.98 & 112.0 & & & 3.90 & & & 97.4 & & \\
\hline 66 & 4.47 & 4.38 & 0.98 & 98.0 & 88.7 & 0.91 & 2.84 & 2.67 & 0.94 & 76.5 & & \\
\hline
\end{tabular}


APPENDIX IV (Cont'd)

\begin{tabular}{|c|c|c|c|c|c|c|c|c|c|c|c|c|c|}
\hline \multirow[b]{3}{*}{$\begin{array}{l}\text { Quadrant } \\
\text { No. } \\
\end{array}$} & \multicolumn{12}{|c|}{$(\mathrm{d} / \mathrm{s} / \mathrm{mg}) \times 10^{-5}$} & \\
\hline & \multicolumn{3}{|c|}{$\mathrm{Fe}$} & \multicolumn{3}{|c|}{$\mathrm{Ni}$} & \multicolumn{3}{|c|}{$\mathrm{Ti}$} & \multicolumn{3}{|c|}{$\mathrm{A} \cdot 1-0.1 \mathrm{wt} \% \mathrm{Co}$} & \\
\hline & $\underline{\mathrm{PPCO}}$ & $\underline{\text { HAPO }}$ & $\begin{array}{l}\text { HAPO/ } \\
\text { PPCo } \\
\end{array}$ & $\underline{\mathrm{PPCO}}$ & HAPO & $\begin{array}{l}\text { HAPO/ } \\
\text { PPCo }\end{array}$ & $\underline{\mathrm{PPCO}}$ & HAPO & $\begin{array}{l}\text { HAPO/ } \\
\text { PPCo }\end{array}$ & $\underline{\mathrm{PPC}}$ & $\underline{\mathrm{HAPO}}$ & $\begin{array}{l}\text { HAPO/ } \\
\text { PPCo }\end{array}$ & \\
\hline 67 & 2.4 & 2.41 & 1.00 & 92.0 & & & & 2.56 & & 34.0 & & & \\
\hline 68 & 1.89 & 1. 89 & 1.00 & 81.0 & & & 1.75 & 1.98 & 1.13 & 28.0 & 28.5 & 1.02 & \\
\hline 69 & 4.8 & 4.75 & 0.99 & 104.0 & & & 3.7 & & & 79.0 & 77.6 & 0.98 & \\
\hline 70 & 3.8 & 3.71 & 0.98 & 92.0 & & & 2.9 & 3.08 & 1.06 & 67.0 & 63.9 & 0.95 & \\
\hline 71 & 5.8 & & & 47.0 & & & & & & & & & \\
\hline 72 & 4.2 & & & 38.0 & & & 3.6 & & & 66.0 & & & \\
\hline 73 & 4.93 & 4.74 & 0.96 & 127.0 & 110.0 & 0.87 & 3.37 & 3.25 & 0.97 & & & & \\
\hline 74 & 4.28 & 4.30 & 1.00 & 120.0 & 104.0 & 0.87 & 2.92 & 2.86 & 0.98 & & & & \\
\hline 75 & 1.34 & 1.34 & 1.00 & 58.0 & 57.9 & 1.00 & 1.32 & 1.52 & 1.14 & & & & \\
\hline 76 & 1.12 & & & 32.0 & 31.6 & 0.99 & & 0.852 & & & & & \\
\hline 77 & 3.3 & 3.32 & 1.01 & 93.0 & 81.7 & 0.88 & 3.0 & 3.05 & 1.02 & & & & \\
\hline 78 & 1.31 & 1.36 & 1.04 & 59.0 & 55.4 & 0.94 & 1.37 & 1.50 & 1.09 & & & & \\
\hline 79 & & & & & & & & & & & & & O \\
\hline 80 & & & & & & & & & & & & & \\
\hline 81 & 0.90 & 0.93 & 1.03 & 44.0 & 41.2 & 0.94 & 0.93 & 1.09 & 1.17 & & & & \\
\hline 82 & 0.92 & 0.95 & 1.03 & 47.0 & 45.1 & 0.96 & 1.01 & 1.15 & 1.14 & & & & \\
\hline 83 & 1.92 & 1.95 & 1.01 & 77.0 & 73.4 & 0.95 & 1.81 & 2.08 & 1.15 & & & & \\
\hline 84 & 2.07 & 2.18 & 1.05 & 84.0 & 79.3 & 0.94 & 1.97 & 2.12 & 1.08 & & & & \\
\hline 85 & 4.60 & 4.68 & 1.02 & 102.0 & 121.0 & 1.19 & 3.5 & & & & & & \\
\hline 86 & 7.3 & 7.32 & 1.0 & 118.0 & 129.0 & 1.09 & 5.1 & 5.05 & 0.99 & & & & \\
\hline 87 & 11.1 & & & 42.0 & & & 5.7 & & & & & & \\
\hline 88 & 11.1 & & & 42.0 & & & 5.3 & & & & & & \\
\hline 89 & 2.58 & 2.70 & 1.05 & 89.0 & & & 2.23 & 2.77 & 1.24 & & & & \\
\hline 90 & 2.06 & 2.09 & 1.01 & 78.0 & & & 1.79 & 2.08 & 1.16 & & & & \\
\hline 91 & 0.60 & 0.595 & 1.00 & 29.8 & 35.7 & 1.20 & 0.68 & & & 2.73 & & & \\
\hline 92 & 0.85 & 0.85 & 1.00 & 37.8 & 43.9 & 1.16 & 1.04 & 1.12 & 1.08 & 2.63 & 2.53 & 0.96 & \\
\hline 93 & 1. 33 & 1.32 & 1.00 & 47.2 & 53.8 & 1.14 & 1.36 & 1.37 & 1.00 & 4.1 & & & \\
\hline 94 & 1.98 & 2.21 & 1.12 & 66.8 & & & 2.04 & 1. 94 & 0.93 & 5.1 & & & \\
\hline 95 & 2.7 & 2.62 & 0.97 & 78.4 & 94.2 & 1.20 & 2.4 & 2.39 & 1.00 & 7.5 & 7.75 & 1.03 & \\
\hline 96 & 2.03 & 2.03 & 1.00 & 72.0 & 80.1 & 1.11 & 1.84 & 1.84 & 1.00 & 5.6 & 5.52 & 0.99 & \\
\hline 97 & 4.11 & 4.09 & 1.00 & 92.0 & & & 3.3 & 3.35 & 1. 02 & 13.7 & & & \\
\hline 98 & 3.0 & 2.97 & 0.99 & 74.0 & 83.8 & 1.13 & 2.46 & 2.33 & 0.95 & 8.2 & 8.1 & 0.99 & 3 \\
\hline 99 & 0.80 & 0.797 & 1.00 & 43.7 & 42.2 & 0.96 & 1.02 & 1.02 & 1.00 & 2.86 & 2.92 & 1.02 & $\sum$ \\
\hline
\end{tabular}


APPENDIX IV (Cont'd)

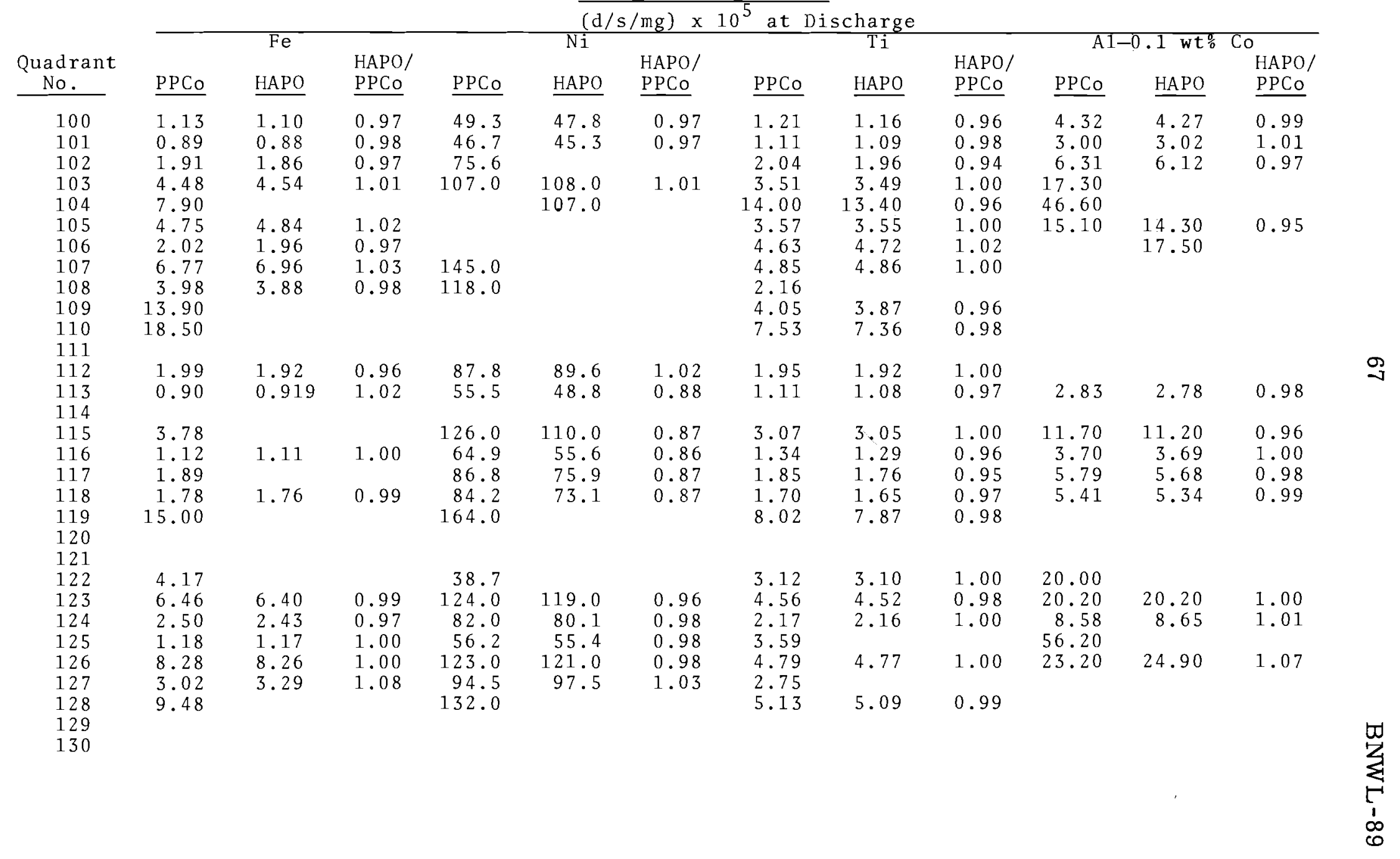


APPENDIX IV(Cont'd)

\begin{tabular}{|c|c|c|c|c|c|c|c|c|c|c|c|c|c|}
\hline \multirow[b]{3}{*}{$\begin{array}{l}\text { Quadrant } \\
\text { No. }\end{array}$} & \multicolumn{7}{|c|}{$(\mathrm{d} / \mathrm{s} / \mathrm{mg}) \times 10^{-5}$} & \multicolumn{5}{|c|}{ at Discharge } & \\
\hline & & $\mathrm{Fe}$ & & & $\mathrm{Ni}$ & & & $\mathrm{Ti}$ & & & $0.1 w t$ & & \\
\hline & $\underline{\mathrm{PPCO}}$ & HAPO & $\begin{array}{l}\text { HAPO } \\
\text { PPCo } \\
\end{array}$ & $\underline{\text { PPCo }}$ & HAPO & $\begin{array}{l}\text { HAPO/ } \\
\text { PPCo }\end{array}$ & $\underline{\mathrm{PPCo}}$ & $\underline{\mathrm{HAPO}}$ & $\begin{array}{l}\text { HAPO/ } \\
\text { PPCo }\end{array}$ & $\underline{\text { PPCo }}$ & HAPO & $\begin{array}{l}\text { HAPO/ } \\
\text { PPCo } \\
\end{array}$ & \\
\hline $\begin{array}{l}131 \\
132 \\
133\end{array}$ & 2.40 & & & 86.0 & & & 1.98 & 2.03 & 1.04 & 6.62 & 6.58 & 1.00 & $\infty$ \\
\hline $\begin{array}{l}134 \\
135 \\
136\end{array}$ & 7.33 & & & 137.0 & & & 4.58 & 4.64 & 1.01 & & & & \\
\hline $\begin{array}{l}137 \\
138 \\
139 \\
140\end{array}$ & $\begin{array}{l}1.65 \\
2.51\end{array}$ & & & $\begin{array}{r}69.5 \\
102.0\end{array}$ & & & $\begin{array}{l}1.54 \\
2.29\end{array}$ & 1.53 & 1.00 & $\begin{array}{l}4.66 \\
5.51\end{array}$ & 5.55 & 1.01 & \\
\hline 141 & 12.4 & & & 132.0 & & & 7.08 & 7.02 & 0.99 & & & & \\
\hline
\end{tabular}

0
2
1
1
0
0 
APPENDIX V

QUADRANT FLUX DATA FOR A FISSION SPECTRUM $(E>1 \mathrm{MeV})$

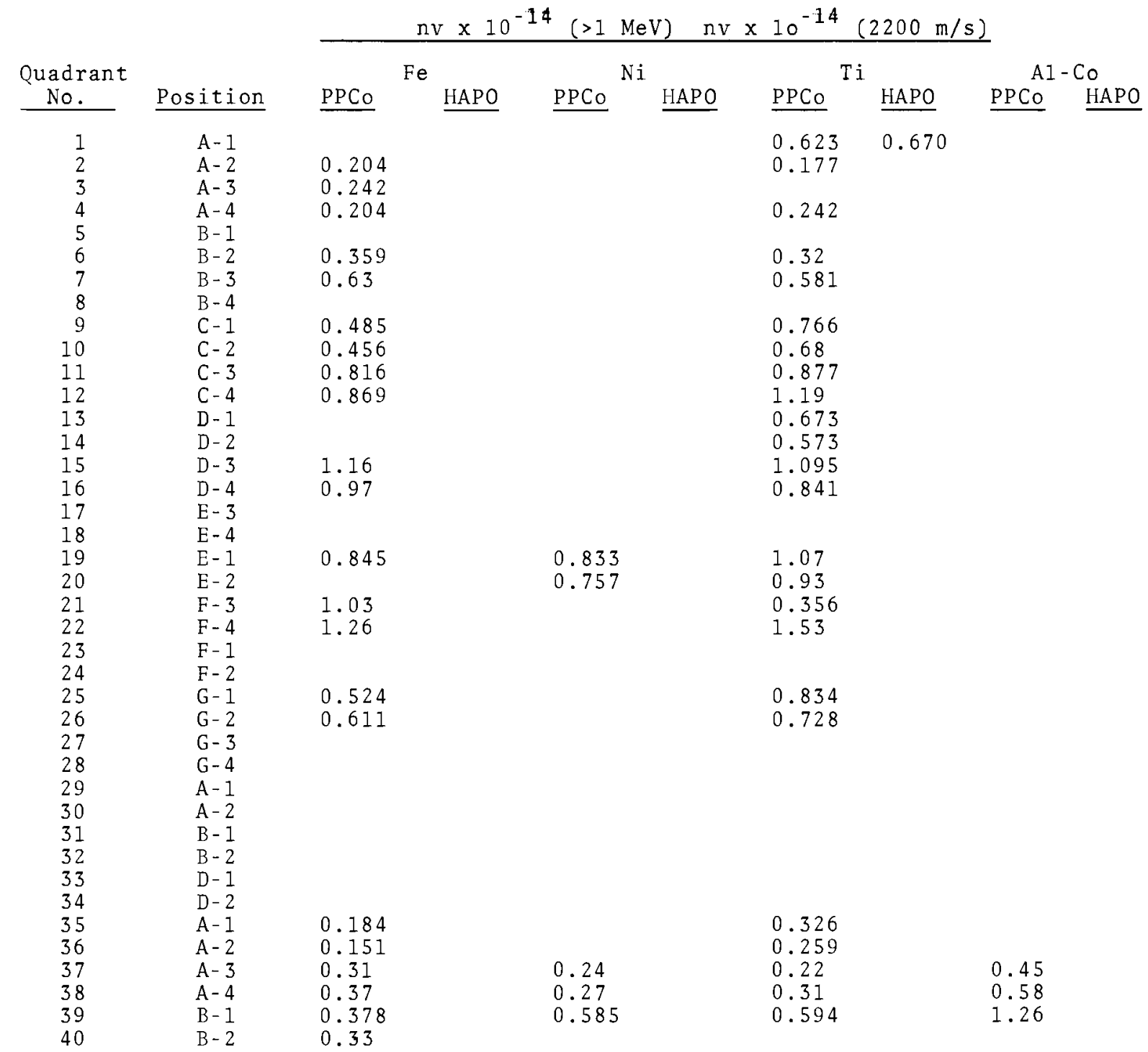




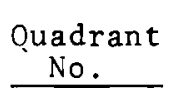

\section{Position}

\section{B- 3}

B -4

D- 3

D- 4

A- 1

A- 2

B - 1

$\mathrm{B}-2$

D- 3

D- 4

$\mathrm{G}-1$

G- 2

A- 1

A- 2

B-1

$B-2$

A- 1

A- 2

B - 1

B -2

C- 1

C- 2

C- 1

C- 2

G - 1

G-2

C- 1

C- 2

C -1

C- 2

E-1

$\mathrm{E}-2$

G- 1

G-2

A - 1

A - 2

B -1

B- 2

D- 3

D- 4

A- 1

A- 2

B- 1

\section{APPENDIX V (Cont'd)}

$\begin{array}{lllll}\mathrm{nv} \times 10^{-14}(>1 \mathrm{MeV}) & \mathrm{nv} \times 10^{-14}(2200 \mathrm{~m} / \mathrm{s}) & \\ \mathrm{Fe} & \mathrm{Ni} & \mathrm{Ti} & \mathrm{Al}-\mathrm{Co}\end{array}$

PPCo
0.63
0.74

0.74

1. 20

0.184

0.167

0.408

0.359

1.00

1. 51

0.82

0.74

0.162

0.184

0.38

0.43

0.201

0.179

0.54

0.43

0.592

0.485

0.563

0.845

1.07

0.757

0.75

0.58

0.88

0.70

1. 50

1.09

0.768

0.666

0.25

0.39

0.61

0.46

0. 166

0.167

0.35

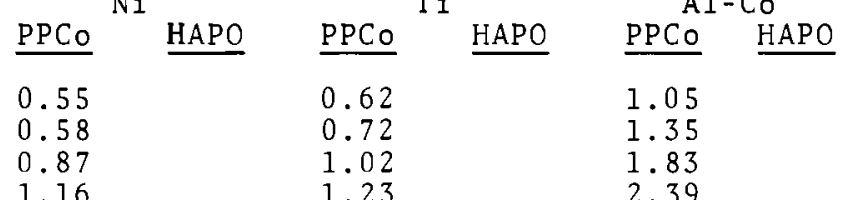

1.16

1.01

1.70

0.65

0.62

0.196

0.218

0.41

0.46

0.233

0.206

0.55

0.45

0.805

0.738

0.603

0.728

0.923

0.698

0.78

0.63

0.86

0.65

1.07

1. 20

0.947

0.802

0.28

0.255

0.57

0.49

1.23

2.39

0.25

0.575

0.508

1.00

1.52
0.79

0.69

0.221

0.249

0.43

0.48

0.333

0.289

0.702

0.54

0.852

0.651

0.603

0.795

0.969

0.705

0.61

1.05

0.82

1. 245

0.757

0.656

0.35

0.30

0.80

0.79

0.35

1. 57

2.40

3.6

1.96

1. 70

0.51

1.02

0.57

0.59

1.45

1.20

2.00

1.67

2.0

2.85

2. 24

1.86

1.55

2.06

3.3

3.0

0.620

1. 32

0.249

0.273

0.479 


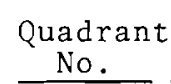
Position

$\mathrm{B}-2$

E- 1

E-2

G-1

$\mathrm{G}-2$

C -1

$\mathrm{C}-2$

A- 2

A- 3

$\mathrm{B}-2$

B -3

C -1

C -2

E- 4

E- 1

A -1

A- 2

A -3

A- 4

B -1

B -2

$\mathrm{B}-3$

B -4

C -1

C -2

E- 1

E-2

A -1

A-3

A- 4

A -2

C -2

A -4

B -1

$\mathrm{B}-3$

C -3

C- 4

B -4

A- 3

C- 1

APPENDIX V (Cont'd)

\begin{tabular}{rlll}
$\mathrm{nv} \times 10^{-14}(>1 \mathrm{MeV})$ & $\mathrm{nv} \times 10^{-14}(2200 \mathrm{~m} / \mathrm{s})$ \\
\hline $\mathrm{Fi}$ & $\mathrm{Ti}$ & $\mathrm{Al}-\mathrm{Co}$
\end{tabular}

$\underline{\text { PPCo }}^{\mathrm{Fe}}$ HAPO $\underline{\text { PPCo }}{ }^{\mathrm{Ni}}$ HAPO $\quad \underline{\text { PPCo }}{ }^{\mathrm{Ti}}$ HAPO $\quad \underline{\text { PPCo }}$ HAPO

\subsection{6}

1.03

1.04

0.738

0.738

0.91

0.73

0.21

0.30

0.73

0.70

0.94

0.72

1.45

1.04

0.232

0.192

0.259

0.324

0.536

0.568

0.242

0.810

0.674

0.227

0.320

0.588

0.300

0.509

0.479
0.95

0.78

0.66

0.65

0.91

0.71

0.25

0.35

0.48

0.72

0.87

0.71

1. 39

0.90

0.275

0.214

0.297

0.367

0.579

1.03

0.796

0.325

0.404

0.706

0.402

0.610

0.579
0.527

1.09

1. 15

0.802

1.00

0.81

0.31

0.47

0.61

0.92

1.08

0.83

1. 50

1. 11

0.388

0.299

0.423

0.508

0.681

0.691

0.896

0.939

0.418

0.351

0.482

0.691

0.476

0.653

0.603
3.00

2.12

1.90

1.90

2.40

1.85

0.87

0.84

1.31

1.60

2.40

1.78

4.40

2.60

0.756

0.633

0.793

0.924

1.71

1.50

2.53

0.868

1.58

0.901

1.41

1.32 
Quadrant

APPENDIX V (Cont'd)

$$
\text { No. }
$$

Position

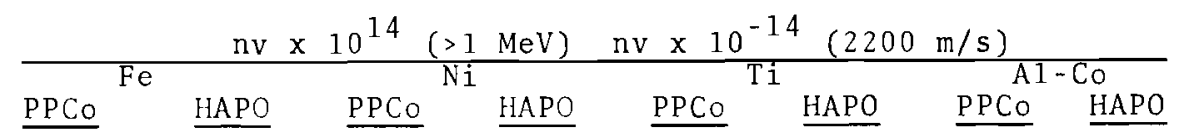

124

125

126

127

128

129

130

131

132

133

134

135

136

137

138

139

140

B -1

B -3

$\mathrm{G}-1$

A -4

$\mathrm{C}-2$

$\mathrm{G}-2$

B -2

B -3 


\section{ONSITE DISTRIBUTION}

\section{Copy Number}

Pacific Northwest Laboratory

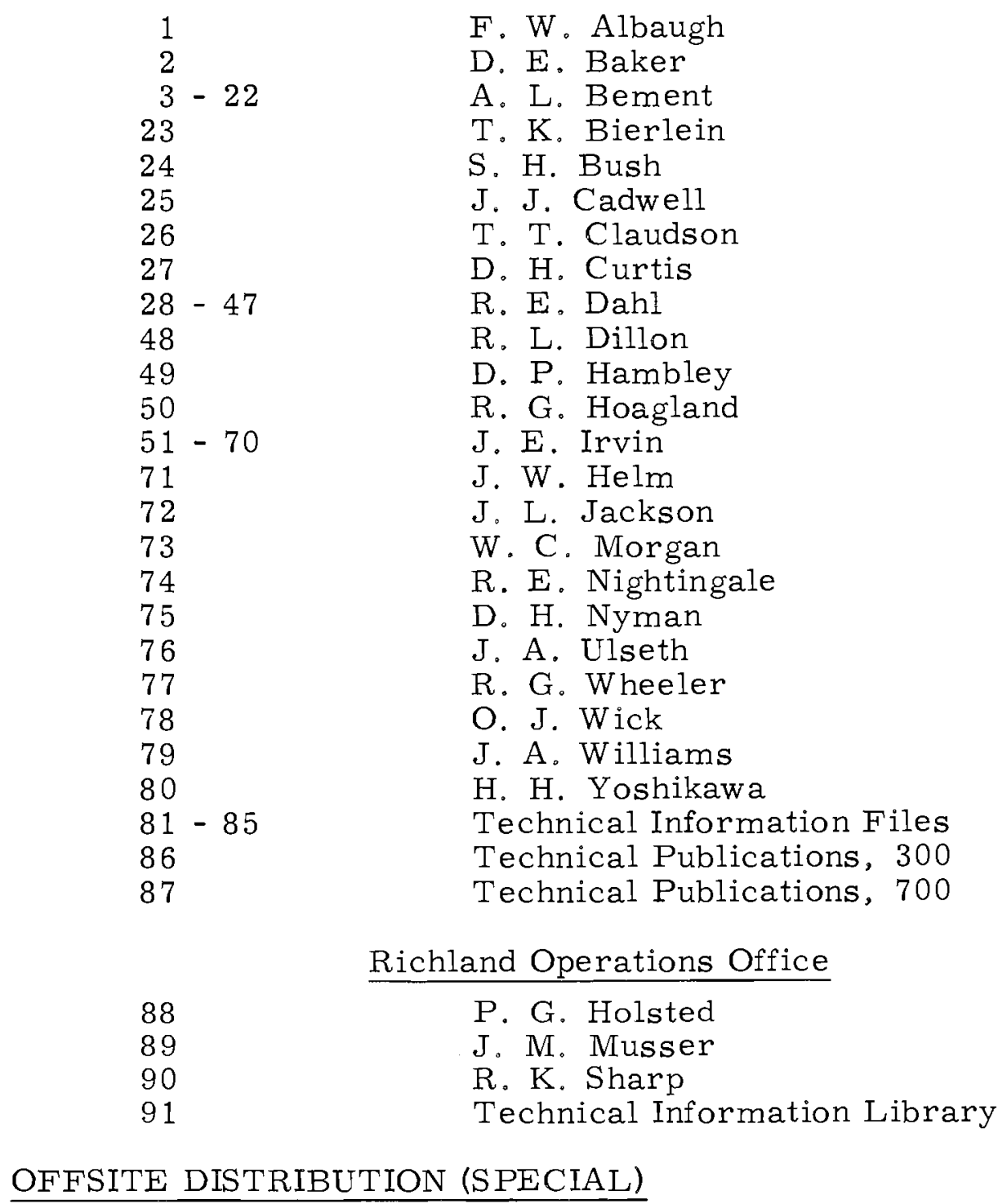

No. of Copies

1

Aerojet-General Nucleonics

Attn: G.W . Titus

Atomic Energy Commission, Washington

Committee on Reactor Safeguards

Attn: R。F。Fraley, Executive Secretary

Division of Licensing and Regulation

Attn: M. Bolotsky

E. G. Case

J. J. DiNunno

A. B. Holt 
OFFSITE DISTRIBUTION (SPECIAL) (contd)

No. of Copies

8

1

1

1

6

1

3

1

1
Atomic Energy Commission, Washington

Division of Reactor Development

Attn: R. C. Cilimberg J. M. Simmons

I. H. Mandil R. H. Steele

J. L. Mershon S. A. Szawlweics

W. L. R. Rice

Division of Research

Attn: D. K. Stevens

AEC Scientific Representative

USAEC London Offize, U.S. Embassy

London, England

Attn: S. G. Nordlinger

Air Force Systems Command

Aeronautical Systems Division

U. S. Air Force Headquarters

Wright-Patterson Air Force Base, Ohio

Attn: Col. L. J. Standifer, Directorate of Materials and Processes

Allis-Chalmers Manufacturing Company

Atomic Energy Division, Nuclear Power Department P. O. Box 5976

Washington, D. C. 20014

Attn: J. F. Haines

Argonne National Laboratory

Attn: R. J. Armani

T. H. Blewitt

J. H. Kittel

F. D. McGinnis, EBR-1, Idaho Falls

A. D. Rossin

D. K. Youngdahl

Battelle Memorial Institute

Attn: F. R. Shober

Brookhaven National Laboratory

Attn: J. G. Y. Chow

D. H. Gurinsky

S. B. McRichard

Babcock \& Wilcox Company

1201 Kemper Street

Lynchburg, Virginia

Attn: L. R. Weisert

Chicago Operations Office

Attn: Claude Purse? 


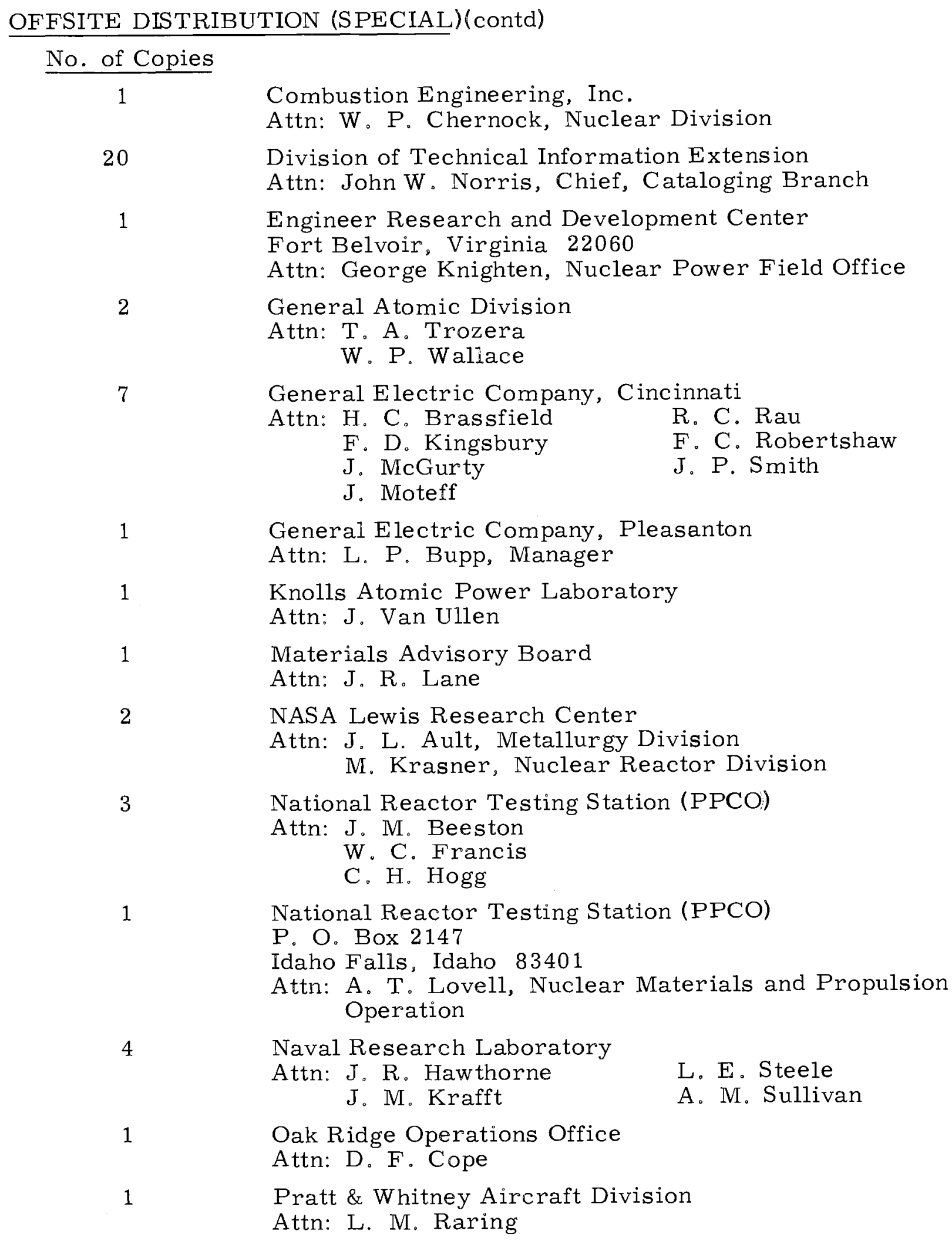




\section{OFFSITE DISTRIBUTION (SPECIAL)(contd)}

\section{No. of Copies}

1

1

10

1

1

1

1

1

1
San Francisco Operations Office

Attn: L. M. Bonnefond, Reactor Division

Special Assistant for Materials

DDR\&E

The Pentagon

Washington 25, D. C.

Attn: E. T. Hayes

Union Carbide Corporation (ORNL)

Attn: R. G. Berggren

W. E. Brundage

N. E. Hinkle

E. C. Miller

S. M. Ohr J. T. Stanley

M. S. Wechsler

J. R. Weir

J. M. Williams

F. W.. Young

Union Carbide Corporation (ORNL-Y-12)

Attn: D. B. Trauger

USAEC

Idaho Operations Office

P. O. Box 2108

Idaho Falls, Idaho

Attn: John F. Kaufmann

U. S. Mission to the European Communities

Acting Senior AEC Representative, Brussels Office APO 667

New York, N. Y.

Attn: Dr. M. B. Biles

University of Cincinnati

Dept. of Chemical Engineering and Metallurgical

Engineering

Cincinnati 21, Ohio

Attn: A. E. Focke

Westinghouse Bettis Atomic Power Laboratory

Attn: R. H. Fillnow

Westinghouse Electric Corporation

Attn: E. Landerman 